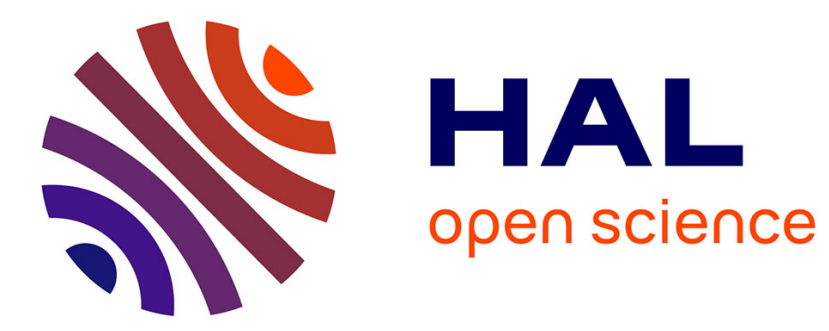

\title{
Dust atmospheric transport over long distances
}

Claudia Di Biagio, Jamie R Banks, Marco Gaetani

\section{To cite this version:}

Claudia Di Biagio, Jamie R Banks, Marco Gaetani. Dust atmospheric transport over long distances. Reference Module in Earth Systems and Environmental Sciences, 2021, 10.1016/B978-0-12-8182345.00033-X . hal-03330916

\section{HAL Id: hal-03330916 https://hal.science/hal-03330916}

Submitted on 1 Sep 2021

HAL is a multi-disciplinary open access archive for the deposit and dissemination of scientific research documents, whether they are published or not. The documents may come from teaching and research institutions in France or abroad, or from public or private research centers.
L'archive ouverte pluridisciplinaire HAL, est destinée au dépôt et à la diffusion de documents scientifiques de niveau recherche, publiés ou non, émanant des établissements d'enseignement et de recherche français ou étrangers, des laboratoires publics ou privés. 


\section{Article Title \\ Dust atmospheric transport over long distances}

\section{Author and Co-author Contact Information}

Corresponding Author Name: Claudia Di Biagio

Full Postal Address - LISA, UMR CNRS 7583, Université Paris-Est-Créteil, Université de Paris, Institut Pierre Simon Laplace, 61 Avenue du General de Gaulle, 94010 Créteil, France

E-mail : claudia.dibiagio@lisa.ipsl.fr

Telephone: 0033 (0)1.82.39.20.51

Co-Author Name: Jamie R. Banks

Full Postal Address - Leibniz Institute for Tropospheric Research, Permoserstr. 15, 04318 Leipzig, Germany

E-mail: banks@tropos.de

Telephone: 004934127177357

Co-Author Name: Marco Gaetani

Full Postal Address - Scuola Universitaria Superiore IUSS, Palazzo del Broletto, Piazza della Vittoria 15, 27100 Pavia, Italy

E-mail : marco.gaetani@iusspavia.it

Telephone: 00390382375846 


\section{Glossary}

Aerosol optical depth (AOD) (or Aerosol optical Thickness (AOT), the two are synonyms; unitless, wavelength-dependent): the integrated optical extinction (scattering plus absorption) at a specific wavelength, usually in the mid-visible spectral region, through the vertical atmospheric column.

African easterly jet (AEJ): mid-tropospheric easterly jet stream driven by the moisture-thermal gradient between the Sahara Desert and the coast of Guinea. It is part of the mid-tropospheric anticyclonic circulation above the Sahara Desert.

Ångström exponent (or Ångström coefficient; unitless): the slope of spectral AOD across a certain wavelength range on a logarithmic scale. A parameter which describes the relationship between AOD and wavelength; larger particles tend to have smaller Ångström exponent values.

Arctic Oscillation (AO): main mode of variability of the atmospheric circulation in the mid-tohigh latitudes of the Northern Hemisphere. It accounts for the variability of the pressure difference between the Arctic region and North Atlantic and North Pacific, and influences the meridional location of the mid-latitude jet stream.

Backscatter coefficient (unit of length ${ }^{-1}$ solid angle ${ }^{-1}$, typically $\mathrm{m}^{-1} \mathrm{sr}^{-1}$; wavelength-dependent): the strength of scattered radiation returned to a light source, the quantity which is retrieved by an elastic lidar system.

Complex refractive index $(\mathbf{m}=\mathbf{n}-\mathbf{i k})$ (unitless, wavelength-dependent): the intensive optical quantity defining the capacity of a medium (bulk material, small particles) to interact with radiation: at each wavelength the real part accounts for scattering, while the imaginary part accounts for absorption.

Depolarization ratio (unitless, wavelength-dependent): in the context of lidar measurements, the ratio of the cross-polarized to the parallel-polarized backscatter signals (can be used to derive particle microphysical properties).

Dust: solid particles ranging in size from below $1 \mu \mathrm{m}$ up to hundreds of micrometers that are projected into the air by both natural and anthropogenic processes. Natural emissions arise by wind acting on undisturbed soils, while anthropogenic emissions result from human activity, such as crushing, grinding, drilling, demolition, etc., but also include land-use changes that modify soil surface conditions, and climate modifications to wind fields, precipitation, etc., altering dust emission processes. 
Effective diameter (unit of length, typically $\mathrm{nm}, 10^{-9} \mathrm{~m}$, or $\mu \mathrm{m}, 10^{-6} \mathrm{~m}$ ): the area weighted mean diameter of an aerosol population.

EI Niño/Southern Oscillation (ENSO): main mode of variability of the sea surface temperature (SST) in the Equatorial Pacific, tightly associated with the variability of the equatorial trade winds. EI Niño (La Niña) conditions refer to positive (negative) SST anomalies and weak (strong) easterly regime and negative (positive) phases of the Southern Oscillation Index (SOI).

Intertropical convergence zone (ITCZ): location in the Tropics where northeasterly and southeasterly trade winds converge, approximately coincident with the thermal equator. It is characterized by deep convection and intense precipitation.

North Atlantic Oscillation (NAO): main mode of variability of the atmospheric circulation in the North Atlantic. It accounts for the variability of the pressure gradient between the Azores high and the Icelandic low, and influences the intensity and tilt of the subpolar jet stream.

Pacific decadal oscillation (PDO): main mode of variability of the Pacific SST at the decadal time scale, accounting for the thermal gradient between equatorial and extratropical Pacific. It can be considered as the low-frequency component of ENSO.

Pacific/North America (PNA) pattern: variability of the atmospheric pressure gradient between the North American continent and North Pacific. The PNA positive (negative) phases feature anomalous high (low) pressure over North America, anomalous low (high) pressure in the North Pacific, and stronger (weaker) East Asian jet stream.

Saharan Air Layer (SAL): an atmospheric layer which forms over the East Atlantic during summer and which provides a stable transport route for dust travelling westwards from the Sahara.

Saharan heat low (SHL): atmospheric thermal depression developing in response to the heating of the Sahara Desert in boreal summer. It is characterized by shallow dry convection and cyclonic circulation in the lower troposphere.

Single scattering albedo (unitless, wavelength-dependent): the ratio of the scattering efficiency to the overall extinction efficiency for an aerosol particle at a given wavelength. It provides the evaluation of the absorbing capacity of the aerosols: an $S S A=0$ corresponds to purely absorbing particles and an SSA $=1$ is for fully scattering particles. 
Southern Oscillation Index (SOI): standardized difference of mean sea level pressure between Tahiti and Darwin, Australia. Positive (negative) phases are associated with strong (weak) easterly wind regime in the Equatorial Pacific and La Niña (El Niño) conditions.

West Pacific (WP) pattern: variability of the atmospheric pressure gradient between northern Asia and the West Pacific. WP positive (negative) phases are associated with stronger (weaker) East Asian jet stream.

Keywords (10-15): mineral dust aerosols, global deserts, atmospheric circulation, remote sensing, satellites, field campaigns, climate index, Mediterranean, Atlantic and Pacific Oceans, Southern Ocean, Arabian Sea, size distribution, mineralogical composition, chemical aging, climatic impact 


\begin{abstract}
Mineral dust aerosols are transported for thousands of kilometers in the atmosphere, and have global effects on the Earth's climate and ecosystems. The development of satellite technology and numerical modelling, several intensive field campaigns performed in different areas of the world, and laboratory experiments, have led to the development of a significant knowledge of dust transport dynamics and spatio-temporal variability, as well as particle physico-chemical and climate-relevant properties and their possible modification with atmospheric aging. In this chapter, we revisit and discuss some of the past and recent literature results to provide an overview of acquired knowledge and missing gaps in dust transport research.
\end{abstract}

Change History Statement: this is not an article update. 


\section{Introduction}

With teragrams of annual emissions, mineral dust aerosols from arid and semiarid regions all over the world are one of the dominant tropospheric aerosol species by mass (Huneeus et al., 2012). Once suspended in the atmosphere, mineral dust aerosols can be transported up to thousands of kilometers away from their sources before being deposited to the Earth's surface, which is usually referred to as the long-range transport of dust (Prospero, 1999; Goudie and Middleton, 2006). The atmospheric residence time of dust aerosols may range from few days up to 1-2 weeks (e.g., Uno et al., 2009; Huneeus et al., 2011; Ménégoz et al., 2012).

The global distribution of dust aerosols in the atmosphere is controlled by the geographical distribution of active sources and the meteorological fields determining emission and transport routes (e.g., Knippertz, 2014). The largest and most persistent sources of mineral dust are located in the subtropical Northern Hemisphere, mainly in a broad "dust belt" ranging from North Africa, across the Middle East, Central and South Asia, to China, and including major global deserts (Ginoux et al., 2012; Prospero et al., 2002; Washington et al., 2003; Choobari et al., 2014). Dust from the Sahara Desert and the Sahel in Northern Africa is efficiently transported towards the Atlantic Ocean reaching both North and South America (e.g., Swap et al., 1992; Prospero, 1999; Reid et al., 2003a; Prospero et al., 2014) and the western to eastern sides of the Mediterranean basin including continental Europe (e.g., Pace et al., 2006; Meloni et al., 2008; Di Mauro et al., 2019). Sources from the Middle East are efficiently transported towards the Arabian Sea, the Red Sea and the Mediterranean, as well as towards India with a transport route over land (e.g., Kalenderski and Stenchikov, 2016; Banks et al., 2017). Asian dusts from the Gobi and the Taklimakan Deserts have been observed up to $5000 \mathrm{~km}$ away from sources on the western coasts of the Pacific Ocean and even to perform a full circuit transport pattern around the globe (Uno et al., 2009). Dust from North Africa and Asia is also identified in Arctic ice cores (Han et al., 2018) whereas emissions from sources in Southern Africa and South America are documented in Antarctic sediments (e.g., Biscaye et al., 1997; Petit et al., 1999). Together with sources in the hot arid and semiarid subtropics, dust is also produced in high latitude $\left(>50^{\circ} \mathrm{N},>40^{\circ} \mathrm{S}\right)$ cold environments, such as Alaska, Canada, Eurasia, Greenland and Iceland in the Northern Hemisphere and Antarctica, New Zealand, and Patagonia in the southern Hemisphere. These sources contribute to about $5 \%$ of global dust emissions (Bullard et al., 2016). High-latitude dust is composed of mineral particles, re-suspended glacier sediments and volcanic ashes and it has been documented to undergo long-range transport across the Arctic and Antarctic regions (e.g., Prospero et al., 2012; Bullard et al., 2016). 
In the past several decades, the long-distance transport of mineral dust aerosols has gained tremendous attention because of the many important impacts that dust exerts on the Earth's climate and planetary ecosystems. Compared to other aerosol types whose mass is dominant but widespread over the global atmosphere, for example sea salt (the most abundant emitted species; Huneeus et al., 2012), the crucial aspect that makes dust long-range transport relevant as a global scale phenomenon is the fact that the large atmospheric mass loads involved are concentrated over frequent but episodic outbreak events. During these events the mass concentration of dust aerosols may reach a few $\mathrm{mg} \mathrm{m}^{-3}$ close to source regions (Kandler et al., 2007), but remain of the order of tenths to hundreds of $\mu \mathrm{g} \mathrm{m}^{-3}$ after thousands of $\mathrm{km}$ of transport in the atmosphere (e.g., Zhou et al., 1996; Marconi et al;, 2014; Zuidema et al., 2019). These concentrations are large enough to make dust dominate the aerosol optical depth (AOD) even thousands of km downwind of sources, and to play a primary role in affecting radiative transfer of solar (or shortwave) and infrared (or longwave) radiation in the atmosphere (the direct radiative effect), cloud formation and properties (the indirect radiative effect), atmospheric chemistry, air quality, transport, human health, and solar energy production (e.g., Christopher et al., 2003; Haywood et al., 2003; Meloni et al., 2015; Rieger et al., 2017). Once removed from the atmosphere, dust is deposited over ocean and land surfaces where it influences the oceanic and terrestrial biogeochemistry through the transport of nutrients, such as iron (Jickells et al., 2005) and phosphorus (Nenes et al., 2011). For instance, North African dust transport has emerged over recent years as a major contributor to the nutrient input to the Atlantic Ocean and to many islands in the Caribbean, the Bahamas (Muhs et al., 2007), Bermuda (Muhs et al., 2012) and the Amazon basin (Ben-Ami et al., 2010).

Because of its episodic nature, the emission, transport, and deposition processes of the global dust aerosols are strongly influenced by meteorology, causing strong seasonal, inter-annual, and decadal variability (Prospero and Lamb, 2003; Knippertz et al., 2014). Additional spatio-temporal variability in dust mobilization and transport may arise from land use changes or changing climate conditions affecting surface properties and meteorological fields (e.g., Moulin and Chiapello, 2006; Hsu et al., 2012). Moreover, significant correlations have emerged between dust and climate variability. As an example, studies based on long term dust datasets report that the dust distribution over the Atlantic is largely influenced by the North Atlantic Oscillation (NAO) in wintertime and the El-Niño/Southern Oscillation (ENSO) in summertime (Hsu et al., 2012), because of the link between major ENSO events and the occurrence of droughts in the Sahel (Prospero and Lamb, 2003; Chiapello et al., 2005). In contrast, the Sahara, receiving much less rainfall than the Sahel, is less influenced by the year to year variability in precipitation. 
The first indications of the long-range transport of mineral dust aerosols over the Atlantic Ocean were reported by Charles Darwin about 170 years ago (Darwin, 1846). Despite this, it was only in the early 1970s, about 120 years after Darwin's initial observations, that we had the first quantitative evidence of the long-range transport of mineral dust over the Atlantic Ocean. This was provided by in situ surface monitoring of the aerosol composition at Barbados showing that African dust routinely reached the Caribbean region 5000 km away (Delany et al., 1967; Prospero et al., 1968). The in situ surface monitoring at Barbados was followed by similar measurements in Miami. Starting in 1974, Miami observations further demonstrated that African dust regularly reached the eastern coasts of the United States (Prospero, 1999). The surface observations initiated at Barbados and Miami never stopped, by now reaching almost 50 years of continuous daily observations (Zuidema et al., 2019). These data constitute the longest and most famous time series of dust surface concentration observations at long-range distance deposition sites and initiated the first studies of the dust transport intensity and seasonal and inter-annual variability in the 1970s and 1980s (Prospero, 1968; Prospero and Carlson, 1980; Prospero and Nees, 1986).

Following the approach of Prospero's group, other ground-based monitoring stations of surface dust concentration were set up during the 1980s and 1990s in other regions of the world to document the mid- and long-range transport of mineral dust aerosols (Zhang et al., 1993; Kubilay et al., 2000; Derimian et al., 2006; Marconi et al., 2014). In the mid-1990s the AERONET (Aerosol Robotic Network. https://aeronet.gsfc.nasa.gov/) ground-based network was also initiated (Holben et al., 1998), with nowadays hundreds of sun/sky photometers located all around the world quantifying the presence and load of dust aerosols by retrieving integrated information over the entire atmospheric column.

Starting from the mid-1970s the investigation of the long-range transport of dust aerosols has significantly advanced thanks to the development of satellite technology. Because of their spatial and temporal resolution and coverage, satellites present intrinsic advantages to characterize regional- and global-scale aerosol transport compared to ground-based observations. Satellites can provide spectacular imagery of major dust events, showing the plumes crossing the oceans and reaching remote areas. Examples of satellite images are provided in Fig. 1 showing a dust plume being transported across the Atlantic Ocean (Fig. 1a), a dust plume over the Arabian Sea (Fig. 1b), a dust plume across the Mediterranean Basin (Fig. 1c), and dust plumes off the coast of Namibia (Fig. 1d). Advances in satellite imagery over the years have provided increasingly 
realistic portraits of the intensity and extent of dust transport episodes all over the world and the ability to track individual dust storms along their transport paths.
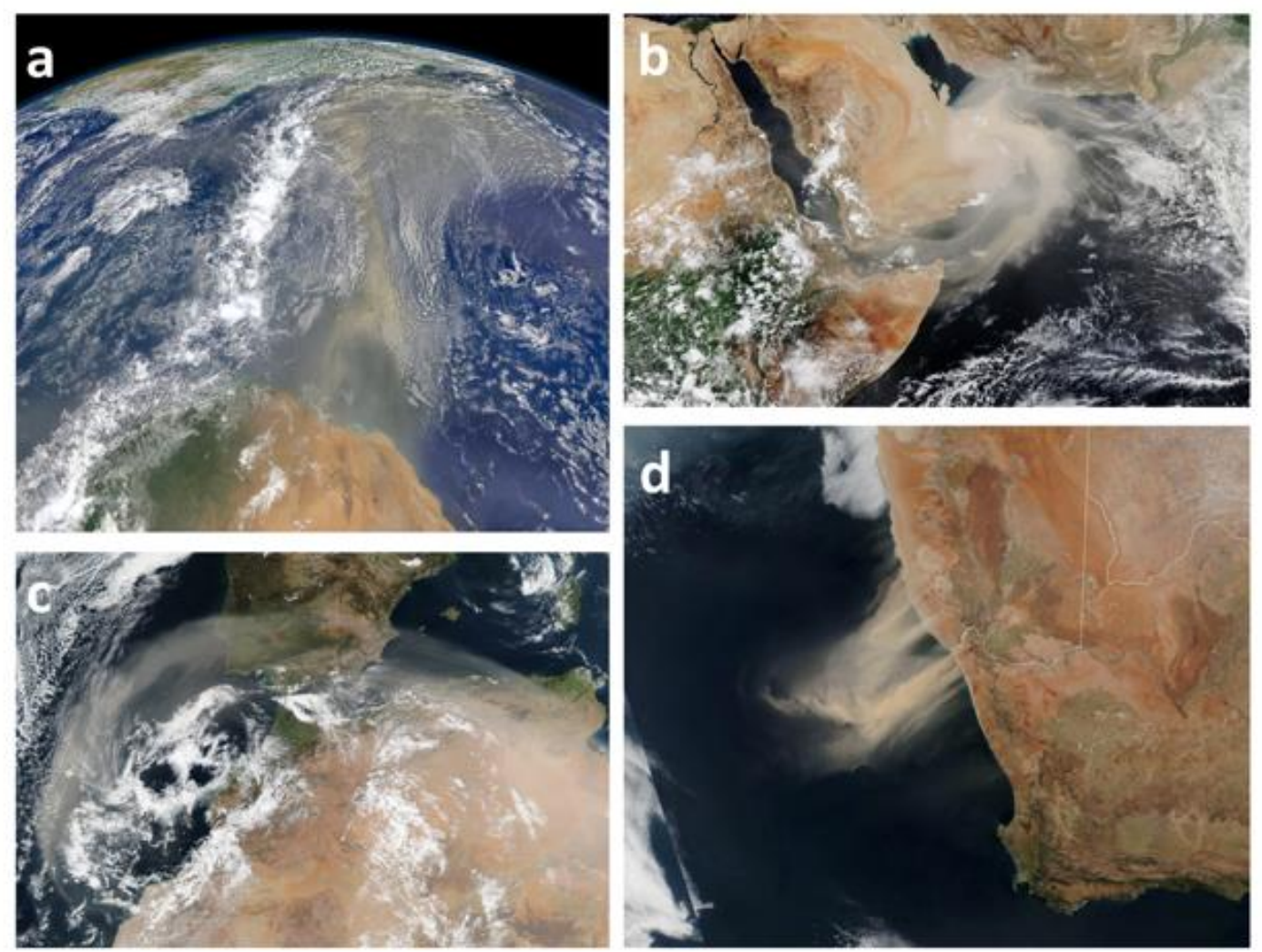

Figure 1. Visible images from the Suomi NPP - VIIRS (National Polar-orbiting PartnershipVisible/Infrared Imager and Radiometer Suite) instrument for a dust plume a) being transported across the Atlantic Ocean (top left, 04 July 2014), b) dust over the Arabian Sea (top right, 30 July 2018), c) dust plume across the Mediterranean Basin (bottom left, 21 February 2017) and d) dust plumes off the coast of Namibia (bottom right, 25 September 2019). Images obtained from NASA Worldview

\section{(https://worldview.earthdata.nasa.gov).}

Satellite technology has continuously advanced over the last decades and particularly during the Earth Observing System (EOS) era starting around 2000 (Yu et al. 2013). Satellites are at present capable of providing global land and ocean measurements of AOD, therefore allowing the largescale quantitative estimates of the horizontal distribution of atmospheric dust. The AOD retrievals over the oceans have shown that oceanic areas with the largest optical depths are those located downwind of active desert sources (Husar et al., 1997; Kaufman et al., 2005), clearly highlighting 
the role of dust in the global aerosol load linked to transport processes. Many more advanced products derived from satellite measurements nowadays permit not only the identification of the presence of dust in the atmosphere but also the retrieval of diverse information on the dust emission strength and properties, including information on the dust size distribution, and optical depths at visible and infrared wavelengths (Diner et al., 2001; Hsu et al., 2004; Pierangelo et al., 2004; Remer et al., 2005; Torres et al., 2007; DeSouza-Machado et al., 2010; Klüser et al., 2011; Banks et al., 2013). Satellites are able to observe small and large dust events over both land and ocean surfaces, by day and night. The vertical distribution of aerosols in the atmosphere can be obtained at high spatial resolution thanks to regular space-borne lidar observations since 2006 (Winker et al., 2009), allowing the tracking of dust transport (Liu et al., 2008) and providing information on the three-dimensional (3D) distribution of dust aerosols at seasonal and interannual scales (Yu et al., 2010). More recent products based on hyper-spectral satellite observations enable the tracking of the 3D structure of dust plumes at high temporal resolution (Cuesta et al., 2015). Satellite sensors can also prove complimentary observations for aerosol transport studies, as for example by measuring trace gases such as $\mathrm{SO}_{2}, \mathrm{NO}_{2}$ and $\mathrm{CO}$ (Martin, 2008). These species originate from different sources than the dust aerosols but can mix within the dust plume when travelling far from arid sources and cause atmospheric aging of the dust particles by heterogeneous chemical reactions and formation of coatings at the particle surface (Usher et al., 2003).

The availability of systematic observations of atmospheric dust at the global scale has supported the development of chemistry and aerosol modules in climate models. Based on the possibility of assimilating aerosol data, several reanalysis products have been made available to the scientific community from the 2000s, allowing studies of aerosol concentrations, optical properties, and direct and indirect radiative effects, in relation to meteorological and climate evolution. From the pioneering Goddard Chemistry Aerosol Radiation and Transport (GOCART) model (Ginoux et al. 2001), simulating the major tropospheric aerosol components, the NASA Goddard Space Flight Center (GSFC) has later implemented the Modern Era Retrospective analysis for Research and Applications Aerosol Reanalysis (MERRAero), providing data back to 2002 (Buchard et al., 2015). In Europe, the European Centre for Medium Range Weather Forecasts provides aerosol reanalysis products dating back to 2003 (the Monitoring Atmospheric Composition and Climate (MACC) and Copernicus Atmosphere Monitoring Service (CAMS) reanalysis; Flemming et al., 2017). Nowadays, dust is routinely monitored and forecast on a regional and global basis by the Barcelona Supercomputer Center (https://ess.bsc.es/bsc-dust-daily-forecast), and the role of dust and its evolution in historical and future climate is simulated by climate models participating in the 
Aerosol Comparisons between Observations and Models (AEROCOM) project (Huneeus et al. 2011) and the Coupled Model Intercomparison Project (CMIP) phase 5 and 6 (Taylor et al., 2012; Eyring et al., 2016).

Starting from the 1970s and intensifying in the 2000s, a large number of field campaigns have been carried out in regions close to dust sources or across and downwind of dust transport pathways. Conducted either from the ground and/or from the air, and combining remote sensing and in situ techniques, field observations during intensive campaigns have documented dust emission and uplift processes, physico-chemical and climate-relevant (optical, hygrocopicity, solubility) properties of airborne particles, and provided estimates of their direct and indirect radiative perturbations, therefore crucially contributing to a regional description of the dust transport conditions, extent, and impacts. Most past field campaigns on dust aerosols have been concentrated in North and West Africa (Redelsperger et al., 2006; McConnell et al., 2008; Heintzeberg, 2009; Haywood et al., 2008, 2011; Ryder et al., 2015) and along transport routes of North African dust in the Mediterranean (Meloni et al., 2015; Mallet et al., 2016), the Atlantic Ocean off the coast of Africa (Raes et al., 2000; Tanré et al., 2003, Ansmann et al., 2011; Ryder et al., 2018), and on the west side of the Atlantic Ocean (Formenti et al., 2001; Reid et al., 2003a; Denjean et al., 2016b; Weinzierl et al., 2017). Field campaigns have been also performed in past years in the Middle East (e.g., Reid et al., 2008), East Asia (Mikami et al., 2002; Hansell et al., 2012), and across the Pacific Ocean (Huebert et al., 2003). There has also been growing attention in recent years on sources in the Southern Hemisphere (e.g., Formenti et al., 2019), in particular Namibia as a source of long-range transport of mineral dust to the central tropical South Atlantic (Swap et al. 1996). Some of the past dust campaigns were (or included) scientific cruises documenting the surface and atmospheric concentration and properties of mineral dust in remote oceanic areas (Duce, 1995; Kanitz et al., 2014). In this sense, cruise observations have been particularly useful to investigate and quantify the contribution of dust deposition to nutrient input into the oceans which is of relevance for understanding the biogeochemical impact of dust.

When travelling in the atmosphere, as anticipated, dust aerosols can mix with air masses carrying other aerosol types and gas constituents, which can initiate a chemical processing of the particles. The investigation of the "fresh" and "aged" dust properties and of the mechanisms leading to the interaction of dust with the atmospheric constituents, started by field observations, has also been complemented by the laboratory approach, particularly increasing, in the last two decades,. The use of laboratory techniques is useful, in some cases even essential, to explain processes occurring in the atmosphere which are difficult to isolate and understand based solely on field or 
remote sensing observations and to retrieve quantities that cannot easily be accessible in the field. In recent years laboratory flow tube or simulation chamber experiments have been realized to investigate the dust chemical aging from the interaction with other atmospheric constituents (e.g., de Reus et al., 2000, 2005; Hatch et al., 2008; Gibson et al., 2007; Sullivan et al., 2009a,b) and laboratory setups have been used to explore the spectral optical and hygroscopic properties of the particles, leading to their direct and indirect climatic effects (i.e., Linke et al., 2006 ; Wagner et al., 2012; Atkinson et al., 2013 ; Laskina et al., 2013; Augustin-Bauditz, 2016; Di Biagio et al., 2014, 2017, 2019).

The combination of these diverse sources of information (surface and satellite observations, intensive field campaigns and laboratory investigations), complemented by the consistent development of numerical regional and global modelling over the past decades, has allowed the scientific community to develop a global picture of the main transport patterns of dust, as well as to identify the main processes affecting the evolution of dust properties relevant to their climatic, environmental and health impacts during transport. As of today, we have acquired a large body of knowledge, but many questions are still open. In particular, many aspects of the dust cycle of relevance for the dust-climate effects, such as the effectiveness and impact of the interaction of dust with gaseous compounds or the mechanisms allowing for the conservation of the dust coarse mode during transport, remain speculative (e.g., Ansmann et al. 2011; Ryder et al. 2015; Weinzierl et al., 2017).

In this chapter, which is an update of the first version provided by Marticorena and Formenti (2013), we revisit and discuss some of the recent literature results to provide more insight on dust transport studies, including the most recent outcomes from in situ field and laboratory experiments and observations from the new generation of available satellite products. The focus here is on subtropical dust sources, and high-latitude dust will be not discussed further. Section 2 analyses the horizontal, vertical and seasonal distribution of dust transport based on the observational record combining surface and satellite AOD observations, and the discussion of illustrative case studies. Section 3 discusses the main meteorological processes responsible for dust emission and long-range transport patterns in different regions and the influence of climate indices on the seasonal and interannual variability of dust episodes and their transport. Section 4 focuses on the role of dust transport in affecting the particle size distribution, composition and morphology, in particular by taking advantage of the body of observations from recent intensive field campaigns. The impact of aging on the optical, hygroscopicity and solubility properties of dust and their climatic effects along transport are also discussed in Section 4 by combining the observational 
evidence from field and laboratory studies. The role of dust transport as a tracer of past climate variability and future projections of dust emission and global distribution are discussed in Section 5. Conclusions are drawn in Section 6.

\section{Observations of Dust Transport Patterns and Pathways}

The distribution of dust and its transport routes in the atmosphere, as previously introduced, is spatially and temporally heterogeneous, governed primarily by the distribution of the major source regions and the associated prevailing wind patterns. Depending on the intensity of the sources and the meteorological processes acting on the lofted dust layers, dust may be transported across continents and oceans (e.g. Prospero et al., 1970; Koren et al., 2006; McKendry et al., 2007). In this Section we explore these patterns and the observations which have revealed and described them, with reference to the global satellite observations and surface measurements (e.g. dust samplers, sunphotometers, and lidars) which have been used to track the long-range transport of dust. In Section 4 we will discuss recent field campaigns which have explored dust activity and properties.

\subsection{Spatial Patterns of Dust derived from the Observational Record}

On the global scale, our knowledge of the spatial patterns of transported dust is underpinned by developments in observational techniques over recent decades, techniques which are diverse and inter-disciplinary, and which are made from the surface (land and ocean), the air, and from space. For obvious practical reasons, as already described in the introductory section, some of the earliest measurements of dust were performed near the surface in numerous locations around the world, using dust samplers. Collating some of this information over the global oceans, Duce (1995) reported near-surface dust concentrations varying from as low as $0.001 \mathrm{\mu g} \mathrm{m}^{-3}$ in the Southern Ocean to as much as $1000 \mu \mathrm{g} \mathrm{m} \mathrm{m}^{-3}$ in the Arabian Sea and in the mid-Atlantic atmosphere downwind (i.e. westwards) of the Saharan African coast.

An invaluable resource for global dust measurements is provided by AERONET, a network of sun photometers which has been making ground-based remote sensing measurements of aerosols for over 25 years (Holben et al., 1998; Giles et al., 2019). As of 2018, the network contained over 600 sites worldwide, with a ship-based maritime network (Smirnov et al., 2009) also in operation. Sun-photometers measure aerosol presence by observing the Sun and contrasting the measured direct-beam irradiance with that for a pristine-sky atmosphere of known atmospheric path length, taking into account the solar elevation above the horizon. Using this information, under clear-sky conditions AERONET sites retrieve the AOD, representing the extinction of solar radiation due to 
aerosols within the atmospheric column. The measurements are spectrally resolved, with channels ranging from 340 to $1640 \mathrm{~nm}$ in wavelength, i.e. from the upper end of the ultraviolet to the lower end of the infrared parts of the spectrum. By convention, AODs are often reported by various sensors at $550 \mathrm{~nm}$, in the middle of the visible spectrum. AERONET sun photometers make direct measurements of the effect of aerosols on solar radiation and hence they have low uncertainties on their AOD retrievals, leading to estimates being commonly considered to be 'ground-truth' measurements. Additional retrieved optical aerosol properties include the aerosol Ångström exponent, which describes the spectral dependence of the AOD and hence can be used to distinguish between aerosol types, and the single scattering albedo, providing a quantification of the aerosol absorbing capacity. The retrieval method for calculating the single scattering albedo is derived from almucantar scans (Dubovik and King, 2000) made at defined measurement angles offset from the Sun so as to measure the multiple scattering of aerosols, and is therefore a qualitatively and quantitatively different method to retrieve aerosol properties compared to the direct-Sun observations used to retrieve the AOD. The almucantar scans also enable the retrieval of aerosol size distributions and the sphericity of the aerosol particles, useful for estimating the dust loading. Due to its sparse but globally-distributed coverage and the longterm record of observations available, AERONET high-quality data have been used to investigate dust variability and properties over different regions of the world (Dubovik et al., 2002; Kim et al., 2011). An important caveat is that its sparse coverage across desert regions, and also across oceanic regions downwind of the dust sources, does leave large spatial gaps in the dust measurement record.

Complementary to AERONET, developments in lidar (light detection and ranging) technology have seen an increase in their use for atmospheric aerosol research (e.g. Ansmann et al., 2009; Baars et al., 2016; Marinou et al., 2017). As an active remote sensing instrument, lidars provide more information on the vertical distribution of aerosols in the atmosphere by measuring the height-resolved aerosol backscatter. Further discrimination of the aerosol type, size and shape is provided by the depolarization ratio (Haarig et al., 2017). Moreover, ground-based atmospheric lidars are often collocated with AERONET sites, for example the NASA Micro-Pulse Lidar Network (MPLNET, e.g. Welton et al., 2001), allowing for a synthesis of the AERONET AOD retrievals in order to help constrain the lidar aerosol retrieval.

In order to obtain a truly global perspective, however, it is necessary to make use of satellite observations. Satellite imagery was first used for identifying atmospheric dust in the 1960s, when, for example, Prospero et al. (1970) used images from the ESSA 5 satellite to identify dust 
transport from the Sahara westwards over the Atlantic. Carlson (1979) provided one of the first satellite tracking of a dust plume transport across the Atlantic Ocean based on VHRR (Very High Resolution radiometer) brightness data from the NOAA (National Oceanic and Atmospheric Administration) 3 satellite. These authors followed the outbreak of a Saharan dust plume for seven days during summer 1974 over a portion of the eastern equatorial North Atlantic. Their analysis first demonstrated that radiometric observations from satellite platforms could be used to resolve the large-scale patterns of dust optical depth and their spatio-temporal evolution. Further developments in aerosol retrievals using satellite data were prompted by the AVHRR (Advanced High-Resolution Radiometer) instruments, which have sufficient spectral resolution to attempt aerosol retrievals (Stowe et al., 1997), and which have provided a data record which stretches back to the 1980s. At solar wavelengths dust is highly scattering (e.g. Dubovik et al., 2002), with a relatively small absorption component, meaning that in visible imagery sufficiently thick dust may be readily observed over darker oceanic surfaces.

The MODIS (MODerate resolution Imaging Spectroradiometer) instruments onboard NASA's Terra and Aqua satellites have provided one of the longest, and most widely used, records of dust AOD, starting in 2000 and still ongoing as of 2020. In sun-synchronous orbit at an altitude of 705 $\mathrm{km}$ and with a swath width of $2330 \mathrm{~km}$ (Levy et al., 2013), MODIS provides global coverage daily. MODIS has 36 spectral channels, from 0.41 to $14.5 \mu \mathrm{m}$, i.e. from the near-UV through the visible to the infrared (IR) part of the spectrum. The 'Dark Target' pair of algorithms are used to retrieve AOD separately over water (Tanré et al., 1997; Remer et al., 2005) and over vegetated or dark land (Levy et al., 2007), based on a lookup-table approach which compares the measured spectral reflectance with values that would be expected given the surface properties of the measured pixel and the possible aerosol types and loadings. The land algorithm tends not to attempt retrievals over desert regions, where the reflectance under dusty conditions is generally very similar to the clear-sky reflectance. Adapting to this problem, the 'Deep Blue' algorithm has been designed to retrieve AOD over desert regions (Hsu et al., 2004, 2013; Sayer et al., 2013) using near-UV channels, at which wavelengths desert surfaces have much lower clear-sky reflectance and hence airborne dust has a clearer contrast with the background surface. Finally, the Multi-Angle Implementation of Atmospheric Correction (MAIAC, Lyapustin et al., 2018) algorithm is also applied to MODIS data to retrieve AOD, and other parameters including the surface bidirectional reflectance distribution function. All of these retrievals are also being applied to data from the VIIRS (Visible Infrared Imaging Radiometer Suite) instruments onboard the Suomi NPP (National Polar-orbiting Partnership) satellites, first launched in 2011 and ongoing, eventually providing a consistent multi-decadal record of dust AODs. 
Also onboard Terra is the MISR (Multi-angle Imaging SpectroRadiometer) instrument, which has four spectral channels in the visible to the near-infrared, but whose advantage is the multi-angle viewing geometries, with nine cameras mounted between $70.5^{\circ}$ fore and aft. This has enabled the development of an aerosol retrieval which can retrieve not only the dust AODs but also the aerosol model (type, shape and size) that produces the best fit to the data (Kahn et al., 2009). Another satellite with the capability to retrieve AODs (total, and discriminated by the coarse and accumulation modes) is the PARASOL (Polarization \& Anisotropy of Reflectances for Atmospheric Sciences coupled with Observations from a Lidar) mission, which makes use of the polarization properties of aerosols in order to infer microphysical properties, for example using the GRASP (Generalized Retrieval of Aerosol and Surface Properties) algorithm (Dubovik et al., 2011).

The Deep Blue algorithm has also been applied to measurements taken by the Sea-viewing Wide Field-of-view Sensor (SeaWiFS) in order to retrieve AOD over land (Sayer et al., 2012). These have been merged with AOD retrievals over ocean to provide a global AOD product (Hsu et al., 2012), an example of which is displayed in Figure 2. The global patterns of dust presence are represented by the mean AODs at $550 \mathrm{~nm}$ and Ångstrom coefficients retrieved by SeaWIFS for the period 2000-2010. Over both ocean and land it is readily apparent that the aerosol loading is more widespread over the northern hemisphere than over the south, reflecting the greater land surface area in the north. The major desert dust sources are also in the north, with the Sahara, Arabia and the Middle East, and some of the desert regions in western China all showing up in Figure 2 as regions with persistently high AODs together with associated low values of the Ångström exponent. Particularly noticeable as an AOD 'hotspot' is the Bodélé Depression $\left(17^{\circ} \mathrm{N}\right.$, $18^{\circ} \mathrm{E}$ ) in Chad, well known as one of the most significant dust sources in the world (e.g. Todd et al., 2007). Meanwhile areas such as Central Africa and India also show up as aerosol hotspots, although these are more likely to be dominated by biomass burning or urban/industrial aerosols. In the case of eastern China, urban/industrial aerosols (characterized by higher Ångström exponents) are joined by dust aerosols blown eastwards from the Gobi Desert. 


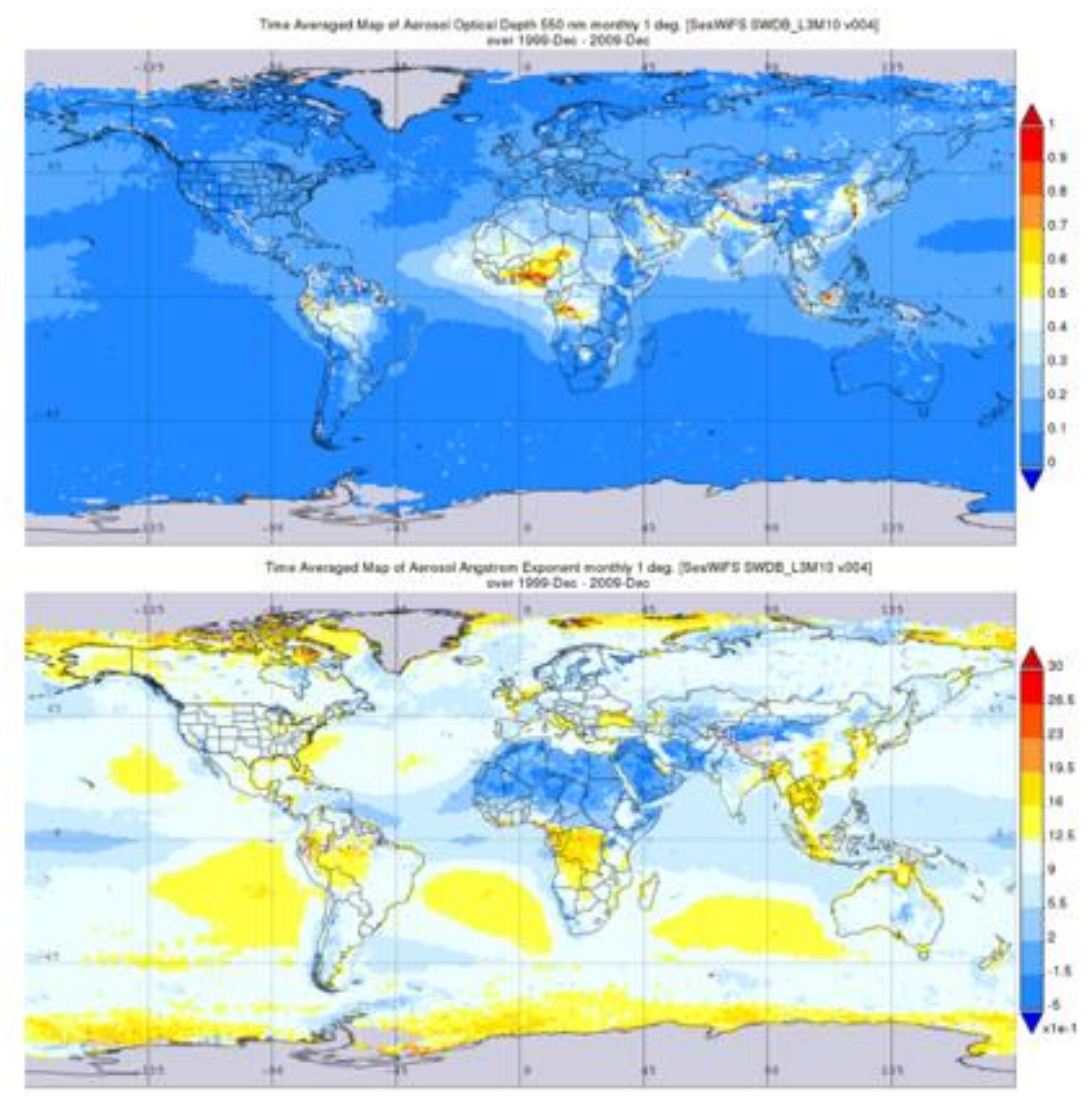

Figure 2. Global maps of $A O D$ at $550 \mathrm{~nm}$ and Ångström exponent from SeaWIFS observations averaged over the period 2000 to 2010 (analysis and visualization produced by the Giovanni online data system, https://giovanni.gsfc.nasa.gov/giovanni/, developed and maintained by the NASA GES DISC).

As evident from Fig. 2, the Sahara Desert is substantially the largest dust source in the world, and as a consequence of its vast geographical extent, the Sahara sends dust in several typical transport routes: south-westwards from the Bodélé Depression in Chad across Nigeria to the tropical Atlantic and towards South America (e.g. Swap et al., 1992; Todd et al., 2008); westwards from the Mauritanian Atlantic coast towards the Caribbean (e.g. Groß et al., 2016), clearly distinct in Figure 2; north-westwards from Algeria towards Iberia and the European East Atlantic (e.g. Osborne et al., 2019); northwards from Libya towards southern Europe, as well as northeastwards and eastwards across Egypt to Cyprus and the countries of the eastern Mediterranean (e.g. Pace et al., 2006); and finally eastwards across the Red Sea from Sudan and Egypt to the Arabian Peninsula. Meanwhile the noteworthy aerosol plume in Fig. 2 off the western coast of Central Africa is dominated by biomass burning aerosols. 


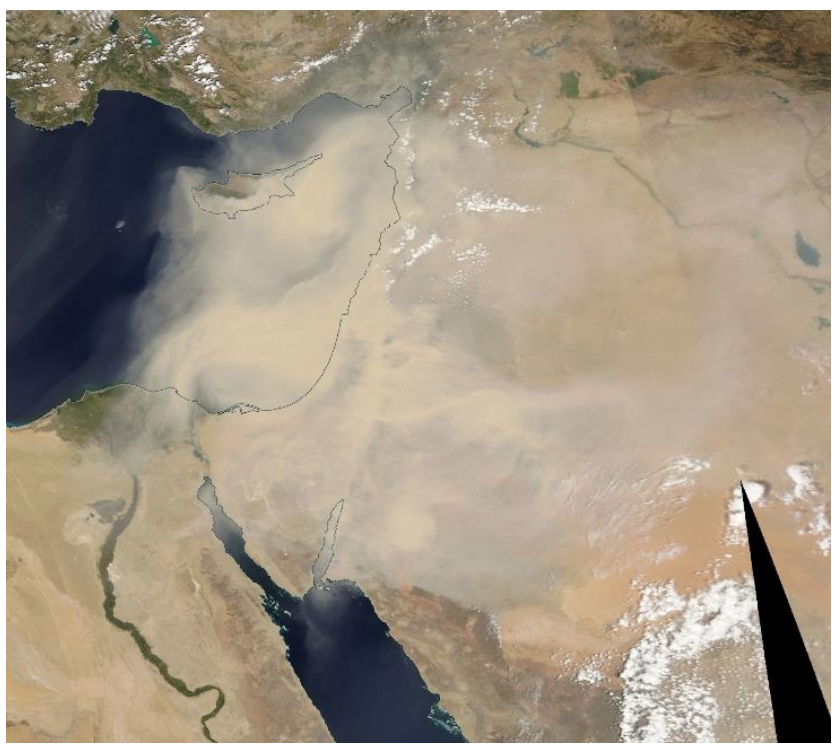

Figure 3. Aqua MODIS visible image over the eastern Mediterranean from 8th September 2015. Image obtained from NASA Worldview (https://worldview.earthdata.nasa.gov).

Dust outflow from the Middle East is also apparent in Fig. 3, heading into the Red Sea (e.g. Kalenderski and Stenchikov, 2016), the Mediterranean (Gasch et al., 2017), the Persian Gulf (Banks et al., 2017), and onwards into the Arabian Sea where it can affect the development of the Indian Monsoon (Vinoj et al., 2014). An example of a Middle Eastern dust storm is shown in Fig. 3, with MODIS AODs during this event exceeding the value of 5 over the city of Limassol in Cyprus, as reported by Mamouri et al. (2016). Using ground-based lidar measurements from Cyprus, the same authors report a double-layering structure in the dust plume in the period leading up to the peak in dust loading, with one particularly concentrated layer between 1 and 1.5 $\mathrm{km}$ above sea level, and with a higher level occurring at around $3 \mathrm{~km}$. In general, MODIS AODs over the Mediterranean show a north-south gradient in aerosol properties and loading, with higher average AODs in the northern Mediterranean where anthropogenic aerosols dominate, whereas the southern Mediterranean is dominated by dust, as has been reported by, e.g., Floutsi et al. (2016).

Active since 2004, the SEVIRI (Spinning Enhanced Visible and InfraRed Imager) instruments onboard the European Meteosat Second Generation (MSG) series of satellites (Schmetz et al., 2002) have proved invaluable for tracking dust transport from Africa and the Middle East into the Atlantic and the Mediterranean, and across to the Americas and to Europe. SEVIRI has the advantage of its 15 minute temporal resolution, enabled by the MSG satellites' geostationary 
orbits stationed over the Gulf of Guinea. Using a succession of consecutive false-color RGB composite images in the visible and in the IR (Lensky and Rosenfeld, 2008), SEVIRI is a powerful tool to track the origin and progression of dust storms (e.g. Schepanski et al., 2007; Ashpole and Washington, 2012), both over desert (using the IR composite, 'Desert Dust') and over ocean (using a visible composite, e.g. 'Day Natural Colours'). It is also possible to retrieve AODs from SEVIRI, using visible channels over ocean (Brindley and Ignatov, 2006; De Paepe et al., 2008), and using IR channels over desert (Brindley and Russell, 2009). Similar instruments are positioned in geostationary orbit over the Americas (on the US GOES satellites, e.g. Wang et al. (2003)) and over the West Pacific (onboard the Japanese Himawari-8 satellite, e.g. Wang et al. (2019)). Meanwhile MSG-1 was moved eastwards to over the Indian Ocean in early 2017 in order to provide the Indian Ocean Data Coverage service, providing also a new perspective on dust activity over Central Asia and including new observations of dust from the desiccating Aral Sea, a known developing dust source (Xi and Sokolik, 2016). Between all of these satellites, there is now near-global coverage of the Earth's surface and atmosphere from geostationary satellites.

An example of SEVIRI's perspective on the world and specifically on dust is provided in Fig. 4, which depicts a visible and a thermal SEVIRI image of several simultaneous dust storms over North Africa and the Middle East, for a day in June 2012. June is a common month for severe Saharan dust activity (e.g. Marsham et al., 2013). In the Desert Dust composite image (right), hot desert surfaces appear light blue (e.g. Brindley et al., 2012; Banks et al., 2019), moister tropical regions appear darker blue, deep clouds often appear red, while dust is apparent with a characteristic pink colour. In this rendering scheme, dust has an especially vivid contrast against hot and dry desert surfaces. In the west, a very large dust storm is in the process of being swept into the Atlantic over the Moroccan coast, a dust storm which extends south deep into Mauritania. This dust storm is also apparent in the visible composite image over the Atlantic, pale grey against the black ocean to the west of the cloud mass. Back-tracking this event through preceding imagery, it had its initial origins two days previously in western Niger and eastern Mali. Several smaller dust storms can still be seen in this area. Three further dust storm clusters can be seen further to the east: one large event is crossing the Red Sea from Egypt and Sudan; another set of dust storms is travelling southeastwards from Iraq over the Arabian Peninsula; and finally on the limb of the image there appears to be a set of dust storms in western Pakistan, with outflow into the Arabian Sea. 

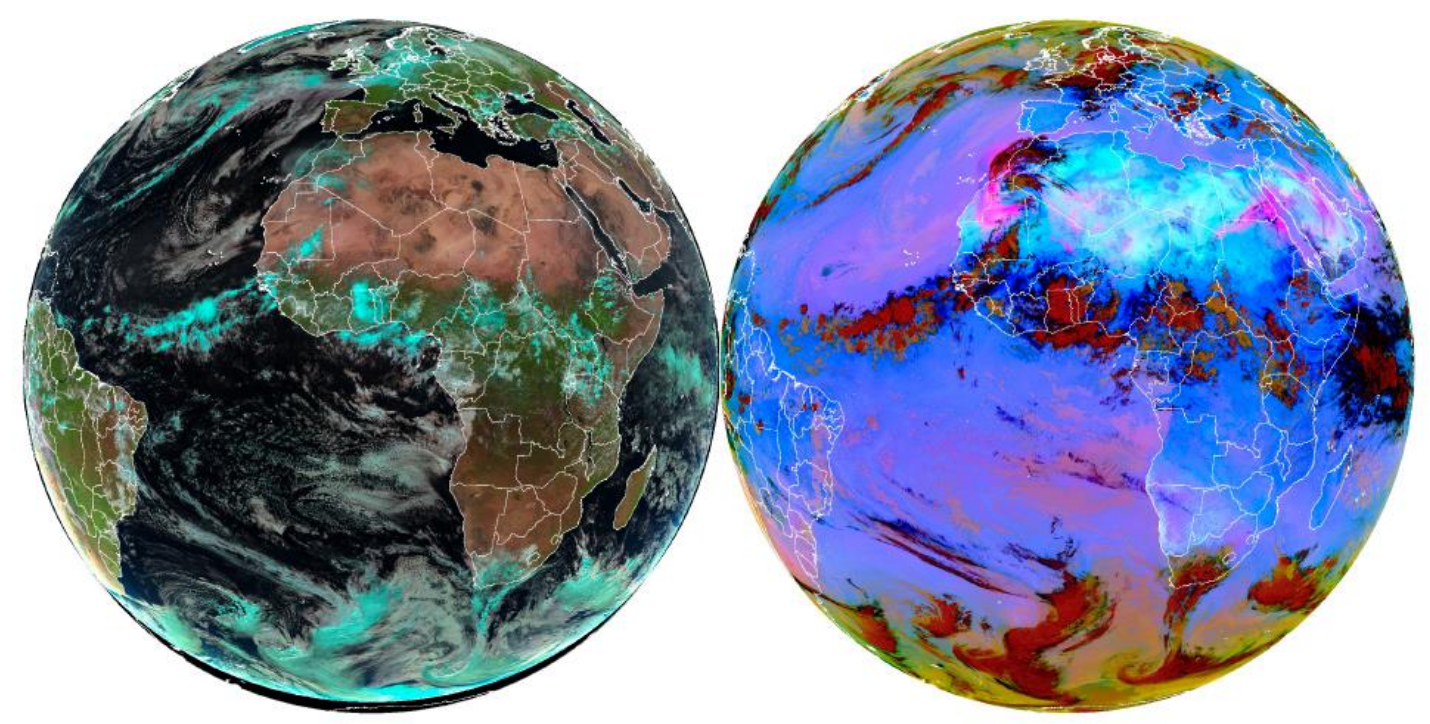

Figure 4. MSG-2 SEVIRI false-color RGB composite images from 1200 UTC on 24th June 2012: (left) 'Day Natural Colours'; (right) 'Desert Dust' (Lensky and Rosenfeld, 2008). Data courtesy of EUMETSAT.

SEVIRI provides also an excellent view over southern Africa. In Namibia, there are discrete patterns of dust transport away from the Etosha Pan and the Namib Desert along the Atlantic coast, including a set of seasonally dry riverbeds (e.g. Bryant, 2003; Vickery et al., 2013). Typically, such dust storms are ejected into the Atlantic, and can be very clearly observed as streaks in visible satellite imagery (see Fig. 1d), although the dust loadings are minor in comparison with dust transported from the Sahara.

A pioneering satellite perspective on dust has been provided by the CALIOP (Cloud-Aerosol Lidar with Orthogonal Polarization) lidar instrument aboard NASA's CALIPSO satellite (Winker et al., 2009; Omar et al., 2009), active since 2006. As with the ground based lidars, this provides information on the aerosol vertical distribution, along with estimates of the aerosol type. Compared to MODIS, the swath width is very narrow, with a 16-day repeat cycle. It is also worth mentioning here the CATS lidar (Cloud-Aerosol Transport System, Pauly et al., 2019) which was located on the International Space Station from 2015 to 2017: this was in a lower orbit than CALIPSO, and as such was able to sample a different diurnal cycle of aerosol activity. A major feature of dust transport that spaceborne lidars can observe is the Saharan Air Layer (SAL, e.g. Carlson and Prospero (1972)). The SAL caps the turbulent marine boundary layer, which is dominated by marine aerosols, while the SAL has been estimated by recent aircraft lidar measurements to extend from approximately 2 to $3 \mathrm{~km}$ in altitude (e.g. Gutleben et al., 2019). An example CALIPSO profile over the SAL is displayed in Fig. 5, along with the co-located visible 
image from Aqua MODIS. The dust plume ejected off the coast of Mauritania in Fig. $5 a$ is clearly apparent in Fig. 5b with increased backscatter signals (appearing yellow to red in the plot) at an elevated altitude of $3-6 \mathrm{~km}$ between $14-27^{\circ} \mathrm{N}$. Clouds are apparent further south, and are characterized by particularly high backscatter values.

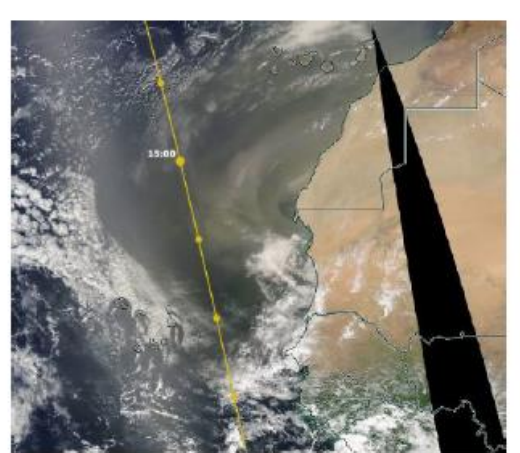

(a)

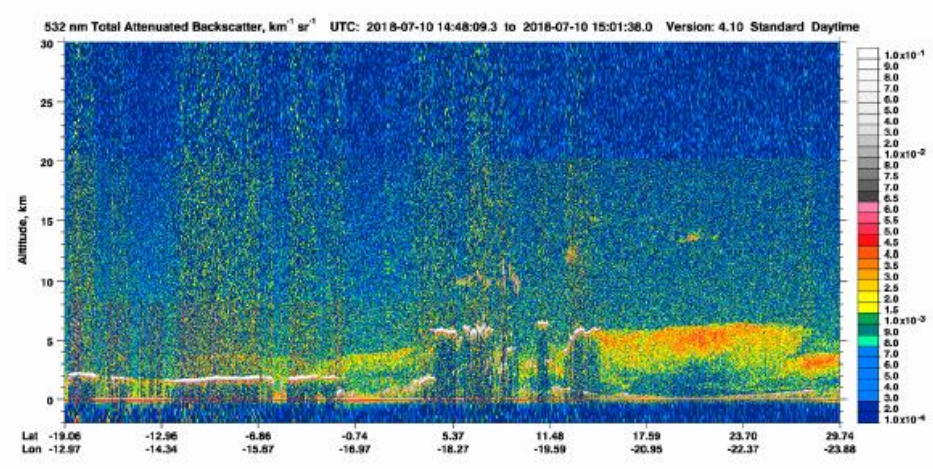

(b)

Figure 5. (a) Aqua MODIS visible image over the eastern Atlantic and western Sahara from 10th July 2018, with the CALIPSO track overlaid; the image extends from 10 to $30^{\circ} \mathrm{N}$. (b) CALIPSO image of the height-resolved total attenuated backscatter at $532 \mathrm{~nm}$ along the orbital track. MODIS image obtained from NASA Worldview (https://worldview.earthdata.nasa.gov); CALIPSO image obtained from the lidar image browse tool at https://www-calipso.larc.nasa.gov.

In eastern Asia, it is apparent from Fig. 2 that there are discrete patterns of dust transport from the Gobi Desert in China and Mongolia to the East China Sea and towards the Korean Peninsula. This region has been the testing-ground for the AEROIASI (Cuesta et al., 2015) retrieval algorithm, designed to retrieve aerosol properties and height from the IASI instrument. Onboard the European Metop satellites, IASI (Infrared Atmospheric Sounding Interferometer) is a hyperspectral instrument counting over 8000 spectral channels, which have been used to retrieve dust (e.g. Klüser et al., 2011). Uniquely, the AEROIASI algorithm makes use of this spectral resolution to estimate not only the dust AOD (at $10 \mu \mathrm{m}$ ) but also the aerosol extinction profiles and the dust layer heights: it therefore seeks to estimate three-dimensional dust distributions from twodimensional spatial measurements. Using a case-study from March 2008, Cuesta et al. (2015) described the evolution of a dust plume transported eastwards from China, with estimated plume heights of $\sim 2.5 \mathrm{~km}$ over the Yellow Sea, plausible in comparison with CALIPSO measurements. The AEROIASI algorithm has also been applied to IASI measurements of Middle Eastern dust storms (Francis et al., 2019) and to the whole dust belt area (Kylling et al., 2018). An example of 
AEROIASI retrievals is provided in Fig. 6. Inversions can be applied twice a day in clear-sky areas to the ensemble of IASI data since 2007 and are ongoing.

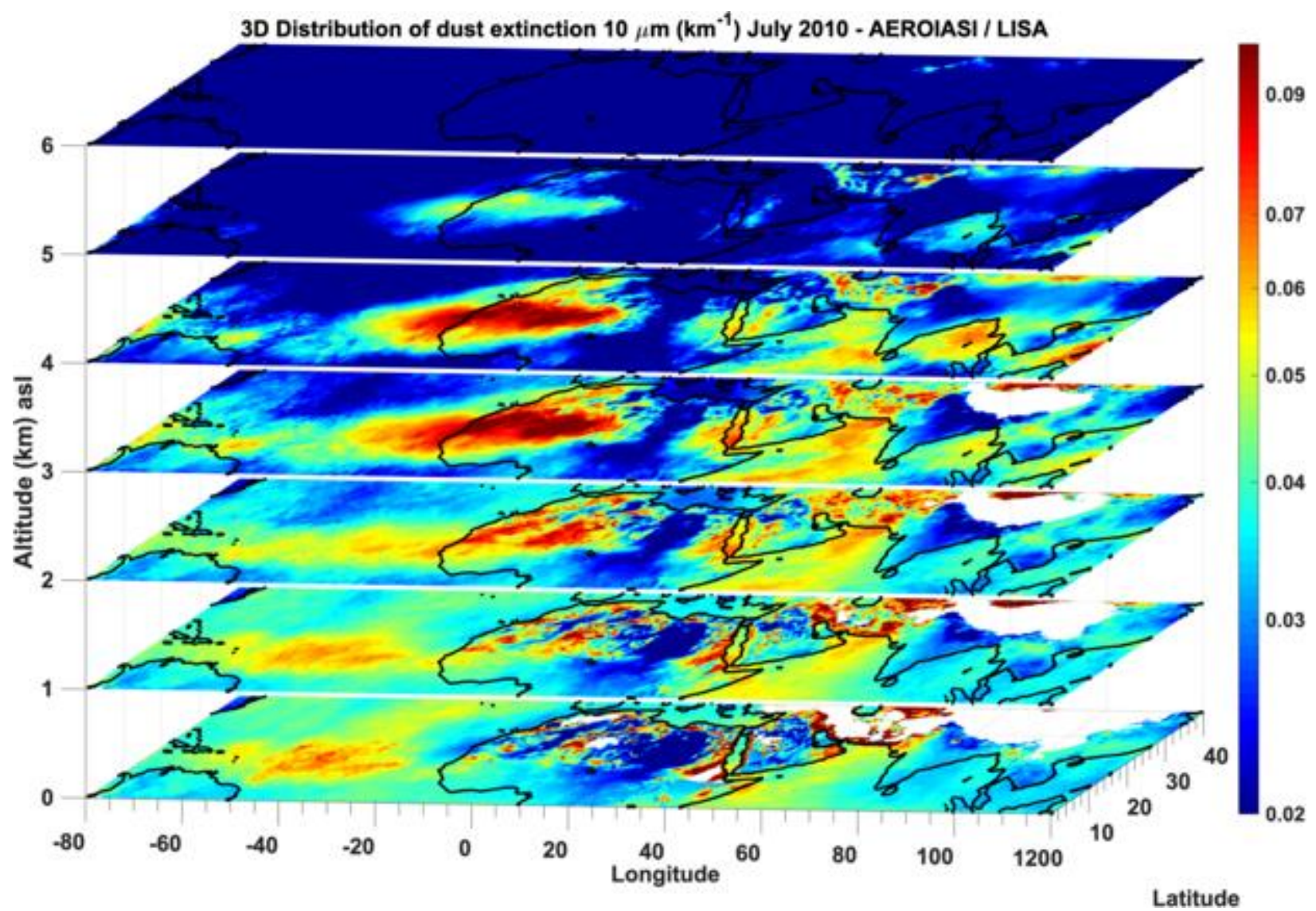

Figure 6. Altitude-resolved spatial map of the dust extinction coefficient at $10 \mu \mathrm{m}$ wavelength, averaged over 1 to 12 July 2010 from the AEROIASI algorithm applied over the dust belt area (courtesy J. Cuesta).

\subsection{Seasonal Patterns of Dust transported from the Global Source Regions}

Seasonal patterns are also apparent in the observational record. Figure 7 displays the AERONET monthly AOD climatology for eight sites affected by Saharan and Middle Eastern dust, including four oceanic sites remote from the source regions. Meanwhile Fig. 8 displays the global MODIS AODs, here subdivided by season. Downwind of the Sahara to the west across the Atlantic are the Cape Verde (Fig. 7a) and Guadeloupe (Fig. 7c) sites, both of which see annual peaks in AOD during June and July. The minima in the Ångström coefficient values help to confirm that these peaks are due to dust (such high AODs are not characteristic of sea salt aerosols, although these have similarly low Ångström coefficient values). The Cape Verde AODs are generally higher than 
at Guadeloupe, indicative of its relative proximity to the source regions and the longitudinal gradient across the Atlantic. This seasonal pattern is corroborated by the trans-Atlantic MODIS AODs, which peak in spring and summer (Fig. 8a and b).

Even closer to the Saharan sources, Zinder Airport (Fig. 7h) is downwind of the Bodélé Depression and is close to local sources in Niger, and displays its peak in spring and early summer, characterized also by the low Ångström coefficient values during this period. Meanwhile Ilorin (Fig. 7d), also downwind of the Bodélé, displays its peak AODs in winter. The winter months are the dry season in southern West Africa, so the high AODs combined with the high Ångström coefficient values at this time are a clear signature that biomass burning aerosols are a significant contributor to the aerosol loading along with dust outbreaks. Dust is less prevalent across the Sahara in winter (Fig. 8d) compared to the other seasons, except over the Bodélé, and it is readily apparent that dust activity across the desert regions of the Sahara and the Arabian Peninsula peaks in spring and summer. This is corroborated by the monthly AODs over KAUST Campus (Fig. 7e) and Solar Village (Fig. 7g), whose AODs are greatest during these seasons. The MODIS AODs are especially high over the Red Sea and the Arabian Sea in summer. During the winter months the Arabian AERONET AODs are lower and the Ångström coefficients are higher, indicating the greater relative contribution by urban/industrial aerosols to the overall aerosol loading.

The Mediterranean sites CUT-TEPAK (Fig. 7b) and Lampedusa (Fig. 7f) display weaker AODs than the other sites, with peak monthly AODs not greatly exceeding 0.2. The Ångström coefficient values are also rather higher than at the other sites, with monthly values always greater than 0.6: this is an indication that these sites are often more affected by anthropogenic pollution than by dust, despite their relative proximity to the Saharan and Middle Eastern dust source regions. This is also indicative of the episodic nature of long-range transported dust events. MODIS AODs are in general greatest over the Mediterranean during spring (Fig. 8a), the season when Sharav (known as Khamsin in Arabic) cyclones are most active along the North African coast (Alpert and Ziv, 1989; Abed et al., 2009) and which are often responsible for generating dust storms over the southern Mediterranean. 

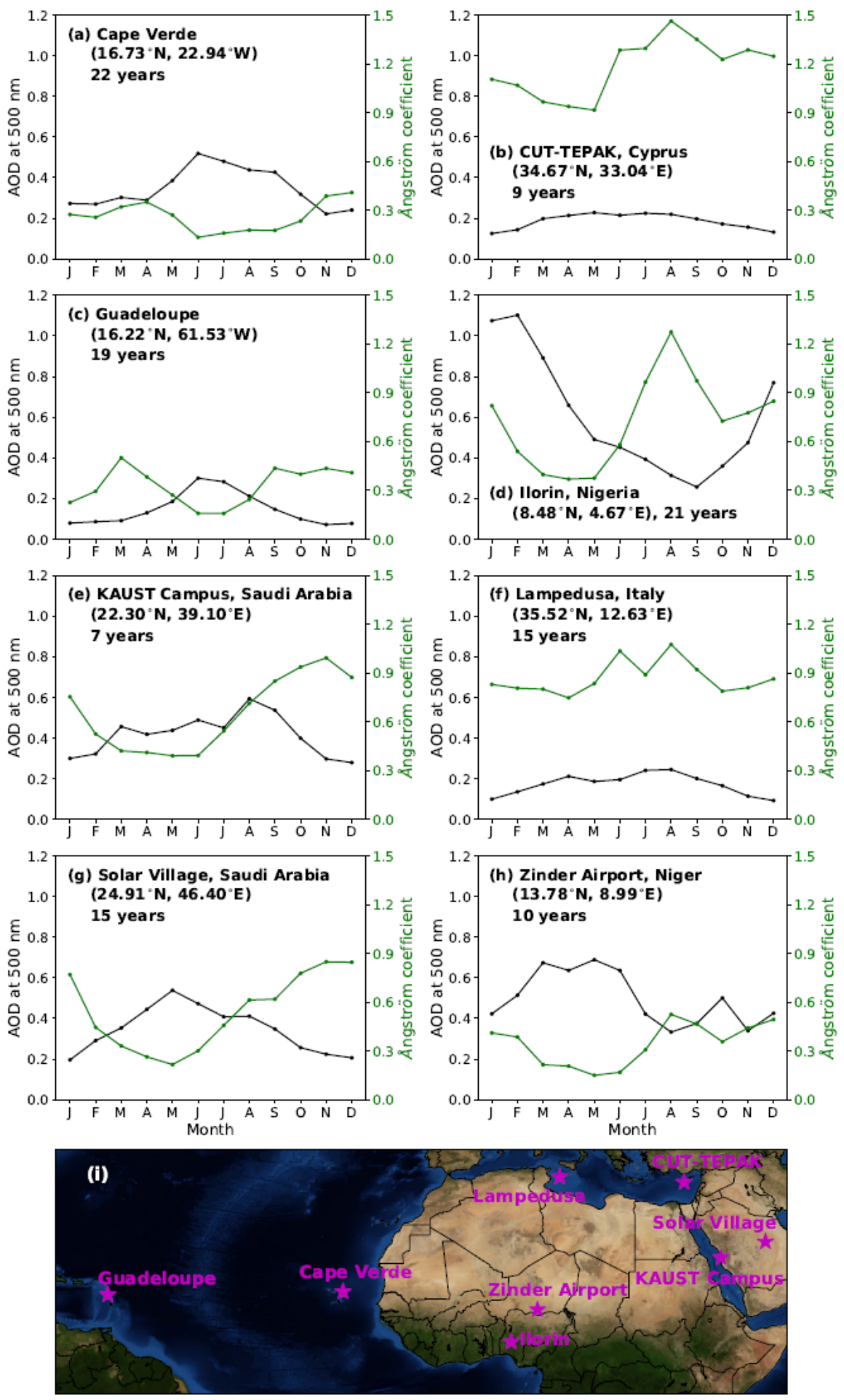

Figure 7. Climatological monthly AERONET AODs at $500 \mathrm{~nm}$ (black), along with the climatological monthly Ångström coefficients between 440 and $870 \mathrm{~nm}$ (green), for eight dust-affected sites, mapped in panel (i). The number of years contributing to each climatology is written on each panel. 


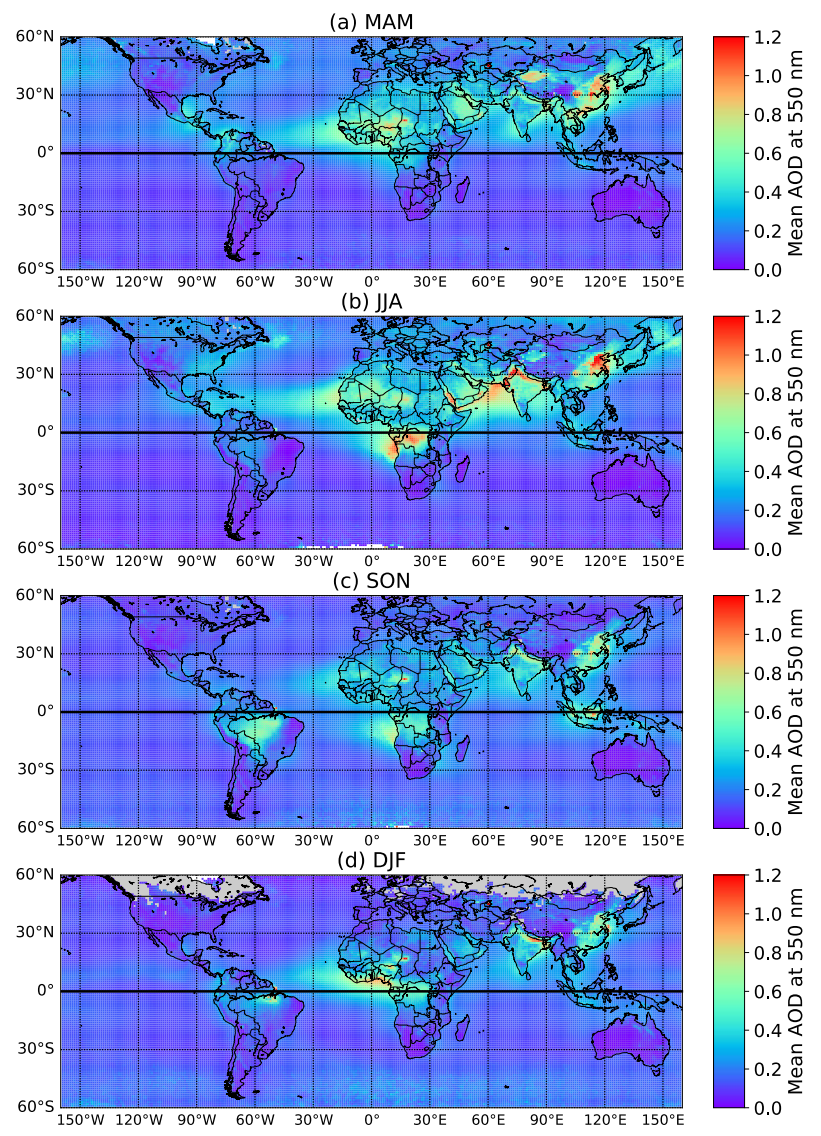

Figure 8. Seasonal averages of Terra MODIS monthly mean AODs, from the MOD08_M3 product (Collection 6.1), using merged Dark Target and Deep Blue AODs. Time-period is 2001-2018. Data obtained from NASA's LAADS DAAC service.

\section{Atmospheric processes associated with dust long-range transport patterns}

The mineral dust lifecycle in the atmosphere is characterized by emission, transport and deposition, which are in turn tightly linked to atmospheric conditions at different spatial and temporal scales. Dust availability for emission is primarily controlled by soil moisture and vegetation cover, and is higher in desert environments and shrublands (Engelstaedter et al., 2003). Winds blowing over dry erodible sediments trigger dust emission when exceeding a threshold (which may vary in the range 6-20 $\mathrm{m} \mathrm{s}^{-1}$, depending on the location (Chomette et al., 1999; Laurent et al., 2006; Marticorena et al., 1997), making instantaneous meteorological conditions the main driver of dust emission. In addition, strong winds necessary to trigger dust emission are favored in closed topographic depressions where the wind is channeled into low level jets (Evan et al., 2016; Washington et al., 2006; Washington and Todd, 2005). Once dust is 
emitted, it can be uplifted to heights of up to $8-10 \mathrm{~km}$, where it is transported over distances reaching thousands of $\mathrm{km}$ embedded into the mid-tropospheric circulation (Uno et al., 2009), to be removed from the atmosphere by means of wet and dry processes. Long-range transport and deposition is then associated with atmospheric processes at synoptic-to-global scale.

This section focuses on the influence of the atmospheric dynamics of the long-range transport paths of dust from the main sources worldwide (Ginoux et al., 2012; Prospero et al., 2002; Washington et al., 2003). Depending on the latitudinal position of the sources, the main transport routes point to the east or to the west. Namely, from North African sources in the Sahara and the Sahel towards the Atlantic and the Mediterranean (Prospero, 1996), from East Asian sources in the Gobi and the Taklimakan Deserts towards the Pacific (Uematsu et al., 1983), from the Middle East and the Arabian Peninsula towards the Arabian Sea and the Mediterranean (Zhu et al., 2007) and from sources in Australia, Patagonia and the Kalahari desert towards the Southern Ocean and Antarctica (Li et al., 2008)
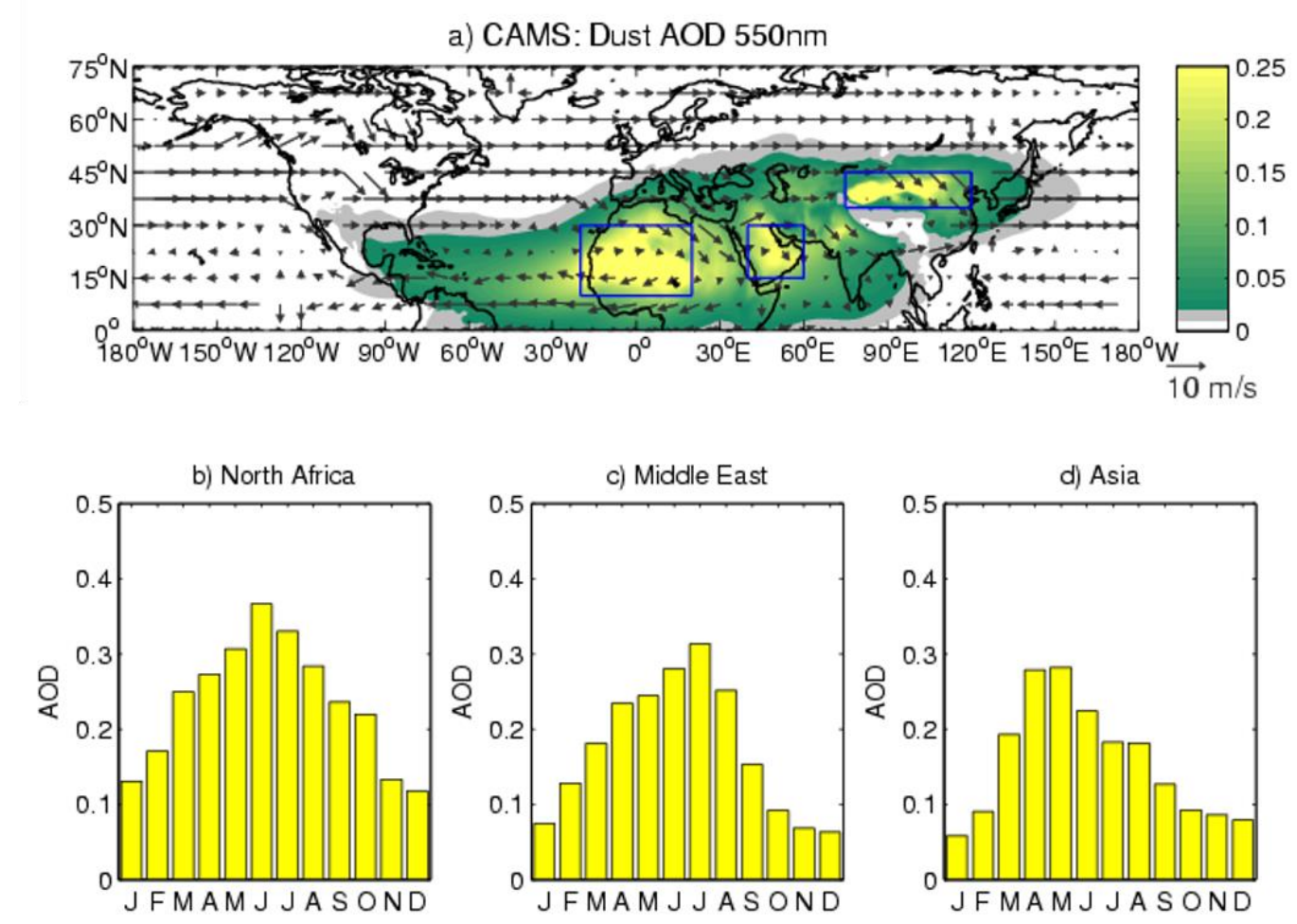

Figure 9. Northern Hemisphere: 2003-2017 climatology computed using data from Copernicus Aerosol Monitoring System (CAMS) reanalysis. (a) Dust AOD at $550 \mathrm{~nm}$ (shadings) and wind at $700 \mathrm{hPa}$ (arrows); seasonal cycle of $A O D$ in (b) North Africa, (c) Middle East and (d) Asia, computed as the average AOD in the blue boxes. CAMS data are available at the European Centre for Medium-range Weather Forecast (ECMWF) data portal: https://apps.ecmwf.int/datasets/. 


\subsection{North African dust transport towards tropical Atlantic and the Mediterranean}

North Africa is estimated to emit about $400-2,200 \mathrm{Tg} \mathrm{yr}^{-1}$ of mineral dust each year, more than half of the global total, from sources located in the Sahara Desert and the Sahel (Fig. 9a; Chiapello, 1997; Evan et al., 2015; Ginoux et al., 2012; Huneeus et al., 2011; Yu et al., 2018). By means of a soil-derived emission scheme, Marticorena and Bergametti (1996) estimated the annual dust emission in the western Sahara at $665 \mathrm{Tg}$ in 1991 and $586 \mathrm{Tg}$ in 1992, with the minimum in December 1992 (8 Tg) and the maximum in March 1991 (163 Tg). This variability reveals a pronounced seasonal cycle, peaking in spring-to-summer (Fig. 9b; Ginoux et al., 2012; Prospero et al., 2002) and associated with different atmospheric processes leading to the activation of sources at different locations (Knippertz and Todd, 2012). Location and seasonality of the sources shape the main transport routes from North Africa. During boreal winter and spring, dust emission is relatively weak and mainly originates from sources in the extremely dry Bodélé Depression (north of Lake Chad), driven by Harmattan surges shaped into low-level jets by local topography (Washington and Todd, 2005). Dust uplifted in the Bodéle Depression is then transported southwestward by the semi-permanent Harmattan northeasterly wind regime which dominates the regional circulation in winter (Marticorena et al., 2010). Spring-to-summer emissions from the northern sector of the Sahara are controlled by synoptic scale cyclones (the Sharav cyclones (Alpert and Ziv, 1989) developing south of the Atlas and travelling eastward along the Mediterranean coastline (Karam et al., 2010). Simultaneously, the development of the monsoonal circulation in West Africa leads to the activation of dust sources in the western Sahara and the Sahel, triggered by cold pools associated with mesoscale convective systems travelling westward across West Africa (Marsham et al., 2008).

The main long-range transport path of North African dust is over the tropical Atlantic, where dust uplifted from sources located in Algeria, Mali and Mauritania travels towards North and South America embedded within the prevailing easterly regime (Gläser et al., 2015), the so-called SAL layer (Fig. 9a). In boreal summer and autumn, the preferred pathway is to the Caribbean, with dust transported within an atmospheric layer up to 5-6 km height, while in winter and spring, dust is mainly transported closer to the surface to South America (Gläser et al., 2015; Huang et al., 2010). A long-term climatology of the route over northern tropical Atlantic is provided by in-situ observations of African dust in Barbados, which date back to 1965 (Delany et al., 1967; Prospero, 1968; Prospero and Carlson, 1980). African dust samples have been also collected in the Yucatan Peninsula, French Guiana and the Amazon Basin (Das et al., 2013; Prospero et al., 1981; Swap et al., 1992). The integration of satellite products with in-situ and proxy observations of 
atmospheric dust allows the development of decade-long datasets and provides evidence for the seasonal cycle, the interannual variability as well as the decadal variability and trends of dust emission and transport from North Africa, in connection with the controlling atmospheric dynamics (Chiapello et al., 2005; Evan and Mukhopadhyay, 2010). The amount of dust deposition into the tropical Atlantic Ocean has been recently estimated at 136-222 $\mathrm{Tg} \mathrm{yr}^{-1}$ (Yu et al., 2019). Dust deposition is highest in boreal summer and lowest in fall, whereas the interannual variability is largest in spring (28-41\%) and smallest (7-15\%) in summer (Yu et al., 2019). Dust export to the Atlantic in summer is controlled by the geopotential difference between tropics and subtropics over North Africa, which regulates the mid-tropospheric easterly flow and precipitation in West Africa (Rodríguez et al., 2015). The modulation of the geopotential field by the mid-latitude Rossby wave regime generates an intra-seasonal pulsation of the dust flux, via the longitudinal displacement of the mid-tropospheric Saharan anticyclone: when the anticyclone is displaced over the western Sahara, the export is westward to the Atlantic, when the anticyclone is displaced over the eastern Sahara dust is exported to the central-western Mediterranean (Cuevas et al., 2017). Dust outbreaks over the Atlantic are associated with warm phases of the Saharan heat low (SHL), which favor the emission from dust sources in the western Sahara and simultaneously intensify the mid-tropospheric African easterly jet (AEJ), opening the route to the west (Schepanski et al., 2017; Wang et al., 2017). The interannual variability of dust transport and deposition in the Caribbean appears to be linked with the meridional position of the intertropical convergence zone (ITCZ) (Doherty et al., 2014, 2012). Specifically, an anomalous southward displacement of the ITCZ during boreal summer in West Africa favors dry conditions and stronger northerly winds over the southern Sahara and the Sahel, which in turn trigger higher than average dust emission. A contribution from global climate variability, such as the ENSO and the NAO, has been also proposed to explain the interannual variability of the Atlantic dust route (DeFlorio et al., 2016; Moulin et al., 1997b). During strong La Niña conditions, the intensification of the lower troposphere easterlies favors the transatlantic transport (DeFlorio et al., 2016). Moreover, during positive NAO phases, North Africa tends to be drier and the subtropical Atlantic anticyclone intensifies, resulting in favorable conditions for dust uplift and westward transport (Moulin et al., 1997b). During the second half of the 20th century, Atlantic dust pathway showed a marked decadal variability (Chiapello et al., 2005; Evan and Mukhopadhyay, 2010). Evan et al. (2016) show that these decadal fluctuations can be explained by the variability of the surface wind pattern in North Africa, which reflects the orographic acceleration of the surface flow necessary for dust emission. A role for the monsoonal dynamics in West Africa has also been suggested to explain the dust peak in the 1980s and the subsequent negative trend. On the one hand, the 
environmental and climatic conditions which accompanied the weakening of the West African monsoon during the 1970s-80s, such as a devastating drought in the Sahel (Chiapello et al., 2005; Prospero and Lamb, 2003) and an anomalous southerly position of the ITCZ (Doherty et al., 2014, 2012), were particularly favorable for large emissions from sources in North Africa. On the other hand, the recent intensification of the SHL and associated low tropospheric cyclonic circulation resulted in a weakening of the wind field, and the consequent dust emission, from the major "hotspots" in the Sahara (Wang et al., 2015). In Fig. 10, the monthly anomalies of CAMS dust AOD in the African-Atlantic sector are correlated with the NAO index and the Sahelian precipitation index. Correlation maps show that dust emission from Saharan sources and the export above the Tropical Atlantic is favored (inhibited) by positive (negative) NAO phases (Fig. 10a) and dry (wet) precipitation anomalies in the Sahel (Fig. 10b), which are in turn associated with a southward (northward) displacement of the ITCZ.
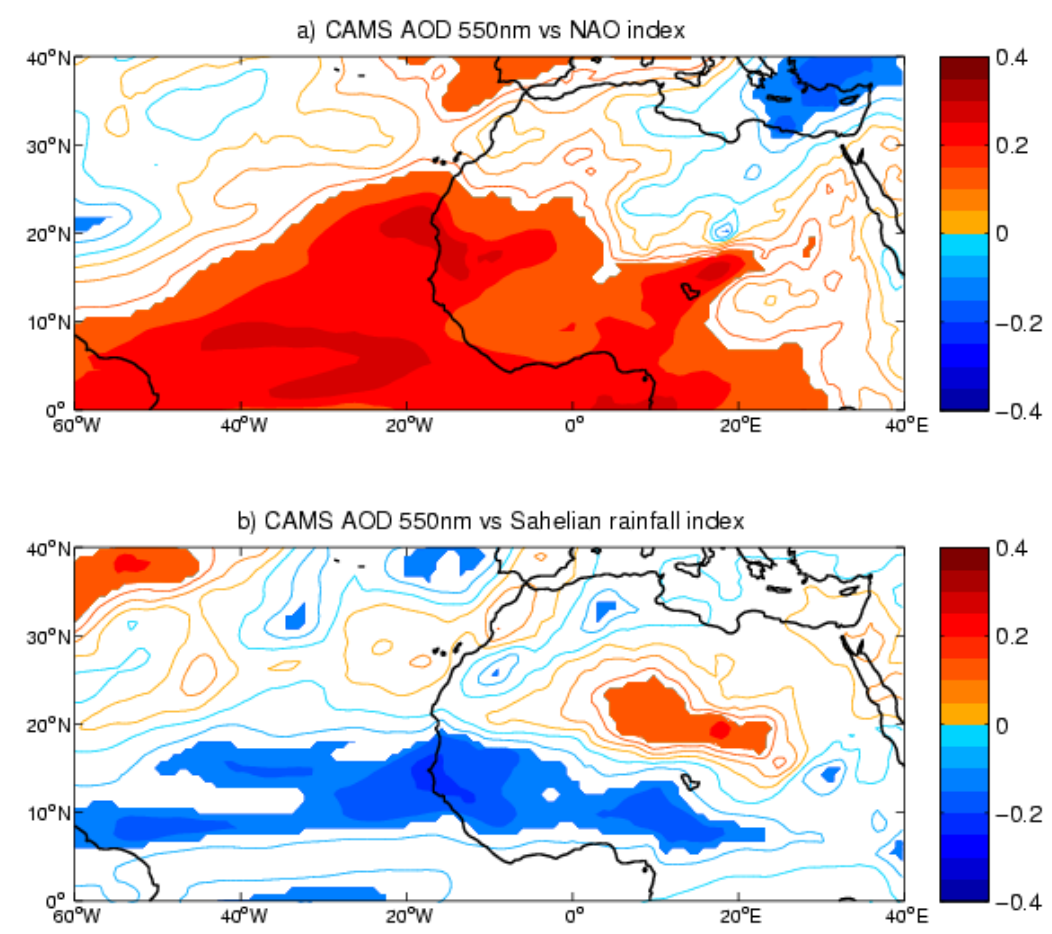

Figure 10. North African dust: monthly correlation map for the period 2003-2017 of the dust AOD at 550 $\mathrm{nm}$ from CAMS and (a) the North Atlantic Oscillation (NAO) index and (b) the Sahelian precipitation index.

Significant correlations $(p<0.10)$ are displayed as shadings. CAMS data are available at the European Centre for Medium-range Weather Forecast (ECMWF) data portal: https://apps.ecmwf.int/datasets/. The

NAO index time series is available at the National Ocean Atmosphere Administration (NOAA) Earth System Research Laboratory (ERSL) portal: https://www.esrl.noaa.gov/psd/data/climateindices/list/. The Sahelian rainfall index is available at the Joint Institute for the Study of the Atmosphere and Ocean (JISAO) of the University of Washington: http://research.jisao.washington.edu/data_sets/sahel/. 
Saharan dust outbreaks into the Mediterranean and southern Europe are common from March to September, mostly fed by sources in the northern sector of the Sahara desert (Israelevich et al., 2002; Moulin et al., 1998; Salvador et al., 2014; Vincent et al., 2016). Southerly dust advection is concentrated in plumes located at altitudes between 2500 and $6000 \mathrm{~m}$, characterized by 1500$3400 \mathrm{~m}$ thickness (Papayannis et al., 2008). The transport route moves from east in spring to west in summer, modulated by the cyclonic activity over North Africa and the Mediterranean (Barkan et al., 2005; Dayan et al., 1991; Gaetani et al., 2016; Gaetani and Pasqui, 2014; Gkikas et al., 2012; Kaskaoutis et al., 2019; Salvador et al., 2014; Varga et al., 2014). Specifically, dust events in the eastern Mediterranean are associated with the development of cyclonic conditions over the central or eastern Mediterranean leading to southerly advection from eastern North Africa. Conversely, anticyclonic conditions in the eastern Mediterranean, confining low-pressure to the west, lead to dust advection from western North Africa into the western Mediterranean. Saharan dust may eventually reach central and Eastern Europe by crossing the central Mediterranean (Ansmann et al., 2003; Israelevich et al., 2012; Koltay et al., 2006). Moreover, cutoff cyclonic circulations reaching western North Africa from the mid-latitude jet stream are able to capture dust that is then transported northward to polar latitudes by the same cyclones on their way back to the main westerly flow (Francis et al., 2018). The Saharan dust loading in the Mediterranean atmosphere shows variability from interannual to decadal time scales (Moulin et al., 1997a; Antoine and Nobileau, 2006). Moulin et al. (1997b) show that the interannual variability can be explained by the impact of the NAO on the Mediterranean climate. During positive NAO phases, the Mediterranean and North Africa are drier and prone to dust emission and mobilization. Conversely, negative NAO phases are characterized by wetter conditions in the region, limiting the intensity of both dust uptake and transport. Jilbert et al. (2010) highlight the role of summer anticyclonic conditions in the Mediterranean on dust advection at the multidecadal time scale: weak (strong) anticyclonic circulation favors stronger (weaker) summer westerlies leading to increased (reduced) dust emission.

\subsection{Middle East dust transport towards the Indian Ocean and the Mediterranean}

The eastern Mediterranean is also affected by dust transport from the Middle East, occurring especially in fall when the synoptic circulation is characterized by the Red Sea Trough or cyclonic conditions in the eastern Mediterranean (Bodenheimer et al., 2019; Dayan et al., 1991; Parolari et al., 2016). The major dust source regions in the Middle East are the Iraqi desert and the AdDahna and the Rub'al Khali deserts in the Arabian Peninsula (Fig. 9a; Yu et al., 2018). Dust emission is maximal during boreal summer (Fig. 9c), triggered by the summer Shamal wind, which 
is also responsible for the long-range transport southeastward (Yu et al., 2018). The Middle Eastern Shamal is a strong northwesterly wind blowing in May to August as part of the cyclonic circulation associated with the development of the Iranian heat low (Yu et al., 2016). The onset and persistence of the Shamal season is sensitive to ENSO conditions, which modulate the Iranian heat low activity at the interannual time scale (Yu et al., 2016). Specifically, La Niña (EI Niño) conditions favor (inhibit) the development of the Iranian heat low in spring and inhibit (favor) its persistence into late summer, leading to early (late) onset and termination of the Shamal regime. Moreover, the intensity of the Shamal wind is influenced by SST anomalies in the Indian Ocean, with cold anomalies producing an anomalously anticyclonic circulation over the central Arabian Peninsula, eventually enhancing the Shamal (Yu et al., 2015). On longer time scales, dust emission from the Middle East is controlled by climatic factors such as precipitation, soil moisture and vegetation. In particular, the recent drying of the region led to an increase in dustiness in the first decades of the 21st century (Namdari et al., 2018; Parolari et al., 2016; Ravi Kumar et al., 2019; Yu et al., 2018). Dust uplifted from sources in the Middle East is exported towards the Arabian Sea, peaking in spring-summer, eventually reaching the Indian subcontinent embedded in the monsoonal flow at altitudes up to $4 \mathrm{~km}$ (Zhu et al., 2007). Part of the dust observed over the Arabian Sea is transported from sources in Somalia (Rashki et al., 2019).

\subsection{Asian dust transport on the North Pacific route}

From North Africa and the Middle East, the "dust belt" continues into western Asia, the Indian subcontinent and central Asia, characterized by almost persistent dust activity peaking in spring (Fig. 9d; Ginoux et al., 2012; Prospero et al., 2002; Washington et al., 2003). In western Asia, a cluster of intermountain sources located between the Caspian Sea, the coast of the Persian Gulf and the Arabian Sea, and the mountains of Tajikistan and Afghanistan, provides dust for atmospheric transport to the Arabian Sea (Fig. 9a). In the northern part of the Indian subcontinent, large dry areas extend in Pakistan and Rajasthan, where the Thar Desert is the main regional dust source (Fig. 9a). Dust distribution in this region is controlled by the Himalayas and the Hindu Kush, which topographically limit the long-range transport, and by the development of the Indian monsoon, which in summer limits dust emission to the west. In the Xinjiang Province in western China, the Tarim Basin, which hosts the Taklimakan Desert, is characterized by dust activity from February-March to August-September, with maximum emission in April-May (Fig. 9a). In winter, dust emission is observed in the Gobi Desert in northern China (Fig. 9a). Between 100 and 460 $\mathrm{Tg}$ of dust is injected into the atmosphere annually when dust storms occur in the Tarim Basin and in the Gobi Desert (Laurent et al., 2006), making Asian sources competitive with the Saharan 
sources in the global dust budget. However, the satellite estimation of the atmospheric dust burden in Asia, especially in populated areas of India and China, is complicated by the presence of large amounts of pollutants, originating from transportation, industrial and domestic emissions (Prospero et al. 2002).

Dust emission from Chinese sources is triggered by fronts emerging from Siberia, the Mongolian cyclonic depression or surges of the East Asian monsoon, which interact with the extreme bounding topography of the region (Sun et al., 2001). In general, dust originating from the Gobi Desert is entrained to elevations up to $3000 \mathrm{~m}$ and transported north of $50^{\circ} \mathrm{N}$, while dust from the Taklimakan Desert may reach $5000 \mathrm{~m}$ and be transported over long distances by mid-latitude westerlies, blowing south of $50^{\circ} \mathrm{N}$ (Sun et al., 2001; Yu et al., 2019). Dust from China is persistently exported eastwards to Korea and Japan, routinely reaches the central North Pacific, and is occasionally detected over North America (Zhu et al., 2007). In the North Pacific, high dust concentrations are observed from February to June and low concentrations from July to January. It is estimated that 6-12 $\mathrm{Tg}$ of Asian dust reach the central North Pacific annually (Merrill et al., 1989; Uematsu et al., 1983). Satellite retrievals of Asian dust vertical distributions also show dust layers at altitudes of 8-10 km, suggesting possible long-range transport via upper tropospheric westerly jets (Huang et al., 2008). Uno et al. (2009) highlighted the possibility of circum-global transport in the Northern Hemisphere for Asian dust, which has been observed to cross North America and reach Greenland (Bory et al., 2003) and Europe (Grousset et al., 2003). Using climate simulations, Gong et al. (2006) studied the variability of the emission and transport of Asian dust in connection with the main circulation patterns in the Asian-Pacific sector. They found that, at the interannual time scale, peak dust emission in spring is negatively correlated with precipitation and surface temperatures. However, the intensity of the East Asian monsoon does appear to be more related to the dust export rather than to dust production itself. Moreover, the meridional distribution of dust loadings in the Pacific is controlled by the extent and intensity of the Asian polar vortex, via the modulation of the mid-latitude westerlies. The zonal distribution of dust deposition in the Pacific, i.e. the fraction of Asian dust reaching North America, is correlated negatively with the Pacific/North America (PNA) pattern index and positively with the Western Pacific (WP) pattern index. The Southern Oscillation index (SOI) displays a significant positive correlation with dust loadings over eastern China and northeast Asia. This implies a negative correlation with the ENSO index, resulting in a northward shift of the trans-Pacific transport path during EI Niño years, and intense emissions from central and northeastern China in La Niña years. However, sizeable levels of dust emission and transport may also be observed during El Niño years in association with negative phases of the Arctic Oscillation (AO) (Lee et al., 2015). At the 
decadal time scale, the Pacific decadal oscillation (PDO) appears to modulate dust loadings in the Asian dust source regions and in the North Pacific and North America (Gong et al., 2006). In Fig. 11, the monthly anomalies of CAMS dust AOD in the African-Atlantic sector are correlated with the PNA and PDO indices. Correlation maps show that dust emission from Asian sources and the export above the North Pacific is favored (inhibited) by negative (positive) phases of the PNA (Fig. 11a) and PDO (Fig. 11b) patterns.

a) CAMS AOD 550nm vs PNA index

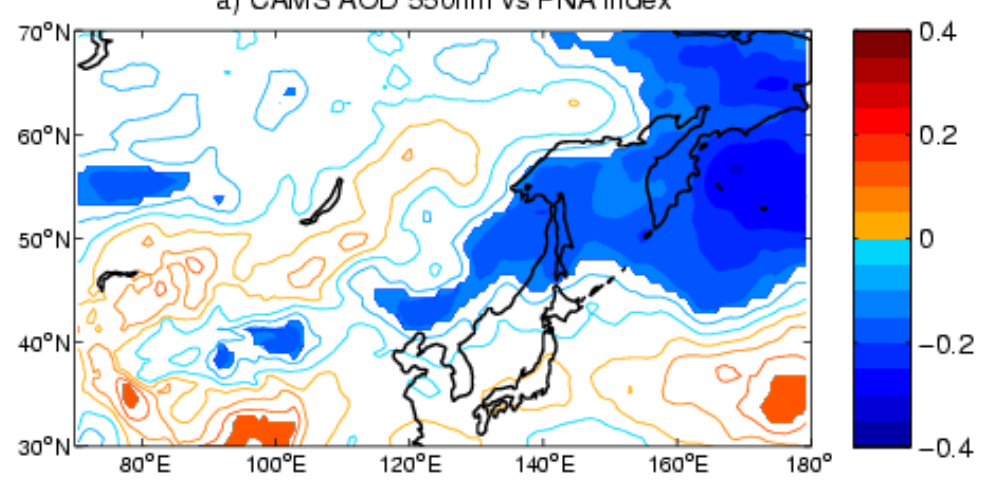

b) CAMS AOD 550nm vs PDO index

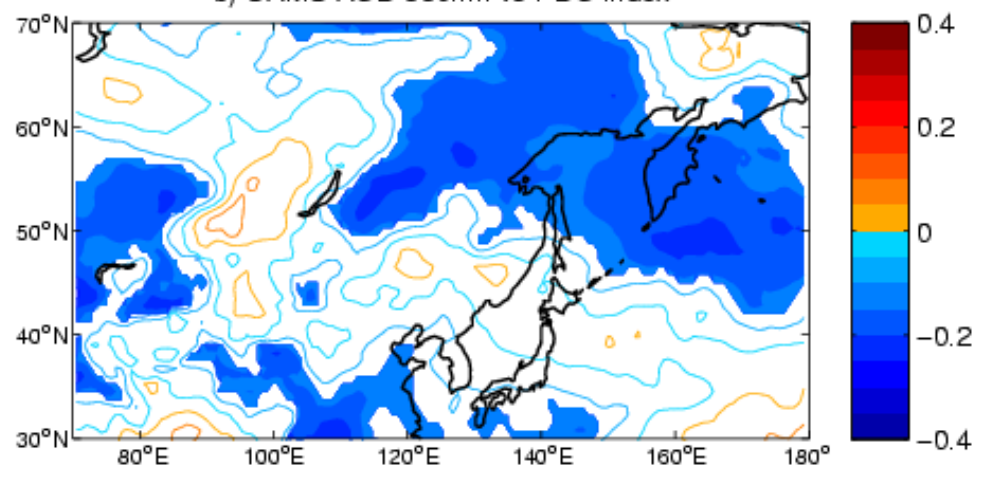

Figure 11. Asian dust: monthly correlation map for the period 2003-2017 of the dust AOD at $550 \mathrm{~nm}$ from CAMS and (a) the Pacific North America (PNA) pattern index and (b) the Pacific Decadal Oscillation $(P D O)$ index. Significant correlations $(p<0.10)$ are displayed as shadings. CAMS data are available at the European Centre for Medium-range Weather Forecast (ECMWF) data portal:

https://apps.ecmwfint/datasets/. The PNA index is time series is available at the National Ocean Atmosphere Administration (NOAA) Earth System Research Laboratory (ERSL) portal: https://www.esrl.noaa.gov/psd/data/climateindices/list/. The PDO index is available at the Joint Institute for the Study of the Atmosphere and Ocean (JISAO) of the University of Washington: from http://jisao.washington.edu/pdo/PDO.latest. 


\subsection{Dust transport in the Southern Hemisphere}

Dust in the Southern Hemisphere is emitted from sources in Australia, Patagonia, and Southern Africa, and is transported from the sources eastwards embedded in the mid-latitude westerly flow, to sediment in the Southern Ocean and Antarctica (Fig. 12a; Li et al., 2008). Emission and transport peak during austral summer (Fig. 12b, c, d).

Australian dust emission is estimated at $120 \mathrm{Tg} \mathrm{y}^{-1}$ (Li et al., 2008). The main emission sources are located in the Kati Thanda-Lake Eyre region of central Australia, and the Darling Riverine Plain in southeastern Australia (Fig. 12a; De Deckker, 2019). Dust uplift is usually associated with non-precipitating cold fronts: either cold fronts embedded in zonal westerlies, or cold fronts in westerlies derived from low pressure systems in the Great Australian Bight, or cold fronts over eastern Australia where high pressure systems in the Great Australian Bight generate strong post-frontal winds (Leslie and Speer, 2006). Suspended dust is eventually exported northeastwards to reach the southern Philippines and southwestwards over much of the South Pacific and Southern Oceans, routinely reaching Antarctica (Fig. 12a; McGowan and Clark, 2008). Dust plumes travel in the northwestern corridor over Indonesia, Borneo and New Guinea at low altitudes, while in the southeastern corridor dust is exported up to $5 \mathrm{~km}$ altitude (McGowan and Clark, 2008).

South America is the second most important dust source in the Southern Hemisphere, exporting $31 \mathrm{Tg}$ of dust annually from Patagonia (Fig. 12a; Li et al., 2010, 2008). Observations and model outputs agree in placing most of the dust plumes in the boundary layer, which suggests significant deposition over the ocean immediately downwind of the sources (Gassó et al., 2010; Li et al., 2008). However, under specific meteorological conditions, dust may reach Antarctica. Export towards East Antarctica occurs in the South Atlantic, driven by the cyclonic circulation associated with low-pressure systems moving eastward in the subpolar low pressure zone (Johnson et al., 2011; Li et al., 2010). Dust can also be directly transported to West Antarctica, when highpressure conditions prevent depressions from travelling through the Drake Passage towards the South Atlantic (Li et al., 2010).

The annual emission of mineral dust from Southern Africa is around 2,300 Mg (Ginoux et al., 2012). Emissions peak from July to January (Fig. 12c; Li et al., 2008), mostly originating from ephemeral inland lakes, coastal pans, and dry river valleys, as well as aeolian deposits in Namibia, Botswana, and South Africa (Fig. 12a; Bhattachan et al., 2012; Vickery et al., 2013). The depressions of the Makgadikgadi Pan in Botswana and Etosha Pan in Namibia are estimated to be the major dust sources in the region (Bryant et al., 2007; Prospero et al., 2002; Washington 
et al., 2003). Emission events are associated with the strengthening of the low-level easterly circulation over the interior of the continent (Washington et al., 2003). Satellite observations of conditions at the surface and dust atmospheric loading suggest that dust loadings are influenced by the extent and frequency of lake inundation and sediment inflows (Bryant et al., 2007). Specifically, dust loadings are reduced during periods of inundation, to increase again after flooded areas have dried (Mahowald et al., 2003). At the interannual time scale, part of the observed variability in the dust and hydrological cycle in the region is attributed to ENSO and Indian Ocean SST anomalies, which have an important role in modulating rainfall variability in southern Africa (Pohl et al., 2018). For instance, cold anomalies in the Indian Ocean during La Niña years may favor the landfall of tropical cyclones and storms, affecting the timing and abundance of dust emission (Bryant et al., 2007). Trajectory analyses show that dust from sources in southern Africa commonly reaches the central tropical South Atlantic embedded in the anticyclonic circulation of the St Helena high (Fig. 12a; Swap et al., 1996). Long-range transport over the Southern Ocean is also documented, when uplifted dust is deflected towards the midlatitude westerly flow (Fig. 12a; Bhattachan et al., 2012; Li et al., 2008).
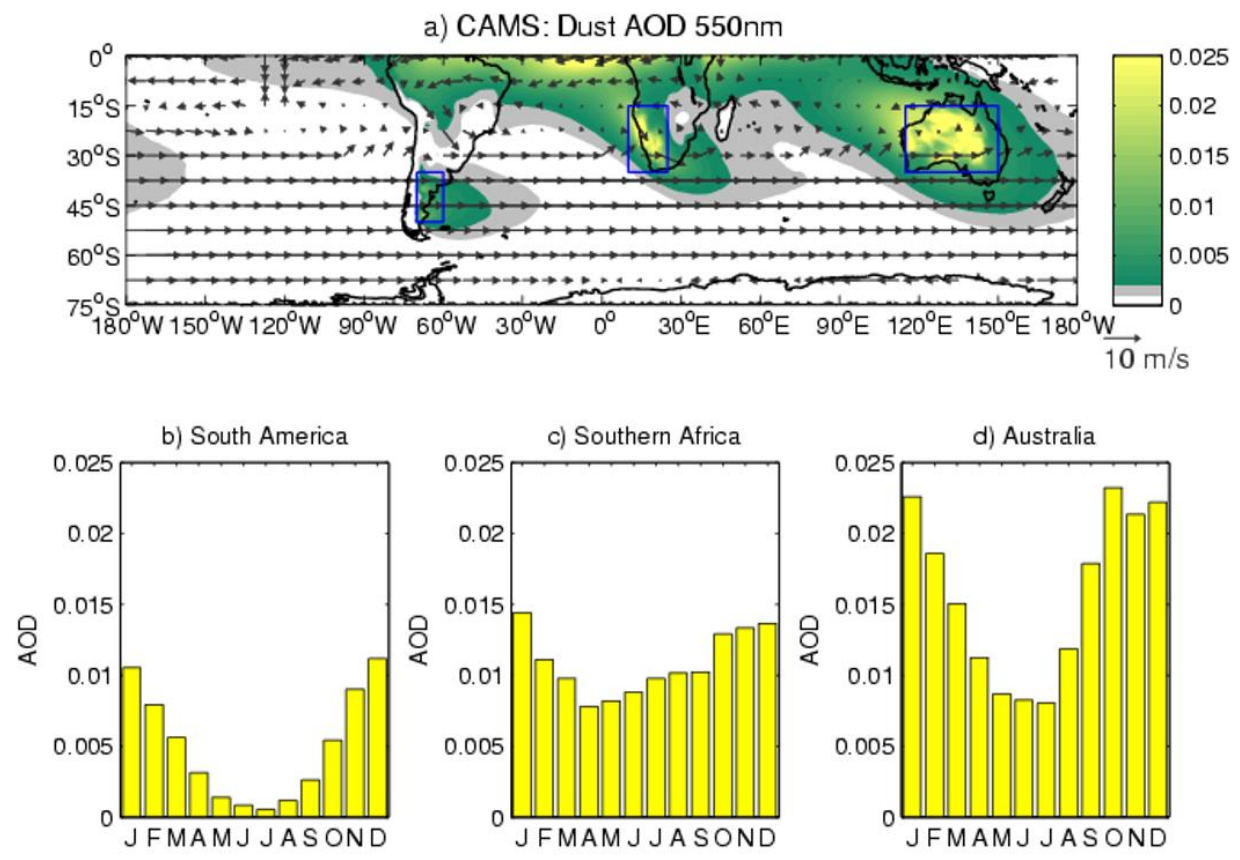

Figure 12. Southern Hemisphere: 2003-2017 climatology computed using data from Copernicus Aerosol Monitoring System (CAMS) reanalysis. (a) Dust AOD at $550 \mathrm{~nm}$ (shadings) and wind at $700 \mathrm{hPa}$ (arrows); seasonal cycle of $A O D$ in (b) South America, (c) southern Africa and (d) Australia, computed as the average $A O D$ in the blue boxes. CAMS data are available at the European Centre for Medium-range

Weather Forecast (ECMWF) data portal: https://apps.ecmwf.int/datasets/. 


\section{The physico-chemical aging of dust aerosols during transport and its implications}

The physico-chemical properties of mineral dust aerosol relevant for their multiple climatic and environmental impacts are the number, volume, and mass size distribution (that is the distribution of the number, volume, and mass concentration per size class), the chemical composition, and the particle morphology (shape and roughness). The size distribution of freshly emitted dust extends from hundreds of nanometers to tenths or even hundreds of micrometers in diameter. Dust is directly entrained into the atmosphere by the mechanical friction of wind on continental surfaces, which results in a dominant volume/mass coarse mode centered between about 5 to 20 um (e.g., Rajot et al., 2008; Ryder et al., 2013a; Kok et al., 2017). Still, contradictory results exist on the dependence of the dust size distribution at emission on wind speed and soil properties (e.g., Alfaro et al., 1998; Kok, 2011; Mahowald et al., 2014). Freshly uplifted dust aerosols are composed of a mixture of minerals including clays (illite, kaolinite, smectite), quartz, feldspars, calcium-rich species (calcite, dolomite), and titanium and iron oxides (hematite, goethite) (Pye, 1987; Kandler et al., 2007; Jeong, 2008; Formenti et al., 2008, 2014; Scheuvens and Kandler, 2014). The composition of dust depends on the mineralogy of the source soils and varies from one source to another both at the local, regional and global scales (Bristow et al., 2010; Formenti et al., 2014; Di Biagio et al., 2017). Also, dust mineralogy changes with the particle size due to the different size distribution of single constituent minerals: quartz, feldspars, and calcium-rich species are generally more abundant in the coarse mode component, while clays dominate the fine fraction (e.g., Pye, 1987). Dust particles have a complex and irregular morphology linked to the shape and roughness properties of its single composing constituents (e.g., Chou et al., 2008; Nouniasien and Kandler, 2015).

After injection into the atmosphere, the physico-chemical properties of dust may be modified due to multiple aging processes that can occur during transport, including gravitational settling, coagulation, heterogeneous reactions with atmospheric gases, mixing with other aerosol types, or cloud processing (e.g., Usher et al., 2003; Formenti et al., 2011). The change of the dust physico-chemical properties as particles age in the atmosphere is important because it may induce modifications on the optical, hygroscopic and solubility properties of the dust, and thus on its multiple impacts. In this Section, first we briefly discuss the challenges associated with measuring dust physico-chemical properties, then we explore the results of recent field experiments investigating the change of these properties during transport and their influence on the climate-relevant properties and impacts of dust aerosols. 


\subsection{The challenge of measuring dust physico-chemical properties}

Up to now the majority of information on dust physico-chemical properties and their changes during atmospheric transport comes from data acquired during intensive field campaigns, in particular those over North and West Africa and along the dust transport pathways over the Atlantic Ocean and the Mediterranean Basin, as well as across the Pacific region. In particular, observations from airborne platforms have provided amongst the only in situ data of dust properties along transport routes over the ocean. Table 1 summarizes major field campaigns performed over the last two decades along the pathways of dust transport in different regions of the world.

\begin{tabular}{|c|c|c|}
\hline Campaign acronym & Campaign full name & Reference \\
\hline \multicolumn{3}{|c|}{ North and West Africa and Tropical eastern Atlantic } \\
\hline SHADE & Saharan Dust Experiment & Tanré et al. (2003) \\
\hline AMMA & African Monsoon Multidisciplinary Analysis & Redelsperger et al. (2006) \\
\hline DODO & Dust Outflow and deposition to the Ocean & McConnell et al. (2008) \\
\hline DABEX & Dust and Biomass-burning Experiment & Haywood et al. (2008) \\
\hline GERBILS & $\begin{array}{c}\text { Geostationary Earth Radiation Budget Intercomparison of Longwave } \\
\text { and Shortwave radiation }\end{array}$ & Haywood et al. (2011) \\
\hline NAMMA & NASA African Monsoon Multidisciplinary Analysis & Chen et al. (2011) \\
\hline SAMUM 1 \& SAMUM 2 & Saharan Mineral Dust Experiment & Weinzierl et al. (2011) \\
\hline FENNEC & Fennec - The Saharan Climate System & Ryder et al. (2013a) \\
\hline AER-D & Aerosol properties - Dust & Ryder et al. (2018) \\
\hline DACCIWA & Dynamics-aerosol- chemistry-cloud interactions in West Africa & Knippertz et al. (2015) \\
\hline \multicolumn{3}{|c|}{ Western Atlantic } \\
\hline LBA - CLAIRE & Cooperative LBA Air-borne Regional Experiment & Formenti et al. (2001) \\
\hline PRIDE & Puerto Rico Dust Experiment & Reid et al. (2003b) \\
\hline DUST-ATTACK & DUST Aging and Transport from Africa to the Caribbean & Denjean et al. (2016b) \\
\hline SALTRACE & $\begin{array}{l}\text { Saharan Aerosol Long-range Transport and Aerosol-Cloud- } \\
\text { interaction Experiment }\end{array}$ & Weinzierl et al. (2017) \\
\hline \multicolumn{3}{|c|}{ Mediterranean basin } \\
\hline MINATROC & MINeral dust and TROpospheric Chemistry & Van Dingenen et al. (2005) \\
\hline ADRIMED & $\begin{array}{l}\text { Aerosol Direct Radiative Impact on the regional climate in the } \\
\qquad \text { MEDiterranean region }\end{array}$ & Mallet et al. (2016) \\
\hline \multicolumn{3}{|c|}{ Pacific area } \\
\hline PEM-West & Pacific Exploratory Mission & Bachmeier et al. (1996) \\
\hline ACE-Asia & Asian Pacific Regional Aerosol Characterization Experiment & Huebert et al. (2003) \\
\hline
\end{tabular}




\begin{tabular}{|c|c|c|}
\hline TRACE-P & Transport and Chemical Evolution-Pacific & Jacob et al. (2003) \\
\hline PACDEX & Pacific Dust Experiment & Stith et al. (2009) \\
\hline INTEX-B & Intercontinental Chemical Transport Experiment-Phase B & Logan et al. (2010) \\
\hline
\end{tabular}

Table 1. List of major field campaigns performed over the transport patterns of African and Asian dust aerosols in recent decades.

Documenting the dust physico-chemical properties is a scientific and technological challenge and facing this challenge has been one of the central goals of the scientific research over recent decades (e.g., Formenti et al., 2011; Mahowald et al., 2014). The main level of difficulty resides in the measurement capacities themselves. As an example, documenting the size distribution of dust aerosols requires measuring particle diameters and number concentrations over about 4 orders of magnitude. This can be done by combining instruments working under different size ranges, targeting different physical properties (scattering efficiency, electrical mobility, inertia to acceleration ...) and therefore referring to a different definition of the aerosol diameter (optical, electrical, aerodynamic...). The full aerosol number size distribution over the entire relevant diameter range can then be retrieved from the combination of these different measurements. This is however not straightforward because of the need to refer to an identical definition of the diameter when combining datasets issued of different techniques. In particular, since dust aerosols present a complex morphology, it follows that different approaches to measure particle size can lead to very different results for the same considered particle (Reid et al., 2003b). Corrections can be applied to convert a diameter definition to another but this operation requires performing a priori assumptions on the physico-chemical properties of the dust aerosol population sampled in the field, properties that are a priori unknown. This can lead to large uncertainties for the retrieval of both the submicron and supermicron size fractions of the dust population that can be quite sensitive to the performed assumptions (Ryder et al., 2013a; Mahowald et al., 2014). Therefore, the use of different measurement techniques and the different data treatments from one study to another often cause discrepancies when comparing and combining different size distribution datasets.

Technical and operational challenges should also be faced when measuring the chemical composition (isotopic, elemental, mineralogical), mixing state, and the morphology of dust aerosols based on different available techniques (microscopy, X-ray diffraction, X-ray fluorescence, particle-induced X-Ray emission, etc.; see Formenti et al. (2011) and Scheuvens and Kandler (2014) for comprehensive revisions of available techniques), with most of them requiring the dust particles to be collected on filter substrates to be then analyzed in the laboratory. 
Whether it is for size distribution measurements or for dust collection on filters for compositional and morphological analyses, characterizing dust properties requires sampling the particles, i.e. to carry them from the natural atmosphere where they are suspended to the instrument or the filter substrate. A critical difficulty when doing this is that size-dependent biases in dust sampling due to inlet restrictions may arise, both when measuring at the ground and on board aircraft (e.g., Ryder et al., 2013a, 2018). As a consequence, field observations rarely document the whole dust coarse fraction, so that measurements do not rely on the entire dust population. This issue at present strongly limits our understanding of the coarse and giant components of the airborne dust. Size-dependent inlet restrictions might differ from one dataset to another depending on the specific experimental configuration, which may cause biases in comparing dust retrieved properties from different field campaigns or setups, therefore further complicating the synthesis of field observations. As reported in Table 1 in Ryder et al. (2018) most campaigns investigating dust based on aircraft observations had dust upper size limits varying between 5 and $40 \mu \mathrm{m}$. Conversely, field measurement setups that involved less significant inlet restrictions, and that documented more robustly the coarse and giant dust particle fraction up to hundreds of microns in the atmosphere, were the FENNEC campaign in Mauritania and Mali (Ryder et al., 2013a), the Saharan Aerosol Long-range TRansport and Aerosol Cloud-interaction Experiment (SALTRACE, Weinzierl et al., 2017) in the Tropical Western Atlantic, and the AERosol properties - Dust (AER-D, Ryder et al., 2018) campaign in the Tropical Eastern Atlantic. The upper size limit for size measurements was $930 \mu \mathrm{m}$ for FENNEC and $100 \mu \mathrm{m}$ for SALTRACE and AER-D.

\subsection{Observations of dust size, composition, and shape modifications during transport}

\subsubsection{Dust size distribution}

One of the main results of the last twenty years of observations is the consistent evidence that the coarse mode of dust aerosols (diameter $>10 \mu \mathrm{m}$ ) is effectively retained during long-range transport (Schütz et al., 1979; Maring et al., 2003; Ryder et al., 2013b; Denjean et al., 2016a, 2016b; Weinzierl et al., 2017; Ryder et al., 2018; Van der Does et al., 2018; Ryder et al., 2019). This is illustrated in Fig. 13 showing a compilation of dust size field observations taken along dust transport routes over the Sahara Desert (e.g., Ryder et al., 2013b; Weinzierl et al., 2009) and across the Atlantic Ocean, the Mediterranean Basin, and the Pacific area during various past field campaigns (e.g., Formenti et al., 2001; Maring et al., 2003; Clarke et al., 2004; Weinzierl et al., 2011, 2017; Denjean et al., 2016a, b; Ryder et al., 2018). Despite possible differences related to the different measurement techniques involved or biases related to sampling restrictions, data in Fig. 13 definitely show that dust diameters up to $30 \mu \mathrm{m}$ or more are consistently sampled after 
intercontinental transport in the atmosphere (e.g., Ryder et al., 2013b; Weinzierl et al., 2017). Giant particles with diameters up to $200 \mu \mathrm{m}$ were reported by Ryder et al. (2013b) for the "aged" dust category in their study, representing the column-averaged size distribution for dust sampled after 12 to $70 \mathrm{~h}$ from emission in West Africa. A large contribution from coarse and giant particles was also measured during the AER-D campaign in the eastern Tropical Atlantic (Ryder et al., 2018). In Ryder et al. (2018) they measured a broad size distribution for dust in the SAL (sizes from 0.3 to $100 \mu \mathrm{m}$ ), peaking at $5-10 \mu \mathrm{m}$. The dust size distribution in the marine boundary layer (MBL) during AER-D (not shown) was observed to have a narrow peak centered at $\sim 5 \mu \mathrm{m}$ and a giant mode at 20 to $60 \mu \mathrm{m}$. Aircraft observations suggested that the giant MBL mode might be dust descending from the overlying $S A L$, in agreement with previous surface observations from Jaenicke and Schutz (1978) and Kandler et al. (2011) at Cape Verde. Aircraft observations of dust aerosols above $1.5 \mathrm{~km}$ in the western Mediterranean during the ADRIMED campaign in summer 2013 were reported in Denjean et al. (2016a). They showed that the number distribution presented a coarse mode between 1.3 and $2.0 \mu \mathrm{m}$ independently of the altitude of the sampled dust, therefore suggesting a vertically well-mixed coarse component of the size distribution. Additional observations performed with a drifting balloon during ADRIMED (Renard et al., 2016; not shown) systematically measured aerosols above $15 \mu \mathrm{m}$ for a dust plume that originated a few days before in North Africa and sampled on the $17^{\text {th }}$ June 2013 over Minorca island. Based on balloon measurements, Renard et al. (2016) additionally detected particles as large as $50 \mu \mathrm{m}$ in diameter consistently during different dust episodes, supporting the hypothesis that a giant mode of dust aerosols is also efficiently transported to the Mediterranean Basin. In a recent study, van der Does et al. (2018) also reported on giant dust particles (>75 $\mu \mathrm{m}$ and up to $450 \mu \mathrm{m}$ diameter) collected at 2400 to $3500 \mathrm{~km}$ from the West African coast at buoy sampling stations across the Atlantic Ocean. 


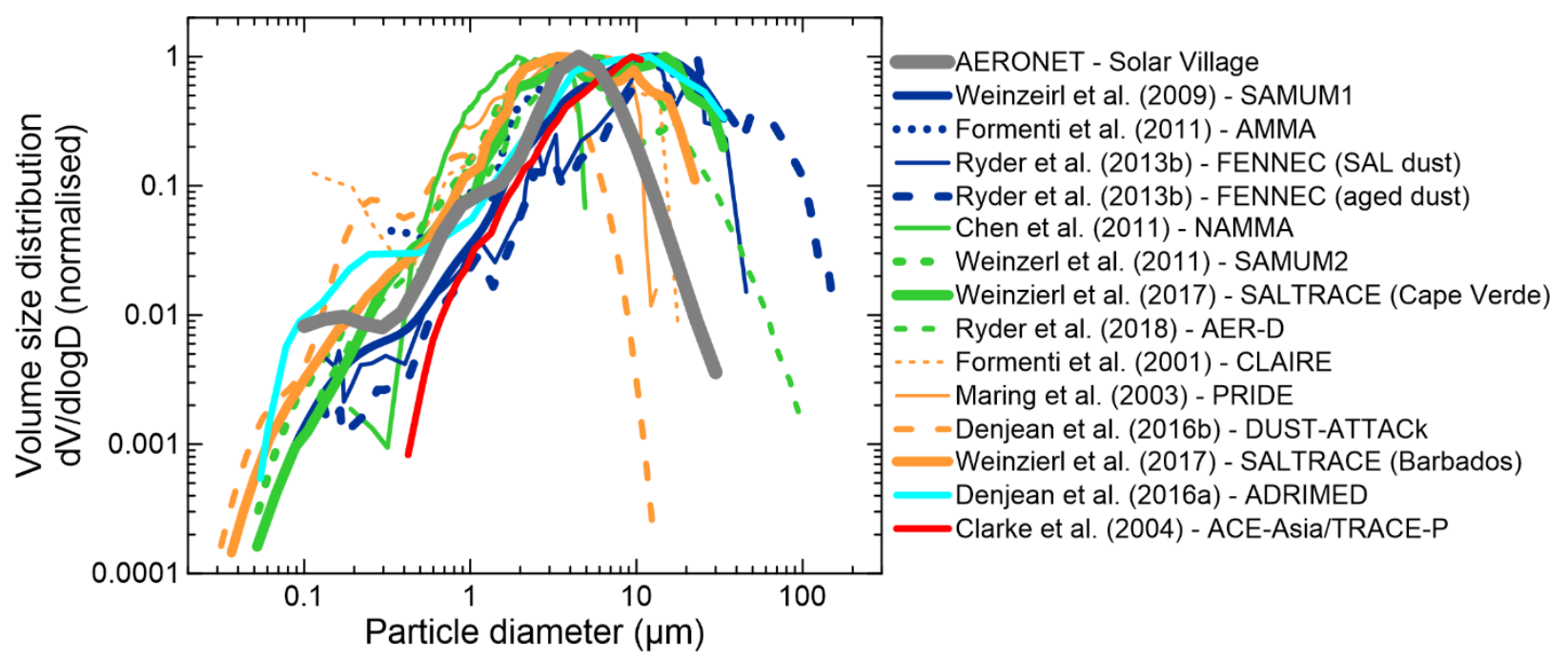

Figure 13. Volume size distributions $d V / d l o g D$ of the dust aerosols from airborne and ground-based in situ field data from campaigns in North and West Africa (blue lines), the eastern Atlantic Ocean (green lines), the western Atlantic Ocean (orange lines), the Mediterranean (cyan line) and the Pacific Ocean (red line). Retrieved average dust size distribution from AERONET remote sensing inversions (level 2 , version3) at the site of Solar Village $\left(46.4^{\circ} \mathrm{E}, 24.9^{\circ} \mathrm{N}, 764 \mathrm{~m}\right.$ a.s.l.) is also reported for comparison. The AERONET data correspond to the average of the size distribution between 2002 and 2012 for dust dominated cases selected to have an Ångström exponent < 0.75 and an AOD440 nm > 2.0. To facilitate the comparison all size data are normalized to 1 at the maximum of the volume distribution. Field campaign data are retrieved from the cited publications, while AERONET data are from https://aeronet.gsfc.nasa.gov/.

Several studies have tried to explain the dynamics of the dust size distribution during transport, concluding that the retention of the coarse mode as observed in field data cannot be justified by gravitational settling alone (Maring et al., 2003; Reid et al., 2008; Weinzierl et al., 2017; van der Does et al., 2018). Gravitational settling would in fact suggest a much faster depletion of the coarse dust mode than observed in the field. For instance, the comparison of airborne size distribution measurements at Cape Verde and Barbados from a Lagrangian case study during SALTRACE indicated that $20 \%$ and $10 \%$ respectively of the number concentration at $20 \mu \mathrm{m}$ and $30 \mu \mathrm{m}$ survived to 5 days transport across the Atlantic in the SAL, while gravitational settling calculations only would predict a maximum diameter of $7 \mu \mathrm{m}$ for dust at Barbados under the same transport conditions (Weinzierl et al., 2017). Therefore a contrasting upward force should act in keeping the coarse dust in suspension during transport. Although the dynamics of dust layers are still not completely understood, model and remote sensing data suggest different processes to be 
possibly responsible for the effective retention of the coarsest dust in the dust plume, such as daytime convective mixing within the SAL (Gasteiger et al., 2017), the presence of temperature inversions in the middle troposphere keeping the dust confined in a stable stratified layer (Denjean et al., 2016a), or also fast horizontal transport, turbulence, and electrical levitation of particles (van der Does et al., 2018). However, whether different mechanisms act differently under different conditions to affect dust size dynamics is still a matter of debate and investigation. In addition, while the retention of the coarse mode for dust is well established from observations, there is still heterogeneity when looking at size-selective depletion rates in particular concerning the coarsest particle fractions for which observations are still limited. Ryder et al. (2013b) reported that at Cape Verde between 60 and $90 \%$ of particles between 30 and $200 \mu \mathrm{m}$ are lost in $12 \mathrm{~h}$ transport by looking at column-integrated size airborne distributions, and that $100 \%$ of these particles are absent in the column mean SAL dust profile. Nevertheless, they report that the column-mean size distribution over the ocean at Cape Verde still has a relatively large coarse mode, with a peak 10 to $20 \mu \mathrm{m}$ in the volume size. Maring et al. (2003) reported from surface measurements that the loss of coarse particles for transport across Atlantic occurred for particles larger than $7.3 \mu \mathrm{m}$. By comparing dust measurements over Morocco to the Atlantic Ocean, Weinzierl et al. (2011) found that particles larger than $40 \mu \mathrm{m}$ were present $20 \%$ of the time over land and $0 \%$ over the ocean.

The conservation of the coarse mode size has in recent studies also been investigated using as a reference parameter the dust effective diameter and by analyzing its changes as a function of dust age. By synthesizing observations over the Atlantic and the Mediterranean, Denjean et al. (2016a) report an effective dust diameter for the coarse mode, i.e., the effective diameter calculated only for the supermicron dust size fraction, in the range of 5 to $10 \mu \mathrm{m}$ for transport in the Mediterranean and 3 and $4 \mu \mathrm{m}$ for transport towards the Atlantic. In both cases the effective diameter does not change with transport duration (estimated at 1 to 5 days for measured episodes) in line with the conservation of the coarse mode with time during transport.

In Fig. 13 we also compare data of the dust size distribution from AERONET observations. The AERONET aerosol size distribution in the range $0.1-30 \mu \mathrm{m}$ in diameter is derived by mathematical inversion of combined direct solar irradiance and sky radiance measurements (Dubovik and King, 2000; Dubovik et al., 2006). In this case, the retrieved size distribution does not refer to a specific altitude or a specific aerosol layer, as happens for airborne observations, but it is columnintegrated, which means that it represents the effective size distribution of the various aerosol layers encountered from the ground level up to the top of the atmosphere. Various studies report 
on AERONET observations at different locations affected by dust (Dubovik et al., 2002; Derimian et al., 2006; Kim et al., 2011; Denjean et al., 2016b; Formenti et al., 2018). Data in Fig. 13 illustrate that AERONET observations lead to a smaller contribution from particle sizes above about $5 \mu \mathrm{m}$ diameters than measured from in situ observations. Previous studies have already evidenced the underestimation by remote sensing techniques of the coarse fraction of aerosols, in particular dust (Reid et al. 2003b; Müller et al. 2010; Toledano et al. 2011). Nonetheless, this issue has become more evident recently thanks to the comparison to this new consistent, and available set of field size distribution data extended up to the giant diameter range.

\subsubsection{Dust composition}

When travelling in the atmosphere, the chemical and mineralogical composition of dust aerosols may change due to the combination of different aging processes. First, the loss of coarse particles has been shown to determine the size-selective depletion of certain minerals more concentrated in the supermicron fraction, such as quartz or feldspars (Glaccum and Prospero, 1980; Pye et al., 1987), so that after long-range transport the dust population can become richer in clay minerals compared to closer to the sources. External or internal particle mixing with other aerosol species was also shown to occur when dust plumes mix with air masses of different origins, such as marine or continental air masses, a process that influences the composition of the dust and in particular the submicron fraction below about $0.5 \mu \mathrm{m}$ (Kandler et al., 2011; Denjean et al., 2016a). This is evident for example in the size distribution data in Fig. 13 from Denjean et al. (2016a), from the central Mediterranean, showing an enhanced mode peaking at about $0.2 \mu \mathrm{m}$ related to the mixing of fine anthropogenic particles in the dust plumes. Dust is also frequently seen to be mixed with sea salt species when transported over the Pacific Ocean (e.g., Zhang et al., 2003). At Cape Verde Kandler et al. (2011) documented from ground-based observations during SAMUM2 that particles smaller than $0.5 \mu \mathrm{m}$ were mainly mineral dust, mineral dust-sulphate mixtures, sulphates and soot-sulphate mixtures, whereas particles larger than $2.5 \mu \mathrm{m}$ diameter were mineral dust, sea-salt and mineral dust-sulphate mixtures. The dominant cases were internal mixtures of mineral dust-sulphate and soot-sulphate particles; conversely mineral dustsea-salt mixtures occurred occasionally and mineral dust-soot mixtures were not observed during the SAMUM2 campaign. Over the western side of the Atlantic, Denjean et al. (2016b) reported from surface measurements in Puerto Rico the submicron dust particles mixing with anthropogenic absorbing aerosols likely from regional marine traffic activity. Only a few studies reported on the presence of internal mixtures of soot and mineral dust (e.g., Hand et al., 2010). In other cases, the external mixing of dust and organic carbon has been reported (Falkovich et 
al., 2004; Kandler et al., 2009). Long-range transported dust in the Swiss Alps and in the Canary Islands were also observed to be mixed with biological material (Kupiszewski et al., 2015; Boose et al., 2016).

Heterogeneous reactions on the particle surface and photochemistry also intervene to affect dust chemical composition during transport. Heterogeneous reactions may induce the formation of inorganic or organic coatings on the dust particle surfaces, which also acts to remove several atmospherically important reactive trace gas species from the atmosphere (Usher et al., 2003; Formenti et al., 2011). The formation of coatings at the dust surface then influences the size distribution of the particles (e.g. increase of the particle radius) and their lifetime, as well as perhaps modifying the particle shape. The main species recognized to react with dust are sulphur dioxide and nitrate oxides leading to the formation of sulfates and nitrates on the particle surface (Usher et al., 2003; Matsuki et al., 2010a; Li and Shao, 2009). Coagulation of dust with ammonium sulfate or sodium chloride has been also documented (Sullivan et al., 2007a,b; Trochkine et al., 2003). At the same time, other studies reported on the "little-aging" of dust after long transport, highlighting that the dust plume is not always chemically modified when travelling in the atmosphere, because the aging process is linked to the aerosol properties, such as composition, as evidenced from laboratory studies and discussed in the next paragraph, and the encountered ambient conditions, which is sometimes unfavorable for inducing chemical reactions. For instance, Denjean et al. (2015) showed that after long-range transport to the Caribbean, Saharan dust was chemically unprocessed and externally mixed. Only a minor portion of mineral dust was internally mixed with sulfate and chloride $(\sim 13-24 \%$ by number) or aggregated with sea-salt particles ( 3-6\%).

While field observations have provided evidence of dust chemical processing (and also nonprocessing) when traveling in the atmosphere, laboratory work has provided the means to study the fundamental chemical and physical mechanisms responsible for such reactions under controlled conditions (e.g., Krueger et al., 2003; Laskin et al., 2005; Shi et al., 2008; Sullivan et al., 2009a,b). Controlled laboratory experiments on proxy single minerals and natural dust samples have demonstrated that heterogeneous processes at the dust surface can be sensitive to relative humidity and the nature of the reactive surface, in particular to dust mineralogy. These studies have permitted to show that sulfate formation is favored on aluminum silicate particles (Laskin et al., 2005; Shi et al., 2008), whereas the presence of calcium carbonate favors nitrate formation (e.g., Sullivan et al., 2007a; Fairlie et al., 2010). This has particular relevance for instance for the long-range transport of Asian dust for which calcium carbonate content is 
generally larger than in North African dust (Scheuvens et al., 2013; Formenti et al., 2011), therefore nitrate formation is favored in these plumes. During transport downwind of dust and pollution sources, calcium-rich Asian dust particles efficiently react through heterogeneous processes with nitric acid, nitrogen dioxide, but also slightly with sulfur dioxide (He et al., 2014), leading to the formation of water-soluble aerosol species, such as calcium nitrate $\mathrm{Ca}\left(\mathrm{NO}_{3}\right)_{2}$ (e.g., Fairlie et al., 2010). Sparse studies also indicate that during transport dust may effectively interact with organic species leading to the formation of secondary organic aerosols on the dust surface (e.g., Liu et al., 2015). However systematic investigation of dust interaction with organic species is still missing to date.

\subsubsection{Dust morphology}

Physical and chemical aging processes occurring during atmospheric transport are also expected to affect dust morphology, which in turn has importance for the interaction of dust with atmospheric radiation (e.g., Nousiainen, 2009), also influencing active remote sensing (Gasteiger et al. 2011), and for the settling behavior of dust (Li and Osada, 2007). The morphology of dusts can be analyzed based on different methods. Microscopy techniques have been often applied to mineral dust particles collected on filter substrates during past field campaigns (Chou et al., 2008; Kandler et al. 2009; 2011; Osada, 2013). The analysis of microscopic images allows the retrieval of a twodimensional projected shape of single dust particles. Shape descriptors, such as the aspect ratio $(\mathrm{AR})$ or the shape factor (SF), are then derived to schematize the information. The aspect ratio is defined as the ratio of the longer to the shorter axis of an ellipse fitted to the particles shape, while the shape factor accounts for the perimeter of the particle. In contrast, no quantitative measurements of the surface roughness of mineral dust are available to date. Measurements over North Africa and along the transport path of dust across the Atlantic report a mean AR between 1.60 and 1.90 and a SF between 1.20 and 1.80 (Formenti et al., 2011; Scheuvens and Kandler, 2014; Huang et al., 2020). The AR is found in most studies not to depend on the particle size, whereas the SF is suggested to increase with particle size (Chou et al., 2008; Reid et al., 2003), which would indicate a more complex aggregate structure for large coarse particles close to sources than in long transport conditions. Long-range transported Saharan dust aerosols show however a higher AR compared to particles close to their emitting source (1.60 for source dust compared to 1.90 for long-range transported dust, Huang et al., 2020), which would indicate a preferential settling of more spherical particles (Scheuvens and Kandler, 2014). Conversely, the AR for Asian dust is estimated to slightly decrease during transport from a median value of 1.64 to 1.58 as recently reported in Huang et al. (2020), therefore suggesting that Asian dust becomes 
more spherical after transport possibly due to the effect of coating formation as dust interacts with marine and polluted air masses. Dust can also mix with other spherical or aspherical aerosols species, potentially also affecting its morphology. However indications of shape modifications during transport linked to these processes remain still sparse.

\subsection{Impact of physico-chemical aging on the dust climate-relevant properties and impacts}

Mineral dust aerosols are a global scale phenomenon with various climatic and environmental impacts. Mineral dust affects the radiation budget of the Earth-atmosphere system both directly via the scattering, absorption and re-emission of shortwave (SW) and longwave (LW) radiation, the so-called direct radiative effect (DRE), and indirectly because they can act as cloud condensation or ice nuclei (CCN, IN) therefore affecting cloud formation and properties (Haywood and Boucher, 2000). Dust also exerts an indirect effect via the impact on biogeochemical cycles because of the fertilization action when particles are deposited in marine and terrestrial ecosystems (Mahowald et al., 2011). The sum of these effects represents the dust forcing on climate. Estimates of the anthropogenic contribution to dust emission and atmospheric load is still very uncertain, but are assessed to remain mostly unchanged in the last decade and to provide a negative forcing that partly opposes and mitigates the global warming by greenhouse gases (Boucher et al., 2013).

The dust effects are governed by the dust spectral optical, hygroscopic, and solubility properties, all of which are dependent on the physico-chemical state of the particles. Changes of the dust size, composition, morphology or mixing state during transport may therefore affect the direct and indirect dust effects. We explore here some of the possible influences of dust aging during transport on the dust climatic effects.

\subsubsection{Impact of transport on the dust direct radiative effect}

Because of their high atmospheric load, characteristic mineralogical composition, and extended particle size spectrum, mineral dust aerosols are able to exert a significant dust direct radiative effect (DRE) in both the shortwave and the longwave regions of the spectrum (i.e., Haywood et al., 2003; Slingo et al., 2006; di Sarra et al., 2011). The shortwave DRE is dominant for fine particles (diameter $<1-2 \mu \mathrm{m}$ ) and is due to scattering and absorption of incoming solar radiation. Dust aerosols scatter on average $90-95 \%$ in the SW range, which determines an increase in the amount of solar radiation reflected towards space at the top of the atmosphere (TOA) (except over surfaces with high reflectivity, such as snow or desert, where the effect may be zero or slightly positive). Dust also absorbs a small fraction of SW radiation, mainly at 
wavelengths shorter than $700 \mathrm{~nm}$ (e.g., Dubovik et al., 2002; Di Biagio et al., 2019), inducing a local heating of the atmosphere. The sum of scattering and absorption by dust reduces the amount of $S W$ radiation reaching the ground, i.e. a negative surface DRE. In the LW, the DRE is due to absorption of the outgoing terrestrial radiation from the surface, which is then re-emitted at higher altitudes and normally lower temperatures. Dust also has a non-negligible LW scattering (Dufresne et al., 2002). The interaction of dust with LW radiation is effective only for particles larger than about 1-2 $\mu \mathrm{m}$ in diameter and induces a surface warming, due to the trapping of radiation in the lowermost atmospheric layers, and an atmospheric cooling, due to particle thermal emission. At the TOA the LW DRE is positive because of a reduction in the amount of the radiation emitted towards space. An example of spatial distribution of the dust SW and LW DRE at the surface, in the atmosphere and at the TOA for two different assumptions of the dust size distribution is reported in Fig. 14.

The dust DRE may be locally very intense because of the high number and mass concentrations close to sources but also in transport regions. Under strong uplift events with visible AOD around 3 , dust may increase the instantaneous solar reflectivity by $100 \mathrm{Wm}^{-2}$ and reduce the surface irradiation by $250 \mathrm{Wm}^{-2}$, with a consequent excess of $150 \mathrm{Wm}^{-2}$ absorbed in the dust atmospheric layer (Slingo et al., 2006). The absorption and re-emission of terrestrial LW radiation causes a surface and TOA heating that may reach tenths of $\mathrm{Wm}^{-2}$ over daily scale (Slingo et al., 2006). The same order of magnitude of the dust radiative perturbation is documented after long-range transport in the Mediterranean Basin and tropical Atlantic under strong events (e.g., Haywood et al., 2003; di Sarra et al., 2011). The short- and long-term consequences of the dust DRE go well beyond the simple influence on the radiation transfer. The presence of a dust layer may affect the atmospheric vertical temperature profile with consequences for the atmospheric stability and meteorological fields (Kishcha et al., 2003; Perez et al., 2006), photochemistry (Casasanta et al., 2011), surface temperature (Lau et al., 2007), and the development of tropical cyclones (Dunion and Velden, 2004). The DRE of dust has also been shown to exert a strong impact on the West African monsoon (Yoshioka et al., 2007; Konaré et al., 2008) and the Indian summer monsoon (Vinoj et al., 2014; Das et al., 2015; Jin et al., 2016), affecting precipitation over a large and high-populated area of the Northern Hemisphere. The DRE ultimately may feedback upon the dust emission because of the possible effects on wind fields and precipitation (Miller et al., 2004). 
a) Dust lognormal size distribution (MMD $=2.5 \mu \mathrm{m}$ )
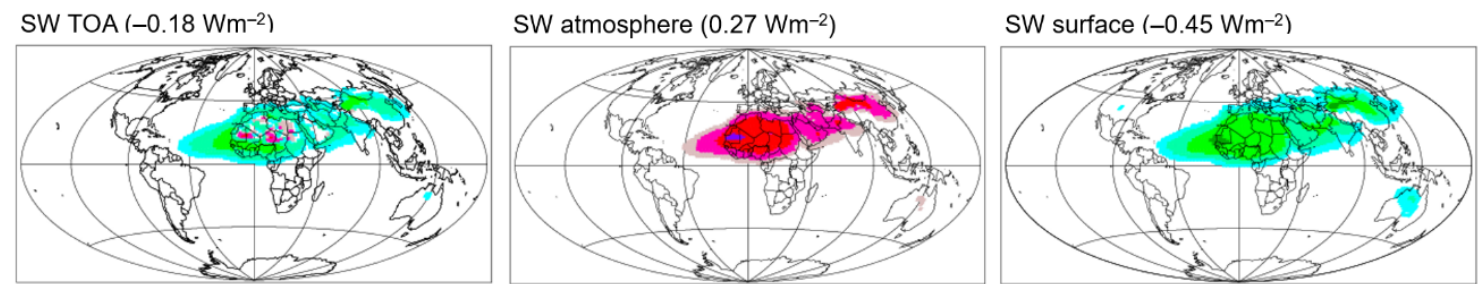

LW TOA $\left(0.06 \mathrm{Wm}^{-2}\right)$

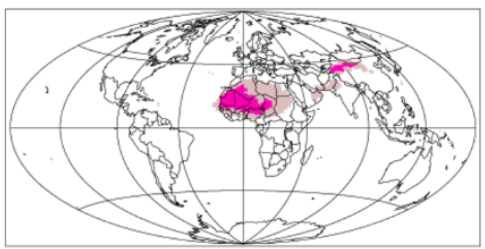

LW atmosphere $\left(-0.05 \mathrm{Wm}^{-2}\right)$

LW surface $\left(0.11 \mathrm{Wm}^{-2}\right)$
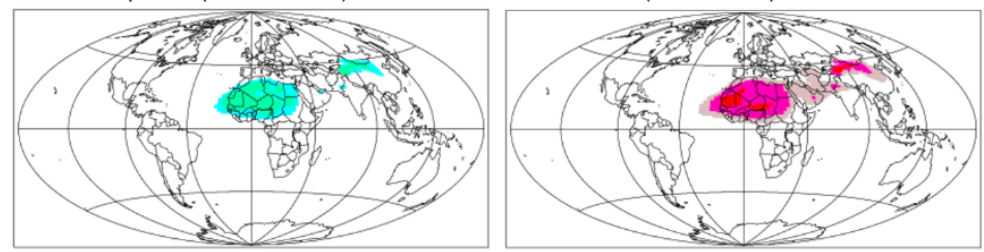

b) Dust lognormal size distribution (MMD $=7.0 \mu \mathrm{m}$ )

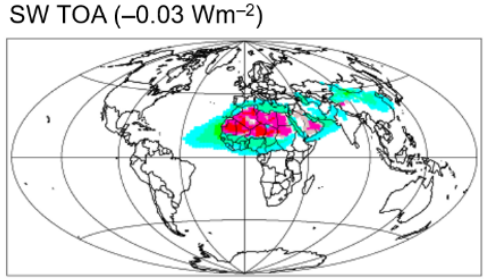

SW atmosphere $\left(0.47 \mathrm{Wm}^{-2}\right)$

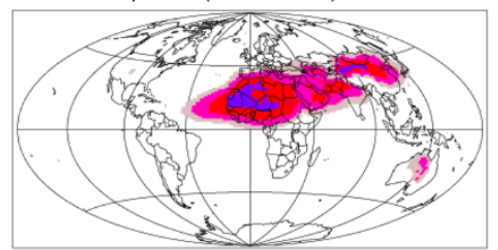

LW atmosphere $\left(-0.16 \mathrm{Wm}^{-2}\right)$

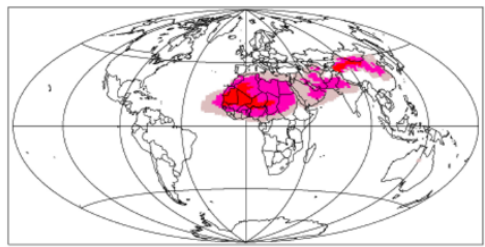

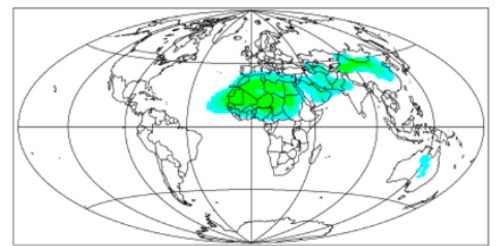

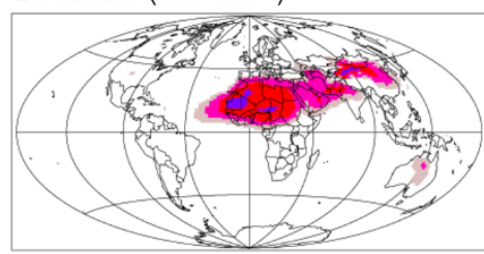

SW surface $\left(-0.50 \mathrm{Wm}^{-2}\right)$

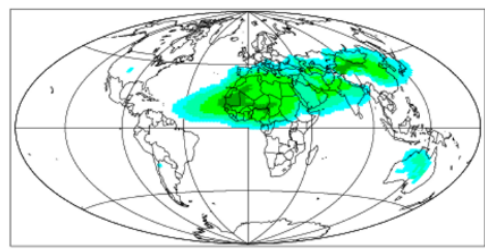

LW surface $\left(0.30 \mathrm{Wm}^{-2}\right)$

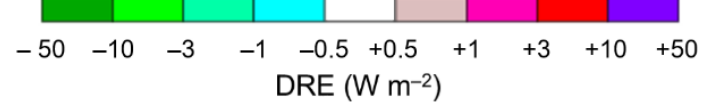

Figure 14. Global map showing examples of the geographical distribution of the shortwave (SW) and longwave ( $L W$ ) all-sky direct radiative effect of dust aerosols at the Top-of-the-Atmosphere (left), within the atmospheric layer (center), and at the surface (right) as obtained with the LMDzOR-INCA global model. Two set of simulations are shown: one assuming at emission a monomodal size distribution for dust centered at $2.5 \mu \mathrm{m}$ mass median diameter and geometric standard deviation of 2.0 (a, top panel) and the second one with $7.0 \mu \mathrm{m}$ mass median diameter and geometric standard deviation of 1.9 (b, bottom panel). In both cases the dust diameter range in the model extends up to $50 \mu \mathrm{m}$. Dust spectral optical properties are set following Balkanski et al. (2007) and Di Biagio et al. (2017). The dust emission

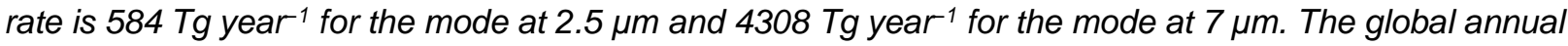
mean AOD (550 nm) of dust is 0.011 in both cases. The global annual mean of the DRE SW and LW at the TOA, atmosphere and surface is indicated in the plot. The LMDzOR-INCA model configuration for dust simulations reported here follow Di Biagio et al. (2020). 
The overall DRE by dust given by the sum of the SW and LW effects is estimated to be globally negative at the TOA from AEROCOM models (http://aerocom.met.no/) for which a best-guess global annual mean synthesis value of $-0.50 \mathrm{Wm}^{-2}$ is reported (varying between -0.78 and -0.03 $\mathrm{Wm}^{-2}$ as $90 \%$ confidence interval) (Huneeus et al., 2011; Kok et al., 2017). Global climate models however still struggle in constraining the radiative perturbation induced by mineral dust aerosols. This is evident by looking at Fig. 15, which illustrates the heterogeneity of model estimates of the dust DRE over the past 20 years. The heterogeneity in retrieved DRE is related to the capacity of models to correctly parameterize the dust cycle, including emission and transport, as well as the particle physico-chemical and optical properties and their spatio-temporal variation. In particular, an accurate description of the coarse mode of mineral dust is vital to predict its DRE since the presence of large particles enhances the capacity of mineral dust to absorb both SW and LW radiation (Ryder et al., 2013b, 2019). By looking at maps in Figure 14 we can see for example that for a same global AOD value the magnitude of the SW DRE in the atmosphere due to dust absorption strongly increases for the simulation at $7 \mu \mathrm{m}\left(0.47 \mathrm{~W} \mathrm{~m}^{-2}\right.$ on global annual average) compared to the one at $2.5 \mu \mathrm{m}\left(0.27 \mathrm{~W} \mathrm{~m}^{-2}\right)$. Up to now global and regional models mostly cut the dust size distribution at emission at $10 \mu \mathrm{m}$ in diameter. The recent findings that dust particles efficiently retain their coarsest mode up to tenths of micrometers during transport has therefore a strong impact for DRE estimations. The studies by Kok et al. (2017) and Di Biagio et al. (2020) (reported at the top of Fig. 15) show that accounting for a coarser dust in models following field observations reduces the dust net DRE from the strong negative value estimated from AEROCOM models, to the value of $-0.03( \pm 0.26) \mathrm{Wm}^{-2}$ as reported in Di Biagio et al. (2020) (to note that this study also revised the dust spectral optical properties and accounted for dust LW scattering compared to AEROCOM simulations). It should however be pointed out that the -0.03 $\mathrm{Wm}^{-2}$ value is a global and annual mean and masks the sharp contrasts between the land (positive) and ocean (negative) direct radiative effects. These recent model studies nonetheless open the possibility that the dust net DRE could be positive at TOA and emphasize in particular the role of the coarse mode size distribution in having the potential to even switch the sign of the radiative effect by dust from a net cooling to a net heating of the Earth-atmosphere system. 


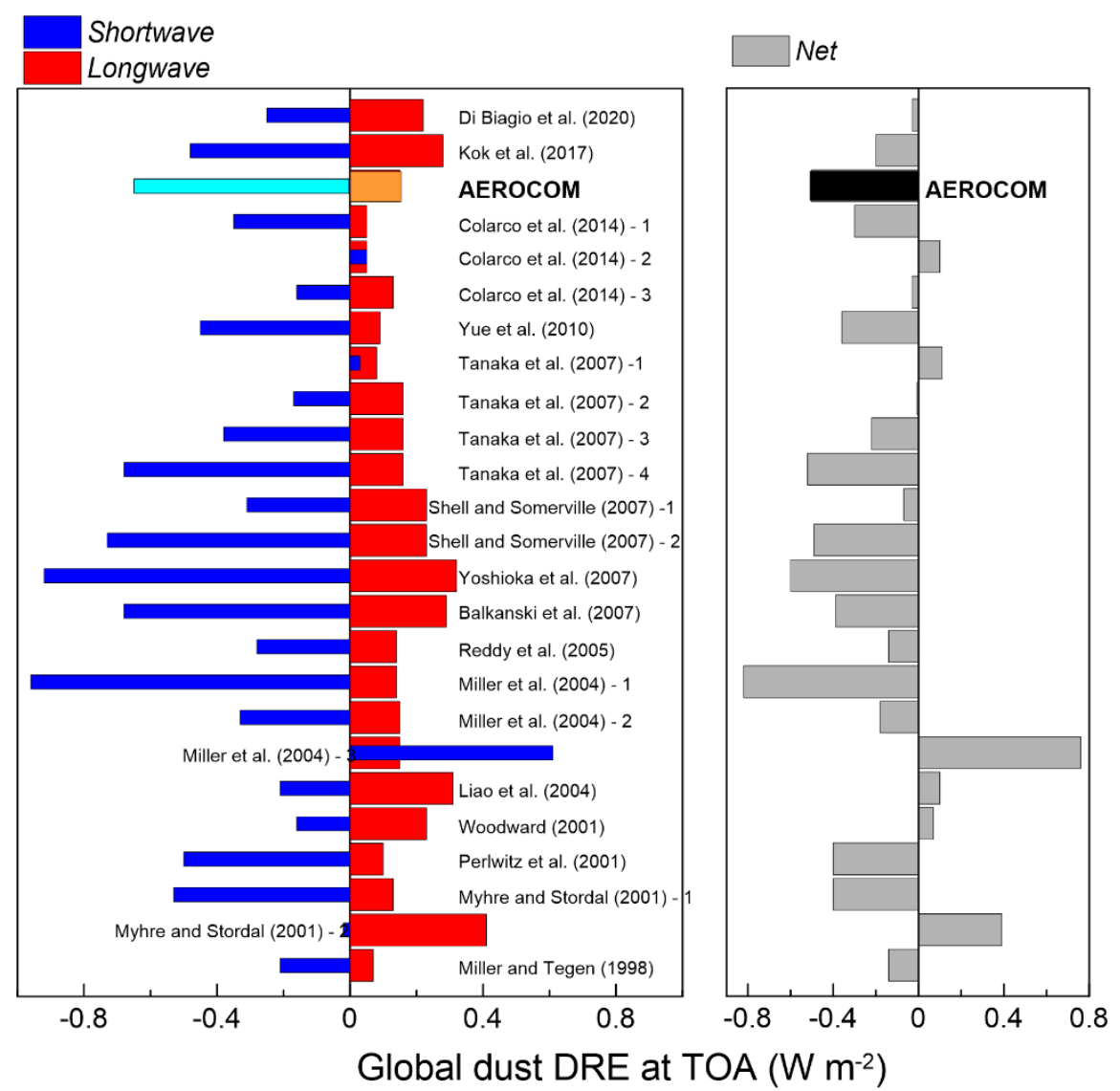

Figure 15. Synthesis of dust global direct radiative effect at the top of the atmosphere in the shortwave and longwave spectral ranges and for the net (shortwave+longwave) as estimated from global climate model studies over the past 20 years. Data indicate global and annual mean values. The estimations for AEROCOM models are from Kok et al. (2017) and highlighted with different colors. Multiple estimates for various studies are indicated with progressive numbers and correspond to different assumed dust spectral optical properties, shapes and spatial distribution of dust aerosols in model calculations. More details can be found in the referenced papers. Note that the two largely positive estimates of the net DRE from Miller et al. (2004) (\#3) and Myhre and Stordal (2001) (\#2) assume a highly absorbing dust in the shortwave range (about $20 \%$ absorption, i.e. a single scattering albedo of about 0.8 , in Miller et al.) and a dust global distribution including human disturbances in Myhre and Stordal.

Together with size distribution, the direct effect of dust is also sensitive to particle composition via the complex refractive index ( $m=n-i k)$ (e.g, Bohren and Huffman, 1983; Liao and Seinfeld, 1998; Sokolik and Toon, 1999). Systematic simulation chamber experiments have been started in recent years to evaluate the dependence of the dust complex refractive index on the composition or origin of dust and its size distribution (Linke et al., 2006; Wagner et al., 2012; Engelbrecht et al., 2016; Di Biagio et al., 2014; 2017; 2019). Simulation chamber studies are 
powerful tools to explain the variability of dust absorption as observed from in situ and remote sensing field observations and from laboratory measurements, all reporting imaginary parts of the dust refractive index varying between $\mathrm{k}=0.0001$ and 0.008 at $550 \mathrm{~nm}$, which means about 2 orders of magnitude difference in the absorption of dust, and corresponding to single scattering albedo values ranging between 0.80 and 0.99 (i.e., Volz, 1972, 1973; Patterson et al., 1977; Dubovik et al., 2002; Haywood et al., 2003; Sinyuk et al., 2003; Osborne et al., 2008; Müller et al., 2009; Otto et al., 2009; Petzold et al., 2009; Schladitz et al., 2009; McConnell et al., 2010; Ryder et al., 2013a; Denjean et al., 2016a, 2016b; Rocha-Lima et al., 2018). Because multiple processes may affect dust properties close to sources and during atmospheric transport, it is necessary to be able to disentangle the different effects related to these different processes in order to understand and model the impact of each of them on dust optical properties. Simulation chamber studies can overcome this level of difficulty by studying dust aerosols in controlled conditions. Recent laboratory studies have permitted the retrieval of the shortwave and longwave real $(n)$ and imaginary $(k)$ parts of the complex refractive index of "pure" dust originated from the worldwide deserts. These studies show that $k$ is highly variable depending on the source region of emission because of the differences in particle mineralogical composition with origin. The magnitude and spectral features of dust absorption in the longwave are linked to the dust content of quartz, clays, and calcite minerals (e.g., Di Biagio et al., 2017), whereas iron and iron oxides control the absorption in the shortwave range (Caponi et al., 2017; Di Biagio et al., 2019). On the other hand, the refractive index seems to be quite insensitive to changes in size distribution and the depletion of coarse particles (Di Biagio et al., 2017, 2019), suggesting that the intrinsic optical properties of the dust are not significantly modified during atmospheric transport because of changes in the mineralogical composition due to gravitational settling.

External or internal mixing of dust with other components can also affect the spectral optical properties during transport, in particular mixing with non-absorbing (i.e., salts) or absorbing (i.e., carbon-like) species may decrease or increase the absorbing capacity of dust aerosols. Field studies show however contrasting results on the role of mixing on the dust optical properties. For instance, Denjean et al. (2016a) reported for dust transported in the Mediterranean area an absorption capacity similar to that of native dust, arguing that the presence of moderate pollution does not significantly modify the properties of the particles. Conversely, Tian et al. (2018) documented an enhanced absorption for dust aerosols mixed with anthropogenic pollution in East Asia. Based on ship borne observations across the Atlantic Ocean, Kanitz et al. (2014) reported different lidar-derived optical properties for dust aerosols with different transport times (10 days versus 2-3 days), supporting the role of different aging processes in modifying particle optical 
properties. Laboratory and theoretical studies show the enhancement of dust scattering capacity because of the heterogeneous reactions with sulfates and nitrates but only if the coating exceeds a certain thickness (e.g., Bauer et al., 2007). These observations would imply that the DRE of dust could become more negative (TOA cooling) due to heterogeneous reactions with inorganic species or, on the opposite, to become less negative or positive due to mixing with pollution.

\subsubsection{Impact of transport on the dust indirect radiative effect and biogeochemistry}

Fresh mineral dust aerosols are mostly hydrophobic, meaning that they basically repel water and so are not able to act as a CCN. However, several laboratory studies have proven that the uptake of inorganic and organic hydrophilic species at the dust surface induced by heterogeneous reactions with the atmospheric constituents may enhance the particle's hygroscopicity (Wurzler et al., 2000; Hatch et al., 2008; Sullivan et al., 2009a,b; Gierlus et al., 2012), therefore making dust to possibly act as a CCN.

Coatings of different chemical nature may lead to different CCN abilities also depending on the particle mineralogy. As an example, the condensation of inorganic acids, such as nitric acid $\left(\mathrm{HNO}_{3}\right)$, at the particle surface can efficiently alter the dust hygroscopicity (i.e., Karydis et al., 2016). Nitric acid reacts with the calcium of the mineral dust surface in the presence of water and the resulting calcium nitrate takes up ambient water vapor starting at a relative humidity as low as $50 \%$. In contrast, coating dust aerosols with sulfuric acid $\left(\mathrm{H}_{2} \mathrm{SO}_{4}\right)$ does not have the same effect, as the relative humidity of deliquescence is close to $100 \%$ for calcium sulfate. Thus, coating by nitrates can more efficiently determine the hygroscopicity of calcium-rich Asian mineral dust particles in the case when dust travels over a polluted atmosphere, but this is not the case for sulfate coatings (Bauer et al., 2007; Sullivan et al., 2007a; Shi et al., 2008; Li et al., 2014). The growth of the dust particles by water adsorption then increases the particles capacity to scatter atmospheric radiation (usually measured by the scattering growth factor, representing the ratio of the scattering cross section for particles having or not undergone water uptake) with consequences for the AOD and the DRE of dust. Water uptake also affects the cloud scavenging efficiency by accelerating the formation of precipitation particles in continental clouds (Yin et al., 2002), potentially increasing the wet and dry removal of dust aerosols from the atmosphere (i.e., reducing their lifetime), and hence increasing their deposition to land and oceans.

Despite experimental evidence that dust can become $\mathrm{CCN}$-active if it undergoes chemical processing, as of today the literature still reports contrasting results about dust hygroscopic properties and the impact of aging from field observations. For instance, many field studies have measured an enhanced hygroscopicity induced by coating formation on African and Asian dust 
when these particles are transported over long-range distances (Bègue et al., 2015; Twohy et al., 2009; Matsuki et al., 2010b). In contrast, Denjean et al. (2015) provided evidence that although thousands of kilometers and several days of transport from Africa to the Caribbean, Saharan dust aerosols remained chemically unprocessed and only the small fraction that was externally mixed with sea salts became hydrophilic. Hydrophobic dusts were also observed after long-range transport of Asian plumes off the coasts of Japan, Korea and China (Massling et al., 2007). The ensemble of field observations therefore suggests that the capacity for mineral dust particles to become hydrophilic is not unique and, in relation to its capacity to undergo heterogeneous reactions, as discussed in Sect. 4.2.2, varies with particle origin, transport pathways and encountered atmospheric conditions.

Atmospheric aging is also expected to affect the ice nucleation capacity of dust aerosols, so the capacity of dust to contribute to the initial formation of ice clouds (Hoose et al., 2008). Mineral dust is evaluated to be the most prevalent ice nucleation particle (INP) type in the atmosphere (Hande et al., 2015) and recent laboratory studies have shown that K-feldspars, i.e. microcline plus orthoclase minerals, are the most active INP amongst dust constituents, activating as INP at warmer temperatures or lower relative humidity than all other minerals (e.g., Atkinson et al., 2013; Paramonov et al., 2018). Several laboratory and field studies have investigated dust INP activity and have provided evidence that diverse aging mechanisms can increase or decrease it. For instance, the formation of a sulfuric acid coating induces a reduction in the capacity of mineral dust to act as INP (i.e., Sullivan et al., 2010). Conversely, exposing dust aerosols to low amounts of ozone increases the INP activity of mineral dust (Kanji et al., 2013), as is the presence of ammonium sulfate (Boose et al., 2016), or mixing with biological material (O'Sullivan et al., 2016). On the other hand, secondary organic aerosol coatings may decrease or increase the ice nucleation ability of dust particles depending on the pathway of IN formation (Möhler et al., 2008; Koehler et al., 2010; Kanji et al., 2019).

Together with its CCN and IN ability, dust also indirectly affects climate via its influence on biogeochemical cycles. The aerosol indirect forcing on climate linked to biogeochemistry is suggested to be comparable to the direct forcing of aerosols on climate (Mahowald et al., 2011). The biogeochemical impact of dust depends on the capacity of particles to provide land and marine ecosystems with the micronutrients they need once dust is deposited at their surface, in particular iron (Fe) and phosphorous (P). The input of these components by dust is crucial for primary marine productivity and biogeochemical cycles in the so-called HNLC (high-nutrient and low-chlorophyll) and LNLC (low-nutrient and low-chlorophyll) zones (Jickells et al., 2005; 
Kanakidou et al, 2018). Observations have evidenced that freshly emitted dust aerosols contain considerable amounts of insoluble trace elements (total $\mathrm{Fe}$ and $\mathrm{P}$ dust emissions range from about 35 to $115 \mathrm{Tg} \mathrm{Fe} \mathrm{yr}^{-1}$ (e.g., Ito and Kok, 2017) and from 1.1 to $3.8 \mathrm{Tg} \mathrm{Pyr}^{-1}$ (e.g., Myriokefalitakis et al., 2016)). Nevertheless, only a small fraction of these elements are in a soluble form and so potentially bioavailable (Tagliabue et al 2017). The Fe solubility is usually below $1 \%$ for fresh atmospheric dust aerosols (e.g. Sholkovitz et al., 2012) and varies with particle mineralogy (Journet et al., 2008). Field observations point out that $\mathrm{Fe}$ and $\mathrm{P}$ solubility is higher in dust collected over the remote atmosphere than close to source areas (e.g., Baker et al., 2006), suggesting that atmospheric aging can increase the solubility of Fe and $\mathrm{P}$ during dust transport. Conversion of nutrients from their insoluble to soluble form requires notably acidic conditions, therefore dust coating with acidic compounds (e.g. sulfates and nitrates) formed by the heterogeneous uptake of $\mathrm{SO}_{2}$ and $\mathrm{HNO}_{3}$ is a possible pattern for increasing $\mathrm{Fe}$ and $\mathrm{P}$ solubility in dust (e.g. Meskhidze et al., 2005). Field observations suggest a positive correlation between Fe solubility and sulfur emissions (Oakes et al 2012), supporting the potential key role of sulfur coating on dust to affect its biogeochemical impact. Other observed processes which may increase $\mathrm{Fe}$ and $\mathrm{P}$ solubility in dust are the dust exposure to oxidants and sunlight, the cloud processing (Desboeufs et al., 2001), gravitational size settling (Baker and Jickells, 2006), the mixing of dust with combustion (Sholkovitz et al., 2012) and biomass burning aerosols (Paris et al., 2010).

\section{Dust as a tracer of climate: past variability and future projections}

Mineral dust emission, transport and deposition are extremely sensitive to meteorological and climatic conditions, so dust deposits provide long-term records that can help with reconstructing past and present meteorology and climatology. Seasonal changes in the conditions at the source, transport path and efficiency, and deposition processes can be identified by analyzing remotesensing and in situ station observations, and accumulation samples in marine sediments or snowpit layers. Moreover, the analysis of mineral dust accumulated in continental deposits, oceanic sediments (Grousset and Biscaye, 2005) and in polar ice caps (Biscaye et al., 1997) contributes to our understanding of paleo-climate variability. Dust properties in paleo-records are used as proxies for the dust life-cycle: accumulation rate is used as a proxy of deposition fluxes, particle size is used as an indicator of wind strength in source regions or changes in the transport pathway, and mineralogy or isotopic signatures are used as fingerprints of dust origin (Maher et al., 2010). Analysis of marine sediments (deMenocal, 2004; Hovan et al., 1991; Martínez-Garcia et al., 2009; Rea, 1994; Winckler et al., 2008) and Greenland and Antarctic ice cores (Grousset and Biscaye, 
2005; Petit et al., 1999; Thompson and Mosley-Thompson, 1981) reveals large variations in dust accumulation rates in relation to glacial-interglacial cycles, indicating much higher mineral dust fluxes during glacial periods, in association with the expansion of arid regions in the Northern Hemisphere. In the northwestern Pacific, dust accumulation in marine sediments correlates well with the loess-paleosol stratigraphy in China, highlighting the relationship between maxima in Asian dust export and extended aridity in the source regions (Hovan et al., 1991). In the North Atlantic, the variability of dust accumulation in marine sediments downwind of the Saharan sources correlates with proxy-data estimations of the extension of vegetation and water bodies in North Africa, providing information as to the past variability of the West African monsoon strength and the occurrence of the African humid periods (Adkins et al., 2006; deMenocal et al., 2000; McGee et al., 2013; Skonieczny et al., 2019; Williams et al., 2016). In the South Atlantic, past 1.1 Ma iron concentrations in marine sediments cores are a proxy for the fertilization of marine biota by dust deposition, explaining the fraction of the past global $\mathrm{CO}_{2}$ variability associated with marine productivity (Martínez-Garcia et al., 2009). The dust variability in the historical period is a robust proxy for climate and environmental changes at the multidecadal time scales. The Atlantic export of Saharan dust is interconnected with the dynamics of the West African monsoon and the SHL (Evan et al., 2016; Schepanski et al., 2017; Wang et al., 2017, 2015), the occurrence of droughts in the Sahel (Chiapello et al., 2005), as well as the phases of the NAO (Moulin et al., 1997b). The Asian dust transported over the North Pacific is associated with the PDO (Gong et al., 2006). The trend in dust transport towards Antarctica in the 20th century is indicative of the ongoing desertification of Patagonia (McConnell et al., 2007).

In the context of the accelerating climate change, the question of how modifications of precipitation and wind patterns are affecting dust emission and distribution in the global atmosphere has arisen. Decadal trends are estimated by means of station data, satellite products and model simulations. However, depending on the data and period considered in the analysis, trend estimations may show differences. In general, there is no consensus on a significant trend at the global scale in recent decades (Chin et al., 2014; Hsu et al., 2012; Shao et al., 2013). By analyzing synoptic data in the period 1984-2012, Shao et al. (2013) found reduced dust activities in North Africa, Northeast Asia, South America, and South Africa, accounting for a near-surface dust concentration decrease of $1.2 \% \mathrm{yr}^{-1}$ at the global scale. From an analysis of visibility data from weather stations in dusty regions, Mahowald et al. (2007) found positive trends in dust emission in North Africa, Central Asia and China in the period 1974-2003, in association with declined precipitation. Reduced dust emission in North Africa over the period 1980-2009 also results from the comparison of global model estimations and observations from multiple satellite 
sensors and ground-based networks, but no trend emerges at the global scale (Chin et al. 2014). The availability of satellite products, now covering up to four decades in the past, allows more representative reconstructions of decadal trends at the global and regional scales. The SeaWiFS measurements in the period 1997-2010 show a weak positive trend over the global ocean, accompanied by large upward trends over the Arabian Peninsula and downwind oceanic region, while a negative-neutral tendency is observed over the Saharan region and the North Atlantic (Hsu et al. 2012). However, in a recently released dataset based on satellite products, dust AOD decreases over Asia and increases significantly over the Sahara and Middle East between 2001 and 2018 (Voss and Evan 2020).

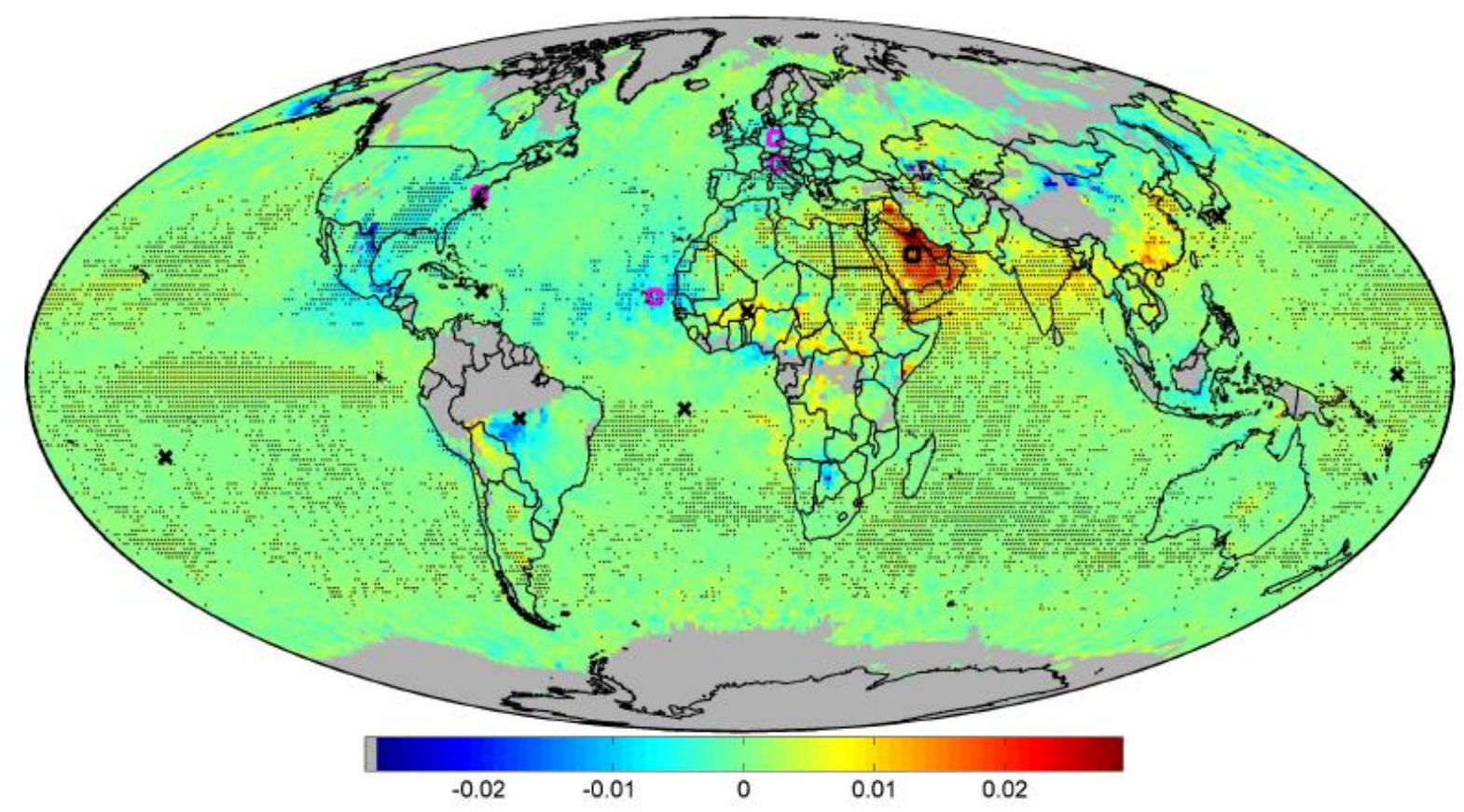

Figure 16. Linear trend based upon deseasonalised monthly anomaly of $A O D$ at $550 \mathrm{~nm}$ for the period 1998-2010. Units are AOD $y r^{-1}$. Dots indicate significance at 95\% confidence level. The black and pink boxes and symbol $(x)$ represent the ground based AERONET locations with AOD tendency of positive, negative, and statistically insignificant values, respectively. Regions shaded in grey indicate no data or insufficient sample size for trend analysis. Adapted from Hsu et al. (2012).

Dust emission and transport is nowadays simulated in state-of-the-art climate models, and future projections are provided in the context of the CMIP phase 5 and 6. Specifically, CMIP5 climate models simulate for the 21 st century less dust in East Asia and more dust in the Sahara (Evan et 
al., 2016; Pu and Ginoux, 2018). However, climate models show important shortcomings in the representation of dust emission, transport, size distribution and optical properties in the historical climate (Evan et al., 2014; Kok et al., 2017; Wu et al., 2018). While seasonal cycle and spatial patterns are generally captured by multi-model means in North Africa and the Middle East, most of the models struggle to represent these variables in South Africa and Australia (Pu and Ginoux, 2018). Moreover, climate models are in general unable to reproduce the interannual and decadal variability of dust emission and transport from major sources in North Africa and East Asia (Evan et al., 2014; Wu et al., 2018), essentially due to inaccurate model representation of surface wind and precipitation (Evan, 2018; Wu et al., 2018). These shortcomings consequently cast doubts on the reliability of future climate predictions, which are indeed affected by large uncertainties, in both the magnitude and sign of the trends (Evan et al., 2016; Pu and Ginoux, 2018). For instance, Evan et al. (2016) demonstrated that the projection of the Saharan dust in CMIP5 simulations estimated using the relationship between surface wind and dust emission shows a negative trend in the 21 st century, whereas the model dust products show a positive trend. Other than the effect that anthropogenic climate change exerts on dust emission and transport by means of modifications of wind and precipitation patterns, possible human-made changes in land-use and land-cover may add further uncertainty to projections. In particular, the implementation of ongoing and planned afforestation projects in arid and semi-arid regions, such as the Sahel (Goffner et al., 2019), India and China (Chen et al., 2019), could reshape the effects of climate change on dust emission and distribution.

\section{Conclusions and future perspectives}

Intercontinental dust transport is significant for climate, life, and ecosystems and its study has been the motor of many scientific and technological advances over recent decades. Studying dust atmospheric transport requires the characterization of different aspects of the dust cycle, from the source activation to the deposition stages, including the characterization of transport routes, horizontal and vertical structure of the dust plume and its evolution, as well as the particle physico-chemical, optical, hygroscopicity and solubility properties and their possible spatiotemporal changes. This is challenging since it requires the combination of many observational and numerical techniques and analysis methods. A large diversity of products with different spatial and temporal resolutions and coverage is currently available to investigate the long-range transport of dust and its implications. These include local and regional aerosol measurements from surface stations and field campaigns, complemented by laboratory analysis and increased by satellite remote sensing. In particular, because of its high frequency of measurement (daily or 
hourly), extended spatial coverage (global or continental) and decadal-scale duration, satellite observations have proven fundamental to study dust transport over extended spatio-temporal scales. Numerical models of dust emission, transport and deposition are also used as a tool to understand the various aspects that control the dust cycle and its impacts, including the large scale signature of dust emission and transport and their long-term changes. While regional models are useful to study in detail the processes that influence dust distribution as well as the dynamics of individual dust events, global climate models are more suitable to investigate the interconnection with past, present and future global climate.

Until now the scientific community has acquired a comprehensive knowledge of the dust cycle but large uncertainties still persist and some processes still remain unknown. First, it should be recognized that modelling the dust cycle and its associated impacts is persistently challenging for both global and regional models. Although models are generally able to reproduce the long-range transport of dust plumes across the continents and the oceans, the patterns of this transport can differ substantially in magnitude and seasonality from one model to another. Large differences exist between the model simulations of the dust atmospheric load, size distribution, vertical distribution, and deposition rates (wet and dry) (e.g., Huneeus et al., 2011; Evan et al., 2014; Kok et al., 2017). This is caused in large part by discrepancies in the parameterization of dust properties and processes that affect the dust emission and transport (e.g. Huneeus et al., 2011; Ridley et al., 2013). In consequence, assessing and predicting the climatic and environmental impact of dust still remains challenging. The broad inter-model spread of results highlights the need for reliable observations that could contribute to improve model performances, in particular by providing the information required to constrain simulations and to ameliorate dust-related parameterizations in model schemes. Improving dust simulations in climate models is particularly relevant to the assessment of current and future climate change, because of the role of aerosols, and dust among them, in determining the global radiative forcing, through their direct interaction with radiation and the effect on cloud lifetime and optical properties, as well as biogeochemical cycles. A prominent effort of the dust model community has been performed in recent years to constrain and upgrade model simulations with the best available field, satellite and laboratory observations in order to improve the capacity to reproduce correctly the dust cycle (e.g., Albani et al., 2014; Kok et al., 2017; Adebiyi et al., 2020; Di Biagio et al., 2020). More work is expected in upcoming years in this direction.

As shown, there are still many uncertainties associated with the role of mineral dust aerosols on climate, and a significant part of this uncertainty is related to the incomplete understanding of the 
influence of aging processes on the climate-related properties of mineral dust. How external or internal mixing, heterogeneous reactions and cloud processing affect dust spectral absorption, scattering, hygroscopicity and solubility is still an area of active research. Whereas laboratory studies provide insight on specific processes and are the most valuable way to provide parameterization schemes to models, field observations remain the first source of information. Field studies still show contrasting results as to the occurrence and role of different aging processes and their impact on dust properties. More observations under diverse conditions are required to provide consistent information for targeted laboratory studies. Additionally, and as discussed previously in some review papers such as Formenti et al. (2011), it is expected that the scientific community should make the strongest efforts to homogenize measurement protocols and analysis techniques in order to make different datasets the most possible directly comparable.

We expect extended capabilities to come in the future based on new satellite missions, for example Meteosat Third Generation, which will enhance the capabilities of Meteosat Second Generation to include vertical sounding information, along with higher spatial, temporal, and spectral resolution on its imager. An upcoming NASA mission, the Earth Surface Mineral Dust Source Investigation (EMIT), carrying a hyperspectral instrument carried onboard the International Space Station, will be specifically focused on the analysis of the mineralogical composition of desert dust sources. Meanwhile the detection and tracking of the evolution of the dust size distribution from satellite sensors is also an active area of research and a potentially valuable source of information for dust transport studies (Kalashnikova and Kahn, 2008). Specifically, large scale information on the coarse fraction of the dust size distribution derived from satellite observations would be of great benefit for improving dust modelling and assessing its climate impacts.

In term of the observational record, while the long-range transport of Saharan dust, particularly across the Atlantic Ocean, has been extensively investigated with satellite and field observations in the last few decades, the transport of Asian dusts across the Pacific Ocean has been less studied. Moreover, other transport routes both in the Northern and Southern Hemisphere should deserve more attention. In this respect, various campaigns have recently focused on sources in Southern Africa (e.g., Formenti et al., 2019) and the Middle East (e.g., Tsiouri et al., 2015). Despite the fact that dust events are most dominant in subtropical and mid-latitude arid regions, significant events also occur in high latitude areas (Prospero et al., 2012). High-latitude dust still remains poorly documented despite well-established indications of its influence on terrestrial, atmospheric, marine, and cryospheric processes, including ice albedo and melt rates, as well as 
its contribution to modern Holocene deposits and degradation of air quality in polar regions (e.g., Bullard et al., 2016). Compared to subtropical sources, high-latitude dust are however more difficult to study based on active and passive satellite sensors because of the limitations given by the long periods of darkness, the limited view by polar orbiting satellites, and the very high cloudiness and the bright surface conditions of high-latitude areas. Field measurements on their side are logistically and technically challenging in polar regions and to date, field research has mostly limited to summer season only (e.g., Bullard and Austin, 2011). Properly quantifying the extent, frequency, and features of high-latitude dust events and their regional and global transport patterns and pathways should require year-round integrated dust and meteorological observations across the Arctic and Antarctic regions. This is an emerging and important topic in dust research given the potential role of high-latitude dust on the climate of polar regions and their expected increase in relevance in the future with rising global temperatures under climate change scenarios.

\section{Acknowledgements.}

We acknowledge the use of imagery from the NASA Worldview application (https://worldview.earthdata.nasa.gov), part of the NASA Earth Observing System Data and Information System (EOSDIS). The MODIS/Terra Aerosol Cloud Water Vapor Ozone Monthly L3 Global 1 Deg. CMG dataset was acquired from the Level-1 and Atmosphere Archive \& Distribution System (LAADS) Distributed Active Archive Center (DAAC), located in the Goddard Space Flight Center in Greenbelt, Maryland (https://ladsweb.nascom.nasa.gov/). The CALIPSO image was obtained using the image browse tool developed and maintained by the NASA Langley Research Center. The CAMS data are available at the European Centre for Medium-range Weather Forecast (ECMWF) data portal: https://apps.ecmwf.int/datasets/. Climate indices time series are available at the National Ocean Atmosphere Administration (NOAA) Earth System Research Laboratory (ERSL) portal (https://www.esrl.noaa.gov/psd/data/climateindices/list/), and at the Joint Institute for the Study of the Atmosphere and Ocean (JISAO) of the University of Washington (http://research.jisao.washington.edu/data sets/sahel/). We thank the PIs and Co-ls of the AERONET sites and their staff for establishing and maintaining the 8 sites used in this chapter. We acknowledge J. Cuesta for providing Figure 6 and the CNES (Centre National des Etudes Spatiales) supporting the AEROIASI development, and C. Hsu for providing Figure 16. We thank E. Journet for useful suggestions. Y. Balkanski and S. Albani are gratefully acknowledged for contributing to the LMDzOR-INCA global model simulations shown in Figure 
14. The authors wish to thank the two reviewers, A. Evan and A. M. Sayer, for their constructive comments that helped to increase the quality of the manuscript.

\section{Reference list}

Abed, A. M., Al-Kuisi, M., and Khair, H. A., 2009. Characterization of the Khamaseen (spring) dust in Jordan. Atmospheric Environment 43, 2868-2876. doi:10.1016/j.atmosenv.2009.03.015.

Adebiyi, A. A., Kok, J. F., Wang, Y., et al., 2020. Dust Constraints from joint Observational-ModellingexperiMental analysis (DustCOMM): comparison with measurements and model simulations. Atmospheric Chemistry and Physics 20, 829-863, https://doi.org/10.5194/acp-20-829-2020.

Adkins, J., deMenocal, P., Eshel, G., 2006. The "African humid period" and the record of marine upwelling from excess 230Th in Ocean Drilling Program Hole 658C. Paleoceanography 21, 1-14. https://doi.org/10.1029/2005PA001200.

Albani, S., Mahowald, N. M., Perry, A. T., et al., 2014. Improved dust representation in the Community Atmosphere Model. Journal of Advances in Modelling Earth Systems6, 541-570. doi:10.1002/2013MS000279.

Alfaro, S.C., Gaudichet, A., Gomes, L., Maille, M., 1998. Mineral aerosol production by wind erosion: aerosol particle sizes and binding energies. Geophysical Research Letters 25, 991-994.

Alpert, P., Ziv, B., 1989. The Sharav Cyclone: observations and some theoretical considerations. Journal of Geophysical Research 94, 18 495-18 514. https://doi.org/10.1029/jd094id15p18495

Ansmann, A., Baars, H., Tesche, M., et al., 2009. Dust and smoke trans- port from Africa to South America: Lidar profiling over Cape Verde and the Amazon rainforest, Geophysical Research Letters 36. doi:10.1029/2009GL037923.

Ansmann, A., Bösenberg, J., Chiakovsky, A., et al., 2003. Long-range transport of Saharan dust to northern Europe: The 11-16 October 2001 outbreak observed with EARLINET. Journal of Geophysical Research D Atmos. 108, 1-15. https://doi.org/10.1029/2003jd003757

Ansmann, A., Petzold, A., Kandler, K., et al., 2011. Saharan Mineral Dust Experiments SAMUM-1 and SAMUM-2: What have we learned? Tellus 63B, 403-429. doi:10.1111/j.1600-0889.2011.00555.x.

Antoine, D., Nobileau, D., 2006. Recent increase of Saharan dust transport over the Mediterranean Sea, as revealed from ocean color satellite (SeaWiFS) observations. Journal of Geophysical Research Atmos. 111, 1-19. https://doi.org/10.1029/2005JD006795

Ashpole, I. and Washington, R., 2012. An Automated dust detection using SEVIRI: A multi-year climatology of summertime dustiness in the central and western Sahara, Journal of Geophysical Research, 117. doi:10.1029/2011JD016845.

Atkinson, J., Murray, B. J., Woodhouse, M. T., et al., 2013. The importance of feldspar for ice nucleation by mineral dust in mixed-phase clouds. Nature 498, 355-358. https://doi.org/10.1038/nature12278.

Augustin-Bauditz, S., Wex, H., Denjean, C., Hartmann, S., Schneider, J., Schmidt, S., Ebert, M., and Stratmann, F., 2016. Laboratory-generated mixtures of mineral dust particles with biological substances: characterization of the particle mixing state and immersion freezing behavior. Atmospheric Chemistry and Physics 16, 5531-5543. https://doi.org/10.5194/acp-16-5531-2016.

Baars, H., Kanitz, T., Engelmann, R., et al., 2016. An overview of the first decade of PollyNET: an emerging network of automated Raman-polarization lidars for continuous aerosol profiling, Atmospheric Chemistry and Physics, 16, 5111-5137. doi:10.5194/acp-16- 5111-2016. https://www.atmos-chemphys.net/16/5111/2016/. 
Bachmeier, A. S., Newell, R. E., Shipham, M. C., et al., 1996. PEM-West A: Meteorological overview. Journal of Geophysical Research 101(D1), 1655- 1677. doi:10.1029/95JD02799.

Baker, A. R., Jickells, T. D., 2006. Mineral particle size as a control on aerosol iron solubility. Geophysical Research Letters 33; L17608.

Baker, A. R., Jickells, T. D., Witt, M., Linge, K. L., 2006. Trends in the solubility of iron, aluminium, manganese and phosphorus in aerosol collected over the Atlantic Ocean. Mar. Chem. 98, 43-58. doi:10.1016/j.marchem.2005.06.004.

Balkanski, Y., Schulz, M., Claquin, T., Guibert, S., 2007. Reevaluation of Mineral aerosol radiative forcings suggests a better agreement with satellite and AERONET data. Atmospheric Chemistry and Physics 7 , 81-95. https://doi.org/10.5194/acp-7-81-2007.

Banks, J. R., Brindley, H. E. 2013. Evaluation of MSG-SEVIRI mineral dust retrieval products over North Africa and the Middle East. Remote Sensing of the Environment 128, 5873,https://doi.org/10.1016/j.rse.2012.07.017.

Banks, J. R., Brindley, H. E., Stenchikov, G., and Schepanski, K., 2017. Satellite retrievals of dust aerosol over the Red Sea and the Persian Gulf, Atmospheric Chemistry and Physics, 17, 3987-4003. doi:10.5194/acp-17-3987-2017.

Banks, J. R., Hünerbein, A., Heinold, B., et al., 2019. The sensitivity of the colour of dust in MSG- SEVIRI Desert Dust infrared composite imagery to surface and atmospheric conditions, Atmospheric Chemistry and Physics, 19, 6893-6911. doi:10.5194/acp-19-6893-2019.

Barkan, J., Alpert, P., Kutiel, H., Kishcha, P., 2005. Synoptics of dust transportation days from Africa toward Italy and central Europe. Journal of Geophysical Research Atmos. 110, 1-14. https://doi.org/10.1029/2004JD005222

Bauer, S. E., Mishchenko, M. I., Lacis, A. A., et al., 2007. Do sulphate and nitrate coatings on mineral dust have important effects on radiative properties and climate modeling?. Journal of Geophysical Research 112, D06307. doi:10.1029/2005JD006977.

Bègue, N., Tulet, P., Pelon, J., et al., 2014. Aerosol processing and CCN formation of an intense Saharan dust plume during the EUCAARI 2008 campaign. Atmospheric Chemistry and Physics 15, 3497-3516, https://doi.org/10.5194/acp-15-3497-2015.

Ben-Ami, Y., Koren, I., Rudich, Y., et al., 2010. Transport of North African dust from the Bodélé depression to the Amazon Basin: a case study, Atmospheric Chemistry and Physics 10, 75337544,doi:10.5194/acp-10-7533-2010.

Bhattachan, A., Dodorico, P., Baddock, M.C., et al., 2012. The Southern Kalahari: A potential new dust source in the Southern Hemisphere? Environmental Research Letters 7. https://doi.org/10.1088/17489326/7/2/024001

Biscaye, P.E., Grousset, F.E., Revel, M., et al., 1997. Asian provenance of glacial dust (stage 2) in the Greenland Ice Sheet Project 2 Ice Core, Summit, Greenland. Journal of Geophysical Research Ocean. 102, 26765-26781. https://doi.org/10.1029/97JC01249

Bodenheimer, S., Lensky, I.M., Dayan, U., 2019. Characterization of Eastern Mediterranean dust storms by area of origin; North Africa vs. Arabian Peninsula. Atmospheric Environment 198, 158-165. https://doi.org/10.1016/j.atmosenv.2018.10.034

Bohren, C. E., Huffman, D. R., 1983. Absorption and Scattering ofLight by Small Particles. Wiley, New York. doi:10.1002/9783527618156

Boose, Y., Sierau, B., García, M. I., et al., 2016. Ice nucleating particles in the Saharan Air Layer. Atmospheric Chemistry and Physics 16, 9067-9087, https://doi.org/10.5194/acp-16-9067-2016.

Bory, A.J.M., Biscaye, P.E., Grousset, F.E., 2003. Two distinct seasonal Asian source regions for mineral dust deposited in Greenland (NorthGRIP). Geophysical Research Letters 30, 1-4. https://doi.org/10.1029/2002GL016446 
Boucher, O., et al., Clouds and Aerosols. Stocker, T., \& Qin, D. (eds), Climate Change 2013: The Physical Science Basis. Contribution of Working Group I to the Fifth Assessment Report of the Intergovernmental Panel on Climate Change. Cambridge Univ. Press, Cambridge, United Kingdom and New York, NY, USA, 2013.

Bou Karam D, Flamant C, Knippertz P (2008) Dust emissions over the Sahel associated with the West African Monsoon inter-tropical discontinuity region: a representative case study. Q J Roy Meteorol Soc 134:621-634

Brindley, H. E. and Ignatov, A., 2006. Retrieval of mineral aerosol optical depth and size information from Meteosat Second Generation SEVIRI solar reflectance bands, Remote Sensing of Environment, 102, 344-363. doi:10.1016/j.rse.2006.02.024.

Brindley, H. E., Knippertz, P., Ryder, C., and Ashpole, I., 2012. A critical evaluation of the ability of the Spinning Enhanced Visible and InfraRed Imager (SEVIRI) thermal infrared red-green-blue rendering to identify dust events: Theoretical analysis, Journal of Geophysical Research, 117. doi:10.1029/2011JD017326.

Brindley, H. E. and Russell, J. E., 2009: An assessment of Saharan dust loading and the corresponding cloud-free longwave direct radiative effect from geostationary satellite observations, Journal of Geophysical Research, 114. doi:10.1029/2008JD011635.

Bristow, C. S., Hudson-Edwards, K. A., Chappell, A., 2010. Fertilizing the Amazon and equatorial Atlantic with West African dust. Geophysical Research Letters 37, L14807. doi:10.1029/2010GL043486.

Bryant, R. G., 2003. Monitoring hydrological controls on dust emissions: preliminary observations from Etosha Pan, Namibia, The Geographical Journal, 169, 131-141. doi:10.1111/1475-4959.04977.

Bryant, R.G., Bigg, G.R., Mahowald, N.M., Eckardt, F.D., Ross, S.G., 2007. Dust emission response to climate in southern Africa. Journal of Geophysical Research Atmosphere112, 1-17. https://doi.org/10.1029/2005JD007025

Buchard, V., da Silva, A. M., Colarco, P. R., et al., 2015. Using the OMI aerosol index and absorption aerosol optical depth to evaluate the NASA MERRA Aerosol Reanalysis, Atmospheric Chemistry and Physics, 15, 5743-5760. doi:10.5194/acp-15-5743-2015

Bullard, J. E., and M. J. Austin (2011), Dust generation on a proglacial floodplain, West Greenland, Aeolian Res., 3, 43-54, doi:10.1016/.aeolia.2011.01.002.

Bullard, J. E., Baddock, M. Bradwell, T. Crusius, et al., 2016. High-latitude dust in the Earth system. Reviews of Geophysics 54, 447-85. doi:10.1002/2016RG000518.

Caponi, L., Formenti, P., Massabó, D., et al., 2017. Spectral- and size-resolved mass absorption efficiency of mineral dust aerosols in the shortwave spectrum: a simulation chamber study, Atmospheric Chemistry and Physics 17, 7175-7191. https://doi.org/10.5194/acp-17-7175-2017.

Carlson, T. N. and Prospero, J. M., 1972. The Large-Scale Movement of Saharan Air Outbreaks over the Northern Equatorial Atlantic, Journal of Applied Meteorology, 11, 283-297. doi:10.1175/15200450(1972)011<0283:TLSMOS>2.0.CO;2.

Casasanta, G., di Sarra, A.G., Meloni, D., et al., 2011. Large aerosol effects on ozone photolysis in the Mediterranean. Atmospheric Environment 45, 3937-3943.

Chen, G., Ziemba, L. D., Chu, D. A., et al., 2011. Observations of Saharan dust microphysical and optical properties from the Eastern Atlantic during NAMMA airborne field campaign. Atmospheric Chemistry and Physics 11, 723-740. https://doi.org/10.5194/acp-11-723-2011.

Chen, C., Park, T., Wang, X., et al., 2019. China and India lead in greening of the world through land-use management. Nature Sustainability 2, 122-129. https://doi.org/10.1038/s41893-019-0220-7

Chiapello, I., 1997. Origins of African dust transported over the northeastern tropical Atlantic. Journal of Geophysical Research Atmosphere 102, 13701-13709. https://doi.org/10.1029/97JD00259 
Chiapello, I., Moulin, C., Prospero, J.M., 2005. Understanding the long-term variability of African dust transport across the Atlantic as recorded in both Barbados surface concentrations and large-scale Total Ozone Mapping Spectrometer (TOMS) optical thickness. Journal of Geophysical Research D Atmosphere 110, 1-9. https://doi.org/10.1029/2004JD005132

Chin, M., Diehl, T., Tan, Q., Prospero, J. M., Kahn, R. A., Remer, L. A., Yu, H., Sayer, A. M., Bian, H., Geogdzhayev, I. V., Holben, B. N., Howell, S. G., Huebert, B. J., Hsu, N. C., Kim, D., Kucsera, T. L., Levy, R. C., Mishchenko, M. I., Pan, X., Quinn, P. K., Schuster, G. L., Streets, D. G., Strode, S. A. and Torres, O., 2014: Multi-decadal aerosol variations from 1980 to 2009: A perspective from observations and a global model, Atmospheric Chemistry and Physics, 14(7), 3657-3690, doi:10.5194/acp-14-36572014

Chomette, O., Legrand, M., Marticorena, B., 1999. Determination of the wind speed threshold for the emission of desert dust using satellite remote sensing in the thermal infrared. Journal of Geophysical Research Atmosphere104, 31207-31215. https://doi.org/10.1029/1999JD900756

Choobari, O. A., Zawar-Reza, P., Sturman, A., 2014. The global distribution of mineral dust and its impacts on the climate system: A review. Atmospheric Research 138, 152-165. doi:10.1016/j.atmosres.2013.11.007, 2014.

Chou, C., Formenti, P., Maille, M., et al., 2008. Size distribution, shape, and composition of mineral dust aerosols collected during the African Monsoon Multidisciplinary Analysis Special Observation Period 0: Dust and Biomass-Burning Experiment field campaign in Niger, January 2006. Journal of Geophysical Research 113, D00C10. doi:10.1029/2008jd009897.

Christopher, S. A., Wang, J., Ji, Q., Tsay, S.-C., 2003. Estimation of diurnal shortwave dust aerosol radiative forcing during PRIDE. Journal of Geophysical Research 108, 8596. doi:10.1029/2002JD002787.

Clarke, A. D., Shinozuka, Y. V., Kapustin, N., et al., 2004. Size distributions and mixtures of dust and black carbon aerosol in Asian outflow: Physiochemistry and optical properties. Journal of Geophysical Research 109, D15S09. doi:10.1029/2003JD004378.

Colarco, P. R., Nowottnick, E. P., Randles, C. A., et al., 2014. Impact of radiatively interactive dust aerosols in the NASA GEOS-5 climate model: Sensitivity to dust particle shape and refractive index. Journal of Geophysical Research: Atmosphere 119, 753- 786. doi:10.1002/2013JD020046.

Cuesta, J., Eremenko, M., Flamant, C., et al., 2015. Three-dimensional distribution of a major desert dust outbreak over East Asia in March 2008 derived from IASI satellite observations, Journal of Geophysical Research Atmospheres, 120, 7099-7127. doi:10.1002/2014JD022406.

Cuevas, E., Gómez-Peláez, A.J., Rodríguez, S., et al., 2017. The pulsating nature of large-scale Saharan dust transport as a result of interplays between mid-latitude Rossby waves and the North African Dipole Intensity. Atmospheric Environment 167, 586-602. https://doi.org/10.1016/j.atmosenv.2017.08.059

Darwin, C.R., 1846. An account of the fine dust which often falls on vessels in the Atlantic Ocean. Quarterly Journal of the Geological Society of London 2, 26-30.

Das, R., Evan, A., Lawrence, D., 2013. Contributions of long-distance dust transport to atmospheric $P$ inputs in the Yucatan Peninsula. Global Biogeochemical Cycles 27, 167-175. https://doi.org/10.1029/2012GB004420.

Das, S., Dey, S., Dash, S. K., Giuliani, G., Solmon, F., 2015. Dust aerosol feedback on the Indian summer monsoon: Sensitivity to absorption property. Journal of Geophysical Research Atmosphere120, 96429652. doi: 10.1002/2015JD023589.

Dayan, U., Heffter, J., Miller, J., Gutman, G., 1991. Dust intrusion events into the Mediterranean basin. J. Applied Meteorology https://doi.org/10.1175/1520-0450(1991)030<1185:DIEITM>2.0.CO;2

De Deckker, P., 2019. An evaluation of Australia as a major source of dust. Earth-Science Review 194, 536-567. https://doi.org/10.1016/j.earscirev.2019.01.008 
De Florio, M.J., Goodwin, I.D., Cayan, D.R., et al., 2016. Interannual modulation of subtropical Atlantic boreal summer dust variability by ENSO. Climate Dynamics 46, 585-599. https://doi.org/10.1007/s00382-015-2600-7

Delany, A.C., Claire Delany, A., Parkin, D.W., et al., 1967. Airborne dust collected at Barbados. Geochimica and Cosmochimica Acta 31. https://doi.org/10.1016/s0016-7037(67)80037-1

deMenocal, P., Ortiz, J., Guilderson, T., et al., 2000. Abrupt onset and termination of the African Humid Period. Quaternary Science Review 19, 347-361. https://doi.org/10.1016/S0277-3791(99)00081-5

deMenocal, P.B., 2004. African climate change and faunal evolution during the Pliocene-Pleistocene. Earth and Planetary Science Letters 220, 3-24. https://doi.org/10.1016/S0012-821X(04)00003-2

Denjean, C., Caquineau, S., Desboeufs, K., et al., 2015. Long-range transport across the Atlantic in summertime does not enhance the hygroscopicity of African mineral dust. Geophysical Research Letters 42, 7835-7843, 10.1002/2015GL065693.

Denjean, C., Cazzola, F., Mazzino, A., et al., 2016a. Size distribution and optical properties of mineral dust aerosols transported in the western Mediterranean. Atmospheric Chemistry and Physics, 16, 10811104. doi:https://doi.org/10.5194/acp-16-1081-2016.

Denjean, C., Formenti, P., Desboeufs, K., et al., 2016b. Size distribution and optical properties of African mineral dust after intercontinental transport. Journal of Geophysical Research Atmosphere121, 71177138. https://doi.org/10.1002/2016JD024783.

De Paepe, B., Ignatov, A., Dewitte, S., and Ipe, A., 2008. Aerosol retrieval over ocean from SEVIRI for the use in GERB Earth's radiation budget analyses, Remote Sensing of Environment, 112, 2455-2468. doi:10.1016/j.rse.2007.11.005.

de Reus, M., Dentener, F., Thomas, A., et al., 2000. Airborne observations of dust aerosol over the North Atlantic Ocean during ACE-2: indications for heterogeneous ozone destruction. Journal of Geophysical Research 105, 15 263-15 275.

de Reus, M., Fischer, H., Sander, R., et al., 2005. Observations and model calculations of trace gas scavenging in a dense Saharan dust plume during MINATROC. Atmospheric Chemistry and Physics 5, 1787-1803. doi:10.5194/acp-5-1787-2005.

Derimian, Y., Karnieli, A., Kaufman, Y. J., et al., 2006. Dust and pollution aerosols over the Negev desert, Israel: Properties, transport, and radiative effect. Journal of Geophysical Research 111, D05205. doi:10.1029/2005JD006549.

Desboeufs, K., Losno, R. Colin, J.-L., 2001. Factors influencing aerosol solubility during cloud process, Atmospheric Environment, 35, 3529-3537.

DeSouza-Machado, S. G., Strow, L., Imbiriba, B., et al., 2010. Infrared retrievals of dust using AIRS: Comparisons of optical depths and heights derived for a North African dust storm to other collocated EOS A-Train and surface observations. Journal of Geophysical Research 115, D15201. doi:10.1029/2009JD012842.

Di Biagio, C., Formenti, P., Styler, S. A., Pangui, E., Doussin, J.-F., 2014. Laboratory chamber measurements of the longwave extinction spectra and complex refractive indices of African and Asian mineral dusts. Geophysical Research Letters 41, 6289-6297. https://doi.org/10.1002/2014GL060213.

Di Biagio, C., Formenti, P., Balkanski, Y., et al., 2017. Global scale variability of the mineral dust long-wave refractive index: a new dataset of in situ measurements for climate modeling and remote sensing. Atmospheric Chemistry and Physics 17, 1901-1929. https://doi.org/10.5194/acp-17-1901-2017.

Di Biagio, C., Formenti, P., Balkanski, Y., et al., 2019. Complex refractive indices and single-scattering albedo of global dust aerosols in the shortwave spectrum and relationship to size and iron content. Atmospheric Chemistry and Physics 19, 15503-15531. https://doi.org/10.5194/acp-19-15503-2019. 
Di Biagio, C., Balkanski, Y., Albani, S., Boucher, O., Formenti, P., 2020. Direct radiative effect by mineral dust aerosols constrained by new microphysical and spectral optical data. Geophysical Research Letters 47, e2019GL086186. https://doi.org/10.1029/2019GL086186.

Di Mauro, B., Garzonio, R., Rossini, M., et al., 2019. Saharan dust events in the European Alps: role in snowmelt and geochemical characterization. The Cryosphere 13, 1147-1165. https://doi.org/10.5194/tc-13-1147-2019.

Diner, D.J., Abdou, W.A., Conel, J.E., et al., 2001. MISR aerosol retrievals over southern Afiica during the SAFARI- 2000 dry season campaign. Geophysical Research Letters 28,3 127-3 130.

di Sarra, A., Di Biagio, C., Meloni, D., 2011. Shortwave and longwave radiative effects on the intense Saharan dust event of 25-26 March 2010 at Lampedusa (Mediterranean Sea). Journal of Geophysical Research 116, D23209. doi:10.1029/2011JD016238.

Doherty, O.M., Riemer, N., Hameed, S., 2012. Control of Saharan mineral dust transport to Barbados in winter by the Intertropical Convergence Zone over West Africa. Journal of Geophysical Research Atmos. 117, 1-13. https://doi.org/10.1029/2012JD017767

Doherty, O.M., Riemer, N., Hameed, S., 2014. Role of the convergence zone over West Africa in controlling Saharan mineral dust load and transport in the boreal summer. Tellus, Ser. B Chem. Phys. Meteorol. 66, 1-18. https://doi.org/10.3402/tellusb.v66.23191

Dubovik, O., King, M. D., 2000. A flexible inversion algorithm for retrieval of aerosol optical properties from Sun and sky radiance measurements. Journal of Geophysical Research 105, 20673 20696,https://doi.org/10.1029/2000JD900282.

Dubovik, O., Holben, B., Eck, T. F., et al., 2002. Variability of Absorption and Optical Properties of Key Aerosol Types Observed in Worldwide Locations, Journal of the Atmospheric Sciences, 59, 590-608. doi:10.1175/1520-0469(2002)059<0590:VOAAOP>2.0.CO;2.

Dubovik, O., Sinyuk, A., Lapyonok, T., et al., 2006. Application of spheroid models to account for aerosol particle non sphericity in remote sensing of desert dust. Journal of Geophysical Research 111, D11208. https://doi.org/10.1029/2005JD006619.

Dubovik, O., Herman, M., Holdak, A., et al., 2011. Statistically optimized inversion algorithm for enhanced retrieval of aerosol properties from spectral multi-angle polarimetric satellite observations. Atmospheric Measurement Techniques, 4, 975-1018. https://doi.org/10.5194/amt-4-975-2011

Duce, R.A., 1995. Sources, distributions, and fluxes of mineral aerosols and their relationship to climate. In: Charlson, R.J., Heintzenberg, J. (Eds.), Aerosol Forcing of Climate. Wiley, New York, pp. 43-72.

Dufresne, J.L., Gautier, C., Ricchiazzi, P., Fouquart, Y., 2002. Longwave scattering effects of mineral aerosols. Journal of the Atmospheric Science 59, 1959-1966. https://doi.org/10.1175/15200469(2002)059<1959:LSEOMA>2.0.CO;2.

Dunion, J. P., Velden, C. S., 2004. The impact of the Saharan air layer on Atlantic tropical cyclone activity. Bulletin of the American Meteorological Society 85(3), 353-365.

Engelbrecht, J. P., Moosmüller, H., Pincock, S., et al., 2016. Technical note: Mineralogical, chemical, morphological, and optical interrelationships of mineral dust re-suspensions. Atmospheric Chemistry and Physics 16, 10809-10830. https://doi.org/10.5194/acp-16-10809-2016.

Engelstaedter, S., Kohfeld, K.E., Tegen, I., Harrison, S.P., 2003. Controls of dust emissions by vegetation and topographic depressions: An evaluation using dust storm frequency data. Geophysical Research Letters 30, 30-33. https://doi.org/10.1029/2002GL016471

Evan, A. T., 2018. Surface winds and dust biases in climate models. Geophysical Research Letters, 45, 1079-1085. https://doi.org/10.1002/2017GL076353

Evan, A.T., Mukhopadhyay, S., 2010. African dust over the northern tropical Atlantic: 1955-2008. J. Applied Meteorology Climatol. 49, 2213-2229. https://doi.org/10.1175/2010JAMC2485.1 
Evan, A.T., Flamant, C., Fiedler, S., Doherty, O., 2014. An analysis of aeolian dust in climate models. Geophysical Research Letters 41, 5996-6001. https://doi.org/10.1002/2014GL060545

Evan, A.T., Fiedler, S., Zhao, C., et al., 2015. Derivation of an observation-based map of North African dust emission. Aeolian Res. 16, 153-162. https://doi.org/10.1016/j.aeolia.2015.01.001

Evan, A.T., Flamant, C., Gaetani, M., Guichard, F., 2016. The past, present and future of African dust. Nature 531, 493-495. https://doi.org/10.1038/nature17149.

Eyring, V., Bony, S., Meehl, G. A., et al., 2016. Overview of the Coupled Model Intercomparison Project Phase 6 (CMIP6) experimental design and organization, Geosci. Model Dev., 9, 1937-1958. doi:10.5194/gmd-9-1937-2016.

Fairlie, T. D., Jacob, D. J., Dibb, J. E., et al., 2010. Impact of mineral dust on nitrate, sulfate, and ozone in transpacific Asian pollution plumes. Atmospheric Chemistry and Physics 10, 3999-4012, https://doi.org/10.5194/acp-10-3999-2010.

Falkovich, A. H., Schkolnik, G., Ganor, E., Rudich, Y., 2004. Adsorption of organic compounds pertinent to urban environments onto mineral dust particles, J. Geophys. Res., 109, D02208. doi:10.1029/2003jd003919.

Flemming, J., Benedetti, A., Inness, A., et al., 2017. The CAMS interim Reanalysis of Carbon Monoxide, Ozone and Aerosol for 2003-2015, Atmospheric Chemistry and Physics, 17, 1945-1983. https://doi.org/10.5194/acp-17-1945-2017

Floutsi, A. A., Korras-Carraca, M. B., Matsoukas, C., Hatzianastassiou, N., Biskos, G., 2016. Climatology and trends of aerosol optical depth over the Mediterranean basin during the last 12 years (2002-2014) based on Collection 006 MODIS-Aqua data, Science of the Total Environment, 551-552, 292-303. doi:10.1016/j.scitotenv.2016.01.192.

Formenti, P., Andreae, M. O., Lange, L., et al., 2001. Saharan dust in Brazil and Suriname during the LargeScale Biosphere-Atmosphere Experiment in Amazonia (LBA) - Cooperative LBA Regional Experiment (CLAIRE) in March 1998. Journal of Geophysical Research 106, 14919-14934. https://doi.org/10.1029/2000jd900827.

Formenti, P., Rajot J.L., Desboeufs, K., et al., 2008. Regional variability of the composition of mineral dust from western Africa: results from the AMMA SOPO/DABEX and DODO field campaigns. J Geophys Res 113, D00C13. doi:10.1029/2008JD009903.

Formenti, P., Caquineau, S., Desboeufs, K., et al., 2014. Mapping the physicochemical properties of mineral dust in western Africa: mineralogical composition. Atmospheric Chemistry and Physics 14, 1066310686. https://doi.org/10.5194/acp-14-10663-2014.

Formenti, P., Mbemba Kabuiku, L., Chiapello, I., et al., 2018. Aerosol optical properties derived from POLDER-3/PARASOL (2005-2013) over the western Mediterranean Sea - Part 1: Quality assessment with AERONET and in situ airborne observations. Atmos. Meas. Tech. 11, 6761-6784. https://doi.org/10.5194/amt-11-6761-2018.

Formenti, P., D'Anna, B. Flamant, C., et al., 2019. The Aerosols, Radiation and Clouds in Southern Africa Field Campaign in Namibia: Overview, Illustrative Observations, and Way Forward. Bull. Amer. Meteor. Soc. 100, 1277-1298. https://doi.org/10.1175/BAMS-D-17-0278.1

Formenti, P., Schütz, L., Balkanski, Y., Desboeufs, K., Ebert, M., Kandler, K., Petzold, A., Scheuvens, D., Weinbruch, S., Zhang, D., 2011b. Recent progress in understanding physical and chemical properties of African and Asian mineral dust. Atmospheric Chemistry and Physics 11, 8231-8256. https://doi.org/10.5194/acp-11-8231-2011.

Francis, D., Eayrs, C., Chaboureau, J.P., Mote, T., Holland, D.M., 2018. Polar Jet Associated Circulation Triggered a Saharan Cyclone and Derived the Poleward Transport of the African Dust Generated by the Cyclone. Journal of Geophysical Research Atmos. 123, 11,899-11,917. https://doi.org/10.1029/2018JD029095. 
Francis, D., Alshamsi, N., Cuesta, J., Isik, A. G., and Dundar, C., 2019. Cyclogenesis and Density Currents in the Middle East and the Associated Dust Activity in September 2015, Geosciences, 9. doi:10.3390/geosciences9090376.

Gaetani, M., Pasqui, M., 2014. Synoptic patterns associated with extreme dust events in the Mediterranean Basin. Reg. Environ. Chang. 14, 1847-1860. https://doi.org/10.1007/s10113-012-0386-2

Gaetani, M., Pasqui, M., Crisci, A., Guarnieri, F., 2016. A synoptic characterization of the dust transport and associated thermal anomalies in the Mediterranean basin. Int. J. Climatol. 36, 2779-2791. https://doi.org/10.1002/joc.3615

Gasch, P., Rieger, D., Walter, C., et al., 2017. Revealing the meteorological drivers of the September 2015 severe dust event in the Eastern Mediterranean, Atmospheric Chemistry and Physics, 17, 13,57313,604. doi:10.5194/acp-17-13573-2017.

Gassó, S., Stein, A., Marino, F., et al., 2010. A combined observational and modeling approach to study modern dust transport from the Patagonia desert to East Antarctica. Atmospheric Chemistry and Physics 10, 8287-8303. https://doi.org/10.5194/acp-10-8287-2010

Gasteiger, J., Wiegner, M., Groß, S., et al., 2011. Modelling lidar-relevant optical properties of complex mineral dust aerosols. Tellus B 63, 725-741. https://doi.org/10.1111/j.1600-0889.2011.00559.x.

Gasteiger, J., S. Groß, B. Weinzierl, D. Sauer, V. Freudenthaler, 2017. Particle settling and convective mixing in the Saharan Air Layer as seen from an integrated model, lidar, and in-situ perspective. Atmospheric Chemistry and Physics 17, 297-311. doi:10.5194/acp-17-297-2017.

Gibson, E., Gierlus, K., Hudson, P., Grassian, V., 2007. Generation of interbally mixed insoluble and soluble aerosol particles to investigate the impact of atmospheric aging and heterogeneous processing on the CCN activity of mineral dust aerosol. Aerosol. Sci.Tech. 41, 914-924. doi:10.1080/02786820701557222.

Gierlus, K.M., Laskina, O., Abernathy, T.L., Grassian, V.H., 2012. Laboratory study of the effect of oxalic acid on the cloud condensation nuclei activity of mineral dust aerosol. Atmos Environ 46, 125-130.

Giles, D. M., Sinyuk, A., Sorokin, M. G., et al., 2019. Advancements in the Aerosol Robotic Network (AERONET) Version 3 database - automated near-real-time quality control algorithm with improved cloud screening for Sun photometer aerosol optical depth (AOD) measurements, Atmospheric Measurement Techniques, 12, 169-209. doi:10.5194/amt-12-169-2019.

Ginoux, P., Chin, M., Tegen, I., et al., 2001. Sources and distributions of dust aerosols simulated with the GOCART model, J. Geophys. Res., 106, 20255- 20273. doi:10.1029/2000JD000053.

Ginoux, P., Prospero, J.M., Gill, T.E., Hsu, N.C., Zhao, M., 2012. Global-scale attribution of anthropogenic and natural dust sources and their emission rates based on MODIS Deep Blue aerosol products. Rev. Geophys. 50, 1-36. https://doi.org/10.1029/2012RG000388

Gkikas, A., Houssos, E.E., Hatzianastassiou, N., Papadimas, C.D., Bartzokas, A., 2012. Synoptic conditions favouring the occurrence of aerosol episodes over the broader Mediterranean basin. Q. J. R. Meteorol. Soc. 138, 932-949. https://doi.org/10.1002/qj.978

Glaccum, R.A., Prospero, J.M., 1980. Saharan aerosols over the tropical north Atlantic - mineralogy. Marine Geology 37, 295-321.

Gläser, G., Wernli, H., Kerkweg, A., Teubler, F., 2015. The transatlantic dust transport from North Africa to the Americas-its characteristics and source regions. Journal of Geophysical Research 120, 11,23111,252. https://doi.org/10.1002/2015JD023792

Goffner, D., Sinare, H., Gordon, L.J., 2019. The Great Green Wall for the Sahara and the Sahel Initiative as an opportunity to enhance resilience in Sahelian landscapes and livelihoods. Reg. Environ. Chang. 19, 1417-1428. https://doi.org/10.1007/s10113-019-01481-z

Gong, S.L., Zhang, X.Y., Zhao, T.L., et al., 2006. A simulated climatology of Asian dust aerosol and its trans-pacific transport. Part II: Interannual variability and climate connections. J. Clim. 19, 104-122. https://doi.org/10.1175/JCLI3606.1 
Goudie, A. S., Middleton, N. J., 2001. Saharan dust storms: nature and consequences. Earth-Sci. Rev. 56, 179-204.

Groß, S., Gasteiger, J., Freudenthaler, V., et al., 2016. Saharan dust contribution to the Caribbean summertime boundary layer - a lidar study during SALTRACE, Atmospheric Chemistry and Physics, 16, 11 535-11 546. doi:10.5194/acp-16-11535-2016.

Grousset, F.E., Ginoux, P., Bory, A., Biscaye, P.E., 2003. Case study of a Chinese dust plume reaching the French Alps. Geophysical Research Letters 30, 23-26. https://doi.org/10.1029/2002GL016833.

Grousset, F.E., Biscaye, P.E., 2005. Tracing dust sources and transport patterns using $\mathrm{Sr}$, $\mathrm{Nd}$ and $\mathrm{Pb}$ isotopes. Chem. Geol. 222, 149-167. https://doi.org/10.1016/j.chemgeo.2005.05.006.

Gutleben, M., Groß, S., and Wirth, M., 2019. Cloud macro-physical properties in Saharan-dust-laden and dust-free North Atlantic trade wind regimes: a lidar case study, Atmospheric Chemistry and Physics, 19, 10 659-10 673. doi:10.5194/acp-19-10659-2019.

Haarig, M., Ansmann, A., Althausen, D., et al., 2017. Triple-wavelength depolarization-ratio profiling of Saharan dust over Barbados during SALTRACE in 2013 and 2014, Atmospheric Chemistry and Physics, 17, 10 767-10 794. doi:10.5194/acp-17-10767-2017.

Han, C., Do Hur, S., Han, Y. et al. High-resolution isotopic evidence for a potential Saharan provenance of Greenland glacial dust. Scientific Reports 8, 15582 (2018). https://doi.org/10.1038/s41598-018-338590.

Hand, V. L., Capes, G., Vaughan, D. J., et al., 2010. Evidence of internal mixing of African dust and biomass burning particles by individual particle analysis using electron beam techniques. Journal of Geophysical Research 115, D13301. doi:10.1029/2009jd012938.

Hande, L. B., Engler, C., Hoose, C., Tegen, I., 2015. Seasonal variability of Saharan desert dust and ice nucleating particles over Europe. Atmospheric Chemistry and Physics 15, 4389-4397, https://doi.org/10.5194/acp-15-4389-2015.

Hansell, R. A., Tsay, R.-C. Hsu, N. C., et al., 2012. An assessment of the surface longwave direct radiative effect of airborne dust in Zhangye, China, during the Asian Monsoon Years field experiment (2008). Journal of Geophysical Research 117, D00K39. doi:10.1029/2011JD017370.

Hatch, C. D., Gierlus, K. M., Schuttlefield, J. D., Grassian, V. H., 2008. Water adsorption and cloud condensation nuclei activity of calcite and calcite coated with model humic and fulvic acids. Atmospheric Environment 42, 5672-5684.

Haywood, J., Boucher, O., 2000. Estimates of the direct and indirect radiative forcing due to tropospheric aerosols: A review. Rev. Geophys. 38(4), 513- 543. doi:10.1029/1999RG000078.

Haywood, J., Francis, P., Osborne, S., et al., 2003. Radiative properties and direct radiative effect of Saharan dust measured by the C-130 aircraft during SHADE: 1. Solar spectrum. J. Geophys. Res.108(D18), 8577. doi:10.1029/2002JD002687.

Haywood, J. M., Pelon, J., Formenti, P., et al., 2008. Overview of the dust and biomass-burning experiment and African Monsoon Multidisciplinary Analysis special ob-serving period-0. Journal of Geophysical Research 113, D00C17. doi:10.1029/2008JD010077.

Haywood, J.M., Johnson, B.T., Osborne, S.R., et al., 2011. Motivation, rationale and key results from the GERBILS Saharan dust measurement campaign. Q.J.R. Meteorol. Soc. 137: 1106-1116. doi:10.1002/qj.797

He, H., Wang, Y., Ma, Q., et al., 2014. Mineral dust and NOx promote the conversion of SO2 to sulfate in heavy pollution days. Sci. Rep. 4, 4172. https://doi.org/10.1038/srep04172.

Heintzenberg, J. O. S. T., 2009. The SAMUM-1 experiment over southern Morocco: Overview and introduction. Tellus 61B, 2-11. doi:10.1111/j.1600-0889.2008.00403.x. 
Holben, B. N., Eck, T. F., Slutsker, I., et al., 1998. AERONET- A Federated Instrument Network and Data Archive for Aerosol Characterization, Remote Sensing of Environment, 66, 1-16. doi:10.1016/S00344257(98)00031-5.

Hoose, C., Lohmann, U., Erdin, R., Tegen, I., 2008. The global influence of dust mineralogical composition on heterogeneous ice nucleation in mixed-phase clouds. Environment Research Letters 3(025003). doi:10.1088/1748-9326/3/2/025003.

Hovan, S.A., Rea, D.K., Pisias, N.G., 1991. Late Pleistocene Continental Climate and Oceanic Variability Recorded in Northwest Pacific Sediments. Paleoceanography 6, 349-370. https://doi.org/10.1029/91PA00559

Hsu, N. C., Tsay, S.-C., King, M. D., and Herman, J. R., 2004. Aerosol Properties Over Bright-Reflecting Source Regions, IEEE Transactions on Geoscience and Remote Sensing, 42, 557-569. doi:10.1109/TGRS.2004.824067.

Hsu, N. C., Gautam, R., Sayer, A. M., et al., 2012. Global and regional trends of aerosol optical depth over land and ocean using SeaWiFS measurements from 1997 to 2010, Atmospheric Chemistry and Physics, 12, 8037-8053. doi:10.5194/acp-12-8037-2012.

Hsu, N. C., Jeong, M.-J., Bettenhausen, C., et al., 2013. Enhanced Deep Blue aerosol retrieval algorithm: The second generation, Journal of Geophysical Research: Atmospheres, 118, 1-20. doi:10.1002/jgrd.50712.

Huang, J., Minnis, P., Chen, B., et al., 2008. Long-range transport and vertical structure of Asian dust from CALIPSO and surface measurements during PACDEX. Journal of Geophysical Research Atmos. 113, 1-13. https://doi.org/10.1029/2008JD010620

Huang, Y., Kok, J. F., Kandler, K., et al., 2020. Climate models and remote sensing retrievals neglect substantial desert dust asphericity. Geophysical Research Letters 47, e2019GL086592. https://doi.org/10.1029/2019GL086592

Huebert, B.J., Bates, T., Russell, P.B., et al., 2003. An overview of ACE-Asia: strategies for quantifying the relationships between Asian aerosols and their climatic impacts. Journal of Geophysical Research 108(D23), 8633. http://dx.doi.org/10.1029/2003JD003550.

Huneeus, N., Schulz, M., Balkanski, Y., et al., 2011. Global dust model intercomparison in AeroCom phase i. Atmospheric Chemistry and Physics 11, 7781-7816. https://doi.org/10.5194/acp-11-7781-2011.

Huneeus, N., Chevallier, F., Boucher, O., 2012. Estimating aerosol emissions by assimilating observed aerosol optical depth in a global aerosol model. Atmospheric Chemistry and Physics 12, 4585-4606. https://doi.org/10.5194/acp-12-4585-2012.

Husar, R.B., Prospero, J.M., Stowe, L.L., 1997. Characterization of tropospheric aerosols over the oceans with the NOAA AVHRR optical thickness product. J Geophys Res 102:16889-16909

Israelevich, P.L., Levin, Z., Joseph, J.H., Ganor, E., 2002. Desert aerosol transport in the Mediterranean region as inferred from the TOMS aerosol index. Journal of Geophysical Research Atmosphere 107, 113. https://doi.org/10.1029/2001JD002011.

Israelevich, P., Ganor, E., Alpert, P., Kishcha, P., Stupp, A., 2012. Predominant transport paths of Saharan dust over the Mediterranean Sea to Europe. Journal of Geophysical Research Atmosphere 117, 1-11. https://doi.org/10.1029/2011JD016482

Ito, A., Kok, J. F., 2017. Do dust emissions from sparsely vegetated regions dominate atmospheric iron supply to the Southern Ocean? Journal of Geophysical Research 122, 3987-4002.

Jacob, D. J., Crawford, J. H., Kleb, M. M., et al., 2003. Transport and Chemical Evolution over the Pacific (TRACE-P) aircraft mission: Design, execution, and first results. Journal of Geophysical Research 108, 9000. doi:10.1029/2002JD003276, D20.

Jaenicke, R., Schütz, L., 1978. Comprehensive study of physical and chemical properties of the surface aerosols in the Cape Verde Islands region. Journal of Geophysical Research 83, 3585-3599. 
Jeong, G. Y., 2008. Bulk and single-particle mineralogy of Asian dust and a comparison with its source soils. Journal of Geophysical Research 113, D02208. doi:10.1029/2007JD008606.

Jickells, T., An, Z. S., Andersen, K. K., et al., 2005. Global iron connections between dust, ocean biogeochemistry and climate, Science 308, 67-71.

Jilbert, T., Reichart, G.J., Aeschlimann, B., et al., 2010. Climate-controlled multidecadal variability in North African dust transport to the Mediterranean. Geology 38, 19-22. https://doi.org/10.1130/G25287.1

Jin, Q., Zang, Z.-L., Wei, J., 2016. High sensitivity of Indian summer monsoon to Middle East dust absorptive properties. Scientific Reports 6, 30690. doi: 10.1038/srep30690.

Huang, J., Zhang, C., Prospero, J.M., 2010. African dust outbreaks: A satellite perspective of temporal and spatial variability over the tropical Atlantic Ocean. Journal of Geophysical Research Atmos. 115, 1-20. https://doi.org/10.1029/2009JD012516

Johnson, M.S., Meskhidze, N., Kiliyanpilakkil, V.P., Gassó, S., 2011. Understanding the transport of Patagonian dust and its influence on marine biological activity in the South Atlantic Ocean. Atmospheric Chemistry and Physics 11, 2487-2502. https://doi.org/10.5194/acp-11-2487-2011

Journet, E., Desboeufs, K. V., Caquineau, S., Colin, J.-L., 2008. Mineralogy as a critical factor of dust iron solubility. Geophysical Research Letters 35, L07805. doi:10.1029/2007GL031589.

Kahn, R. A., Nelson, D. L., Garay, M. J., et al., 2009. MISR Aerosol Product Attributes and Statistical Comparisons With MODIS, IEEE Transactions on Geoscience and Remote Sensing, 47, 4095-4114. doi:10.1109/TGRS.2009.2023115.

Kalashnikova, O. V., Kahn, R. A., 2008. Mineral dust plume evolution over the Atlantic from MISR and MODIS aerosol retrievals. Journal of Geophysical Research 113, D24204. doi:10.1029/2008JD010083.

Kalenderski, S. and Stenchikov, G., 2016. High-resolution regional modeling of summertime transport and impact of African dust over the Red Sea and Arabian Peninsula, Journal of Geophysical Research: Atmospheres, 121. doi:10.1002/2015JD024480.

Kanakidou, M., Myriokefalitakis, S., Tsigaridis, K., 2018. Aerosols in atmospheric chemistry and biogeochemical cycles of nutrients. Environmental Research Letters 13, 6, 063004. doi:10.1088/17489326/aabcdb.

Kandler, K., Benker, N., Bundke, U., et al., 2007. Chemical composition and complex refractive index of Saharan mineral dust at Izana, Tenerife (Spain) derived by electron microscopy. Atmospheric Environment 41, 8058-8074.

Kandler, K., Schütz, L., Deutscher, C., et al., 2009. Size distribution, mass concentration, chemical and mineralogical composition and derived optical parameters of the boundary layer aerosol at Tinfou, Morocco, during SAMUM 2006. Tellus B 61, 32-50,https://doi.org/10.1111/j.1600-0889.2008.00385.x.

Kandler, K., Lieke, K., Benker, N., et al., 2011. Electron microscopy of particles collected at Praia, Cape Verde, during the Saharan Mineral Dust Experiment: Particle chemistry, shape, mixing state and complex refractive index. Tellus 63B, 475-496. https://doi.org/10.1111/j.1600-0889.2011.00550.x.

Kanitz, T., Engelmann, R., Heinold, B., et al., 2014. Tracking the Saharan Air Layer with shipborne lidar across the tropical Atlantic. Geophysical Research Letters 41, 1044-1050. doi:10.1002/2013GL058780.

Kanji, Z. A., Welti, A., Chou, C., Stetzer, O., Lohmann, U., 2013. Laboratory studies of immersion and deposition mode ice nucleation of ozone aged mineral dust particles. Atmospheric Chemistry and Physics 13, 9097-9118, https://doi.org/10.5194/acp-13-9097-2013.

Kanji, Z. A., Sullivan, R. C., Niemand, M., et al., 2019. Heterogeneous ice nucleation properties of natural desert dust particles coated with a surrogate of secondary organic aerosol. Atmospheric Chemistry and Physics 19, 5091-5110, https://doi.org/10.5194/acp-19-5091-2019.

Karam, D.B., Flamant, C., Cuesta, J., Pelon, J., Williams, E., 2010. Dust emission and transport associated with a Saharan depression: February 2007 case. Journal of Geophysical Research Atmos. 115, 1-19. https://doi.org/10.1029/2009JD012390 
Karydis, V. A., Tsimpidi, A. P., Pozzer, A., Astitha, M., Lelieveld, J., 2016. Effects of mineral dust on global atmospheric nitrate concentrations. Atmospheric Chemistry and Physics 16, 14911509,doi:10.5194/acp-16-1491-2016.

Kaskaoutis, D.G., Rashki, A., Dumka, U.C., et al., 2019. Atmospheric dynamics associated with exceptionally dusty conditions over the eastern Mediterranean and Greece in March 2018. Atmospheric Research 218, 269-284. https://doi.org/10.1016/j.atmosres.2018.12.009

Kaufman, Y. J., Boucher, O., Tanré, D., Chin, M., Remer, L. A., Takemura, T., 2005. Aerosol anthropogenic component estimated from satellite data. Geophysical Research Letters 32, L17804, doi:10.1029/2005GL023125.

Kim, D., Chin, M., Yu, H., et al., 2011. Dust optical properties over North Africa and Arabian peninsula derived from the AERONET dataset. Atmospheric Chemistry and Physics 11,10733-10741.

Kishcha, P., Alpert, P., Barkan, J., Kirchner, I., Machenhauer, B., 2003. Atmospheric response to Saharan dust deduced from ECMWF reanalysis (ERA) temperature increments. Tellus, Ser. B 55, 901-913.

Klüser, L., Martynenko, D., and Holzer-Popp, T., 2011. Thermal infrared remote sensing of mineral dust over land and ocean: a spectral SVD based retrieval approach for IASI, Atmospheric Measurement Techniques, 4, 757-773. doi:10.5194/amt-4-757-2011.

Koehler, K. A., Kreidenweis, S. M., DeMott, P. J., et al., 2010. Laboratory investigations of the impact of mineral dust aerosol on cold cloud formation. Atmospheric Chemistry and Physics 10, 11955-11968, https://doi.org/10.5194/acp-10-11955-2010.

Knippertz, P., Todd, M.C., 2012. Mineral dust aerosols over the Sahara: Meteorological controls on emission and transport and implications for modeling. Reviews of Geophysics 50. https://doi.org/10.1029/2011RG000362.

Knippertz, P., 2014. Meteorological aspects of dust storms. In: Mineral Dust: A Key Player in the Earth System, edited by: Knippertz, P. and Stuut, J.-B. W., Springer, 267-286. https://doi.org/10.1007/97894-017-8978-3_13.

Knippertz, P., Coe, H. Chiu, J. C., et al., 2015. The DACCIWA project: Dynamics-aerosol- chemistry-cloud interactions in West Africa. Bulletin of the American Meteorological Society 96, 1451-1460. https://doi.org/10.1175/BAMS-D-14- 00108.1.

Kok, J.F., 2011. Does the size distribution of mineral dust aerosols depend on the wind speed at emission? Atmospheric Chemistry and Physics 11, 10149-10156.

Kok, J.F., Ridley, D.A., Zhou, Q., et al., 2017. Smaller desert dust cooling effect estimated from analysis of dust size and abundance. Nature Geoscience 10, 274-278. https://doi.org/10.1038/ngeo2912

Koltay, E., Borbély-Kiss, I., Kertész, Z., Kiss, Á.Z., Szabó, G., 2006. Assignment of Saharan dust sources to episodes in Hungarian atmosphere by PIXE and TOMS observations. Journal of Radioanalitical and Nuclear Chemistry 267, 449-459. https://doi.org/10.1007/s10967-006-0073-1

Konaré, A., Zakey, A. S., Solmon, F., et al., 2008. A regional climate modeling study of the effect of desert dust on the West African monsoon. Journal of Geophysical Research 113, D12206. doi:10.1029/2007JD009322.

Koren, I., Kaufman, Y. J., Washington, R., et al., 2006. The Bodélé depression: a single spot in the Sahara that provides most of the dust to the Amazon forest, Environmental Research Letters, 1. 014005. doi:10.1088/1748-9326/1/1/014005.

Krueger, B. J., Grassian, V. H., Laskin, A., Cowin, J. P., 2003. The transformation of solid atmospheric particles into liquid droplets through heterogeneous chemistry: Laboratory insights into the processing of calcium containing mineral dust aerosol in the troposphere. Geophysical Research Letters 30, 1148. doi:10.1029/2002gl016563.

Kubilay, N., Nickovic, S., Moulin, C., Dulac, F., 2000. An illustration of the transport and deposition of mineral dust onto the Mediterranean Sea. Atmospheric Environment 22, 1293-1303. 
Kupiszewski, P., Weingartner, E., Vochezer, P., et al., 2015. The Ice Selective Inlet: a novel technique for exclusive extraction of pristine ice crystals in mixed-phase clouds. Atmospheric Measurement Techniques 8, 3087-3106, https://doi.org/10.5194/amt-8-3087-2015.

Kylling, A., Vandenbussche, S., Capelle, V., Cuesta, J., Klüser, L., Lelli, L., Popp, T., Stebel, K., Veefkind, P., 2018. Comparison of dust-layer heights from active and passive satellite sensors. Atmospheric Measurement Techniques 11, 2911-2936, https://doi.org/10.5194/amt-11-2911-2018.

Laskin, A., ledema, M. J., Ichkovich, A., et al., 2005. Direct observation of completely processed calcium carbonate dust particles, Faraday Discussions, 130, 453-468.

Laskina, O., Young, M. A., Kleiber, P. D., Grassian, V. H., 2013. Infrared extinction spectroscopy and microRaman spectroscopy of select components of mineral dust mixed with organic compounds. Journal of Geophysical Research Atmosphere 118, 6593- 6606. doi:10.1002/jgrd.50494.

Lau, K. M., Kim, K. M., 2007. Cooling of the Atlantic by Saharan dust. Geophysical Research Letters 34, L23811, doi:10.1029/2007GL031538.

Laurent, B., Marticorena, B., Bergametti, G., Mei, F., 2006. Modeling mineral dust emissions from Chinese and Mongolian deserts. Global and Planetary Change 52, 121-141. https://doi.org/10.1016/j.gloplacha.2006.02.012

Lee, Y.G., Kim, J., Ho, C.H., et al., 2015. The effects of ENSO under negative AO phase on spring dust activity over northern China: An observational investigation. International Journal of Climatology 35, 935-947. https://doi.org/10.1002/joc.4028

Lensky, I. M. and Rosenfeld, D., 2008. Clouds-Aerosols-Precipitation Satellite Analysis Tool (CAPSAT), Atmospheric Chemistry and Physics, 8, 6739-6753. doi:10.5194/acp-8-6739-2008.

Leslie, L.M., Speer, M.S., 2006. Modelling dust transport over central eastern Australia. Meteorological Applications 13, 141-167. https://doi.org/10.1017/S1350482706002155

Levy, R. C., Remer, L. A., Mattoo, S., Vermote, E. F., and Kaufman, Y. J., 2007. Second-generation operational algorithm: Retrieval of aerosol properties over land from inversion of Moderate Resolution Imaging Spectroradiometer spectral reflectance, Journal of Geophysical Research, 112. doi:10.1029/2006JD007811.

Levy, R. C., Mattoo, S., Munchak, L. A., et al., 2013. The Collection 6 MODIS aerosol products over land and ocean, Atmospheric Measurement Techniques, 6, 2989-3034. doi:10.5194/amt-6-2989-2013.

Li, F., Ginoux, P., Ramaswamy, V., 2008. Distribution, transport, and deposition of mineral dust in the Southern Ocean and Antarctica: Contribution of major sources. Journal of Geophysical Research Atmos. 113, 1-15. https://doi.org/10.1029/2007JD009190

Li, F., Ginoux, P., Ramaswamy, V., 2010. Transport of Patagonian dust to Antarctica. Journal of Geophysical Research Atmosphere 115, 1-9. https://doi.org/10.1029/2009JD012356

Li, J., Osada, K., 2007. Water-insoluble particles in spring snow at Mt. Tateyama, Japan: characteristics of the shape factors and size distribution in relation with their origin and transportation. Journal of the Meteorological Society of Japan 85, 137-149.

Li, W. J., Shao, L. Y., 2009. Observation of nitrate coatings on atmospheric mineral dust particles. Atmospheric Chemistry and Physics 9, 1863-1871, https://doi.org/10.5194/acp-9-1863-2009.

Li, W., Shao, L., Shi, Z., et al., 2014. Mixing state and hygroscopicity of dust and haze particles before leaving Asian continent. Journal of Geophysical Research Atmosphere 119, 1044- 1059. doi:10.1002/2013JD021003.

Liao, H., Seinfeld, J. H., 1998. Radiative forcing by mineral dust aerosols: Sensitivity to key variables. Journal of Geophysical Research 103, 31,637-31,646. https://doi.org/10.1029/1998JD200036

Liao, H., Seinfeld, J. H., Adams, P. J., Mickley, L. J., 2004. Global radiative forcing of coupled tropospheric ozone and aerosols in a unified general circulation model. Journal of Geophysical Research 109, D16207, doi: 16210.11029/12003JD004456. 
Linke, C., Möhler, O., Veres, A., et al., 2006. Optical properties and mineralogical composition of different Saharan mineral dust samples: a laboratory study. Atmospheric Chemistry and Physics 6, 3315-3323.

Liu, C., Chu, B.W., Liu, Y.C., et al., 2013. Effect of mineral dust on secondaryorganic aerosol yield and aerosol size in a-pinene/NOx photo-oxidation. Atmospheric Environment 77, 781-789.

Liu, D., Wang, Z., Liu, Z., Winker, D., Trepte, C., 2008. A height resolved global view of dust aerosols from the first year CALIPSO lidar measurements. Journal of Geophysical Research 113, D16214. doi:10.1029/2007JD009776.

Logan, T., Xi, B., Dong, X., et al., 2010. A study of Asian dust plumes using satellite, surface, and aircraft measurements during the INTEX-B field experiment. Journal of Geophysical Research 115, D00K25. doi:10.1029/2010JD014134.

Lyapustin, A., Wang, Y., Korkin, S., Huang, D., 2018. MODIS Collection 6 MAIAC algorithm. Atmospheric Measurement Techniques, 11, 5741-5765. https://doi.org/10.5194/amt-11-5741-2018

Maher, B.A., Prospero, J.M., Mackie, D., et al., 2010. Global connections between aeolian dust, climate and ocean biogeochemistry at the present day and at the last glacial maximum. Earth-Science Reviews 99, 61-97. https://doi.org/10.1016/j.earscirev.2009.12.001

Mahowald, N. M., Ballantine, J. A., Feddema, J. and Ramankutty, N., 2007. Global trends in visibility: Implications for dust sources, Atmospheric Chemistry and Physics, 7(12), 3309-3339, doi:10.5194/acp7-3309-2007

Mahowald, N.M., Bryant, R.G., del Corral, J., Steinberger, L., 2003. Ephemeral lakes and desert dust sources. Geophysical Research Letters 30, 30-33. https://doi.org/10.1029/2002GL016041

Mahowald, N., Ward, D.S., Kloster, S., et al., 2011. Aerosol impacts on climate and biogeochemistry. Annual Review of Environment and Resorces, 36,45-74.

Mahowald, N., Albani, S., Kok, J. F., et al., 2014. The size distribution of desert dust aerosols and its impact on the Earth system. Aeolian Research doi:10.1016/j.aeolia.2013.09.002.

Mallet, M., Dulac, F., Formenti, P., et al., 2016. Overview of the Chemistry-Aerosol Mediterranean Experiment/Aerosol Direct Radiative Forcing on the Mediterranean Climate (ChArMEx/ADRIMED) summer 2013 campaign. Atmospheric Chemistry and Physics 16, 455-504. https://doi.org/10.5194/acp-16-455-2016.

Mamouri, R.-E., Ansmann, A., Nisantzi, A., et al., 2016. Extreme dust storm over the eastern Mediterranean in September 2015: satellite, lidar, and surface observations in the Cyprus region, Atmospheric Chemistry and Physics, 16, 13 711- 13 724. doi:10.5194/acp-16-13711-2016.

Marconi, M., Sferlazzo, D. M., Becagli, S., et al., 2014. Saharan dust aerosol over the central Mediterranean Sea: PM10 chemical composition and concentration versus optical columnar measurements. Atmospheric Chemistry and Physics 14, 2039-2054. https://doi.org/10.5194/acp-14-2039-2014.

Maring, H., Savoie, D. L., Izaguirre, M. A., Custals, L., Reid, J. S., 2003. Mineral dust aerosol size distribution change during atmospheric transport. Journal of Geophysical Research 108, 8592. doi:10.1029/2002jd002536.

Marinou, E., Amiridis, V., Binietoglou, I., et al., 2017. Three-dimensional evolution of Saharan dust transport towards Europe based on a 9-year EARLINET-optimized CALIPSO dataset, Atmospheric Chemistry and Physics, 17, 5893-5919. doi:10.5194/acp-17-5893-2017.

Marsham, J.H., Parker, D.J., Grams, C.M., Taylor, C.M., Haywood, J.M., 2008. Uplift of Saharan dust south of the intertropical discontinuity. Journal of Geophysical Research Atmospheres 113, 1-14. https://doi.org/10.1029/2008JD009844.

Marsham, J. H., Hobby, M., Allen, C. J. T., et al., 2013. Meteorology and dust in the central Sahara: Observations from Fennec supersite-1 during the June 2011 Intensive Observation Period, Journal of Geophysical Research Atmospheres, 118, 1-21. doi:10.1002/jgrd.50211. 
Marticorena, B., Bergametti, G., 1996. Two-years simulations of seasonal and interannual changes of the Saharan Dust Emissions, Geophysical Research Letters 23, 1921-1924. https://doi.org/10.1029/96GL01432

Marticorena, B., Bergametti, G., Aumont, B., et al., 1997. Modeling the atmospheric dust cycle 2. Simulation of Saharan dust sources. Journal of Geophysical Research Atmospheres 102(D4), 4387-4404. https://doi.org/10.1029/96jd02964

Marticorena, B., Chatenet, B., Rajot, J.L., et al., 2010. Temporal variability of mineral dust concentrations over West Africa: Analyses of a pluriannual monitoring from the AMMA Sahelian Dust Transect. Atmospheric Chemistry and Physics 10, 8899-8915. https://doi.org/10.5194/acp-10-8899-2010

Marticorena, B, Formenti, P., 2013. Fundamentals of Aeolian Sediment Transport: Long-Range Transport of Dust. In: John F. Shroder (ed.) Treatise on Geomorphology, San Diego: Academic Press, 11, 64-84.

Martin, R.V., 2008. Satellite remote sensing of surface air quality. Atmospheric Environment 42, 78237843.

Martínez-Garcia, A., Rosell-Melé, A., Geibert, W., et al., 2009. Links between iron supply, marine productivity, sea surface temperature, and $\mathrm{CO} 2$ over the last $1.1 \mathrm{Ma}$. Paleoceanography 24, 1-14. https://doi.org/10.1029/2008PA001657

Massling, A., Leinert, S., Wiedensohler, A., Covert, D., 2007. Hygroscopic growth of sub-micrometer and one-micrometer aerosol particles measured during ACE-Asia. Atmospheric Chemistry and Physics 7, 3249- 3259. doi:10.5194/acp-7-3249-2007

Matsuki, A., Quennehen, B., Schwarzenboeck, A., et al., 2010a. Temporal and vertical variations of aerosol physical and chemical properties over West Africa: AMMA aircraft campaign in summer 2006. Atmospheric Chemistry and Physics 10, 8437-8451. doi:10.5194/acp-10-8437-2010.

Matsuki, A., Schwarzenboeck, A., Venzac, H., et al., 2010b. Cloud processing of mineral dust: Direct comparison of cloud residual and clear sky particles during AMMA aircraft campaign in summer 2006. Atmospheric Chemistry and Physics 10, 1057- 1069. doi:10.5194/acp-10-1057-2010.

McConnell, C. L., Highwood, E. J., Coe, H., et al., 2008. Seasonal variations of the physical and optical characteristics of Saharan dust: Results from the Dust Outflow and Deposition to the Ocean (DODO) experiment. Journal of Geophysical Research 113, D14S05. doi:10.1029/2007jd009606.

McConnell, J.R., Aristarain, A.J., Banta, J.R., Edwards, P.R., Simões, J.C., 2007. 20th-Century doubling in dust archived in an Antarctic Peninsula ice core parallels climate change and desertification in South America. Proceedings of the National Academy of Sciences 104, 5743-5748. https://doi.org/10.1073/pnas.0607657104

McGee, D., deMenocal, P.B., Winckler, G., Stuut, J.B.W., Bradtmiller, L.I., 2013. The magnitude, timing and abruptness of changes in North African dust deposition over the last 20,000 yr. Earth and Planetary Science Letters 371-372, 163-176. https://doi.org/10.1016/j.epsl.2013.03.054

McGowan, H., Clark, A., 2008. Identification of dust transport pathways from Lake Eyre, Australia using Hysplit. Atmospheric Environment 42, 6915-6925. https://doi.org/10.1016/j.atmosenv.2008.05.053

McKendry, I. G., Strawbridge, K. B., O'Neill, N. T., et al., 2007. Trans-Pacific transport of Saharan dust to western North America: A case study, Journal of Geophysical Research, 112, D01103. doi:10.1029/2006JD007129.

Meloni, D., di Sarra, A., Monteleone, F., et al., 2008. Seasonal transport patterns of intense Saharan dust events at the Mediterranean island of Lampedusa. Atmospheric Research 88, 134- 148. doi:10.1016/j.atmosres.2007.10.007.

Meloni, D, Junkermann, W, di Sarra, A, et al., 2015. Altitude-resolved shortwave and longwave radiative effects of desert dust in the Mediterranean during the GAMARF campaign: Indications of a net daily cooling in the dust layer. Journal of Geophysical Research Atmospheres 120, 3386- 3407. doi: 10.1002/2014JD022312. 
Ménégoz, M., Voldoire, A., Teyssèdre, H., et al., 2012. How does the atmospheric variability drive the aerosol residence time in the Arctic region?, Tellus B: Chemical and Physical Meteorology 64:1, doi: 10.3402/tellusb.v64i0.11596.

Merrill, J.T., Uematsu, M., Bleck, R., 1989. Meteorological analysis of long range transport of mineral aerosols over the North Pacific. Journal of Geophysical Research 94, 8584-8598. https://doi.org/10.1029/JD094iD06p08584

Meskhidze N., Chameides W. L., Nenes A., 2005. Dust and pollution: a recipe for enhanced ocean fertilization? J.Geophys. Res. D Atmos 110D005082

Mikami, M., Abe, O., Du, M., et al., 2002. The impact of Aeolian dust on climate: Sino-Japanese cooperative project ADEC. Journal of Arid Land Studies 11(4), 211-222.

Miller, R. L., Tegen, I., 1998. Climate response to soil dust aerosols. Journal of Climate 11, 3247-3267.

Miller, R. L., Tegen, I., Perlwitz, J., 2004. Surface radiative forcing by soil dust aerosols and the hydrologic cycle, Journal of Geophysical Research, 109, D04203. doi:10.1029/2003JD004085.

Möhler, O., Benz, S., Saathoff, H., et al., 2008. The effect of organic coating on the heterogeneous ice nucleation efficiency of mineral dust aerosols. Environmental Research Letters 3, 025007, https://doi.org/10.1088/1748-9326/3/2/025007.

Moosmüller, H., Engelbrecht, J. P., Skiba, M., Frey, G., Chakrabarty, R. K., and Arnott, W. P., 2012. Single scattering albedo of fine mineral dust aerosols controlled by iron concentration. Journal of Geophyical Research 117, D11210, https://doi.org/10.1029/2011JD016909.

Moulin, C., Guillard, F., Dulac, F., Lambert, C.E., 1997a. Long-term daily monitoring of Saharan dust load over ocean using Meteosat ISCCP-B2 data 1. Methodology and preliminary results for 1983-1994 in the Mediterranean. Journal of Geophysical Research Atmos. 102, 16947-16958. https://doi.org/10.1029/96jd02620

Moulin, C., Lambert, C.E., Dayan, U., et al., 1998. Satellite climatology of African dust transport in the Mediterranean atmosphere. Journal of Geophysical Research Atmos. 103, 13137-13144. https://doi.org/10.1029/98JD00171

Moulin, C., Lambert, C.E., Dulac, F., Dayan, U., 1997b. Control of atmospheric export of dust from North Africa by the North Atlantic Oscillation. Nature 387, 691-694. https://doi.org/10.1038/42679

Moulin, C., Chiapello, I., 2006. Impact of human-induced desertification on the intensification of Sahel dust emission and export over the last decades. Geophysical Research. Letters 33(18), L18808.

Muhs, D. R., Budahn, J. R., Prospero, J. M., Skipp, G., Herwitz, S. R., 2012. Soil genesis on the island of Bermuda in the Quaternary: The importance of African dust transport and deposition Journal of Geophysical Research 117, F03025,doi:10.1029/2012JF002366.

Muhs, D.R., Budahn, J.R., Prospero, J.M., Carey, S.N., 2007. Geochemical evidence for African dust inputs to soils of western Atlantic islands: Barbados, the Bahamas, and Florida. Journal of Geophysical Research 112, F02009. http://dx.doi.org/10.1029/2005JF000445.

Müller, D., Ansmann, A.,Freudenthaler, V., et al., 2010. Mineral dust observed with AERONET Sun photometer, Raman lidar, and in situ instruments during SAMUM 2006: Shape-dependent particle properties. Journal of Geophysical Research 115, D11207. doi:10.1029/2009JD012523.

Müller, T., Schladitz, A., Massling, A., et al., 2009. Spectral absorption coefficients and imaginary parts of refractive indices of Saharan dust during SAMUM-1. Tellus 61B, 79-95.

Myhre, G., Stordal, F., 2001. Global sensitivity experiments of the radiative forcing due to mineral aerosols. Journal of Geophysical Research 106, 18193-18204.

Myriokefalitakis, S., Nenes, A., Baker, A. R., Mihalopoulos, N., Kanakidou, M., 2016. Bioavailable atmospheric phosphorous supply to the global ocean: a 3D global modeling study. Biogeosciences 13, 6519-43. 
Namdari, S., Karimi, N., Sorooshian, A., Mohammadi, G.H., Sehatkashani, S., 2018. Impacts of climate and synoptic fluctuations on dust storm activity over the Middle East. Atmospheric Environment 173, 265276. https://doi.org/10.1016/j.atmosenv.2017.11.016

Nenes, A., Krom, M. D., Mihalopoulos, N., et al., 2011. Atmospheric acidification of mineral aerosols: a source of bioavailable phosphorus for the oceans. Atmospheric Chemistry and Physics 11, 6265-6272. https://doi.org/10.5194/acp-11-6265-2011.

Nousiainen, T., 2009. Optical modeling of mineral dust particles: A review. Journal of Quantitative Spectroscopy and Radiative Transfer 110, 1261-1279.

Nousiainen, T., Kandler, K., 2015. Light scattering by atmospheric mineral dust particles. in: Light Scattering Reviews 9, edited by: Kokhanovsky, A. A., Springer Praxis Books, Springer, Berlin, Heidelberg, 3-52. doi:10.1007/978-3-642-37985-7.

Oakes, M., Ingall, E. D., Lai, B., Shafer, M. M., Hays, M. D., Liu, Z. G., Russell, A. G., Weber, R. J., 2012. Iron solubility related to particle sulfur content in source emission and ambient fine particles. Environmental Science and Technology 46, 6637-44.

Okada, K., Heintzenberg, J., Kai, K., and Qin, Y.: Shape of atmospheric mineral particles collected in three Chinese arid-regions, Geophysical Research Letters, 28, 3123-3126, 2001.

Omar, A. H., Winker, D. M., Kittaka, C., et al., 2009. The CALIPSO Automated Aerosol Classification and Lidar Ratio Selection Algorithm, Journal of Atmospheric and Oceanic Technology, 26, 1994-2014. doi:10.1175/2009JTECHA1231.1.

Osada, K., 2013. Water soluble fraction of Asian dust particles. Atmospheric Research 124:101-108.

Osborne, M., Malavelle, F. F., Adam, M., et al., 2019. Saharan dust and biomass burning aerosols during ex-hurricane Ophelia: observations from the new UK lidar and sun-photometer network, Atmospheric Chemistry and Physics, 19, 3557-3578. doi:10.5194/acp-19-3557-2019.

Osborne, S.R., Johnson, B.T., Haywood, J.M., et al., 2008. Physical and optical properties of mineral dust aerosol during the Dust and Biomass-burning Experiment. Journal of Geophysical Research 113, D00C03. doi:10.1029/2007jd009551.

O'Sullivan, D., Murray, B. J., Ross, J. F., Webb, M. E., 2016. The adsorption of fungal ice-nucleating proteins on mineral dusts: a terrestrial reservoir of atmospheric ice-nucleating particles. Atmospheric Chemistry and Physics 16, 7879-7887, https://doi.org/10.5194/acp-16-7879-2016.

Otto, S., Bierwirth, E., Weinzierl, B., et al., 2009. Solar radiative effects of a Saharan dust plume observed during SAMUM assuming spheroidal model particles. Tellus B 61, 270-296. doi:10.1111/j.16000889.2008.00389.x.

Pace, G., di Sarra, A., Meloni, D., Piacentino, S., and Chamard, P., 2006. Aerosol optical properties at Lampedusa (Central Mediterranean). 1. Influence of transport and identification of different aerosol types. Atmospheric Chemistry and Physics 6, 697-713. https://doi.org/10.5194/acp-6-697-2006.

Papayannis, A., Amiridis, V., Mona, L., et al., 2008. Systematic lidar observations of Saharan dust over Europe in the frame of EARLINET (2000-2002). Journal of Geophysical Research Atmospheres 113, 1-17. https://doi.org/10.1029/2007JD009028

Paramonov, M., David, R. O., Kretzschmar, R., Kanji, Z. A., 2018. A laboratory investigation of the ice nucleation efficiency of three types of mineral and soil dust. Atmospheric Chemistry and Physics 18, 16515-16536, https://doi.org/10.5194/acp-18-16515-2018.

Paris, R., Desboeufs K., Formenti, P., Nava, S., Chou, C., 2010. Chemical characterisation of iron in dust and biomass burning aerosols during AMMA-SOP0/DABEX: implication for iron solubility. Atmospheric Chemistry and Physics 10, 4273-4282.

Parolari, A.J., Li, D., Bou-Zeid, E., Katul, G.G., Assouline, S., 2016. Climate, not conflict, explains extreme Middle East dust storm. Environmental Research Letters 11. https://doi.org/10.1088/17489326/11/11/114013 
Patterson, E.M., Filette, D. A., Stockton, B. H., 1977. Complex index of refraction between 300 and 700 nm for Saharan aerosols. Journal of Geophysical Research 82, 3153-3160.

Pauly, R. M., Yorks, J. E., Hlavka, D. L., McGill, M. J., Amiridis, V., Palm, S. P., Rodier, S. D., Vaughan, M. A., Selmer, P. A., Kupchock, A. W., Baars, H., Gialitaki, A., 2019. Cloud-Aerosol Transport System (CATS) $1064 \mathrm{~nm}$ calibration and validation. Atmospheric Measurement Techniques, 12, 6241-6258. https://doi.org/10.5194/amt-12-6241-2019

Pérez, C., Nickovic, S., Pejanovic, G., Baldasano, J. M., and Özsoy, E., 2006. Interactive dust-radiation modeling: A step toimprove weather forecast. Journal of Geophysical Research 111, D16206,doi:10.1029/2005JD006717.

Perlwitz, J., Tegen, I., Miller, R. L., 2001. Interactive soil dust aerosol model in the GISS GCM: 1. Sensitivity of the soil dust cycle to radiative properties of soil dust aerosols. Journal of Geophysical Research 106, 18167-18192.

Petit, J.R., Jouzel, J., Raynaud, D., et al., 1999. Climate and atmospheric history of the past 420,000 years from the Vostok ice core, Antarctica. Nature 399, 429-436.

Petzold, A., Rasp, K., Weinzierl, B., et al., 2009. Saharan dust absorption and refractive index from aircraftbased observations during SAMUM 2006, Tellus B 61: 118-130.

Pierangelo, C., Chédin, A., Heilliette, S., Jacquinet-Husson, N., Armante, R., 2004. Dust altitude and infrared optical depth from AIRS. Atmospheric Chemistry and Physics 4, 1813-1822.

Pohl, B., Dieppois, B., Crétat, J., Lawler, D., Rouault, M., 2018. From Synoptic to Interdecadal Variability in Southern African Rainfall: Toward a Unified View across Time Scales. Journal of Climate 31, 58455872. https://doi.org/10.1175/JCLI-D-17-0405.1

Prospero, J.M., 1968. Atmospheric dust studies on Barbados. Bulletin of the Americn Meteorological Society 49, 645-652. https://doi.org/10.1175/1520-0477-49.6.645

Prospero, J. M., Bonatti, E., Schubert, C., and Carlson, T. N., 1970. Dust in the Caribbean atmosphere traced to an African dust storm, Earth and Planetary Science Letters, 9, 287-293. doi:10.1016/0012821X(70)90039-7.

Prospero, J.M., Carlson, T.N., 1980. Saharan air outbreaks over the tropical North Atlantic. Pure and Applied Geophysics 119, 677-691. https://doi.org/10.1007/BF00878167

Prospero, J.M., Glaccum, R.A., Nees, R.T., 1981. Atmospheric transport of soil dust from Africa to South America. Nature 289, 570-572. https://doi.org/10.1038/289570a0

Prospero, J.M., Nees, R.T., 1986. Impact of the North African drought and El Niño on mineral dust in the Barbados trade wind. Nature 320, 735-738.

Prospero, J.M., 1996. Saharan Dust Transport Over the North Atlantic Ocean and Mediterranean: An Overview, in: Guerzoni, S., Chester, R. (Eds.), The Impact of Desert Dust Across the Mediterranean. Springer Netherlands, Dordrecht, pp. 133-151. https://doi.org/10.1007/978-94-017-3354-0_13

Prospero, J.M., 1999. Long-range transport of mineral dust in the global atmosphere: impact of African dust on the environment of the southeastern United States. Proceedings of the National academy of Sciences of the United States of America 96, 3396-3403.

Prospero, J.M., Ginoux, P., Torres, O., Nicholson, S.E., Gill, T.E., 2002. Environmental characterization of global sources of atmospheric soil dust identified with the Nimbus 7 Total Ozone Mapping Spectrometer (TOMS) absorbing aerosol product. Reviews of Geophysics 40, 1-31. https://doi.org/10.1029/2000RG000095

Prospero, J.M., Lamb, P.J., 2003. African Droughts and Dust Transport to the Caribbean: Climate Change Implications. Science 80. 302, 1024 LP - 1027. https://doi.org/10.1126/science.1089915

Prospero, J. M., Bullard, J. E., Hodgkins, R., 2012. High-Latitude Dust Over the North Atlantic: Inputs from Ice-landic Proglacial Dust Storms. Science 335, 1078-1082,https://doi.org/10.1126/science.1217447. 
Prospero, J. M., Collard, F.-X., Molinié, J., Jeannot, A., 2014. Characterizing the annual cycle of African dust transport to the Caribbean Basin and South America and its impact on the environment and air quality. Global Biogeochemical Cycles 29, 757- 773. doi:10.1002/2013GB004802.

Pu, B., Ginoux, P., 2018. How reliable are CMIP5 models in simulating dust optical depth? Atmospheric Chemistry and Physics 18, 12491-12510. https://doi.org/10.5194/acp-18-12491-2018

Pye, K., 1987. Aeolian Dust and Dust Deposits, Academic Press, London, 334 pp..

Raes, F., Bates, T., McGovern, F., Van Liedekerke, M., 2000. The 2nd aerosol characterization experiment (ACE-2): general overview and main results. Tellus B. 52(2), 111-125.

Rajot, J. L., Formenti, P., Alfaro, S., et al., 2008. AMMA dust experiment: an overview of measurements performed during the dry season special observation period (SOP0) at the Banizoumbou (Niger) supersite. Journal of Geophysical Research 113, D00C14. doi:10.1029/2008jd009906.

Rashki, A., Kaskaoutis, D.G., Mofidi, A., et al., 2019. Effects of Monsoon, Shamal and Levar winds on dust accumulation over the Arabian Sea during summer - The July 2016 case. Aeolian Research 36, 27-44. https://doi.org/10.1016/j.aeolia.2018.11.002

Ravi Kumar, K., Attada, R., Dasari, H.P., et al., 2019. On the Recent Amplification of Dust over the Arabian Peninsula during 2002 - 2012. Journal of Geophysical Research Atmospheres 2019JD030695. https://doi.org/10.1029/2019JD030695

Rea, D.K., 1994. The paleoclimatic record provided by eolian deposition in the deep sea: The geologic history of wind. Review of Geophysics 32, 159-195. https://doi.org/10.1029/93RG03257

Reddy, M. S., Boucher, O., Balkanski, Y., Schulz, M., 2005. Aerosol optical depths and direct radiative perturbations by species and source type. Geophysical Research Letters 32, L12803, doi: 12810.11029/12004GL021743.

Redelsperger, J.-L., Thorncroft, C. D., Diedhiou, A., et al., 2006. African Monsoon Multidisciplinary Analysis: An International Research Project and Field Campaign. Bulletin of the American Meteorological Society 87. 1739-1746.

Reid, E.A., Reid, J.S., Meier, M.M., et al., 2003. Characterization of African dust transported to Puerto Rico by individual particle and size segregated bulk analysis. Journal of Geophysical Research 108(D19), 8591. http://dx.doi.org/ 10.1029/2002JD002935.

Reid, J.S., Jonsson, H.H., Maring, H.B., et al., 2003b. Comparison of size and morphological measurements of coarse mode dust particles from Africa. Journal of Geophysical Research 108(D19), 8593. http://dx.doi.org/10.1029/2002JD002485.

Reid, J.S., Kinney, J.E., Westphal, D.L., et al., 2003a. Analysis of measurements of Saharan dust by airborne and ground-based remote sensing methods during the Puerto Rico Dust Experiment (PRIDE). Journal of Geophysical Research 108(D19), 8586. http://dx.doi.org/10.1029/2002JD002493.

Reid, J.S., Stuart, J.P., Walker, A.L., et al., 2008. An overview of UAE2 flight operations: observations of summertime atmospheric thermodynamic and aerosol profiles of the southern Arabian Gulf. Journal of Geophysical Research 113, D14213. http://dx.doi.org/10.1029/2007JD009435.

Remer, L. A., Kaufman, Y. J., Tanré, D., et al., 2005. The MODIS Aerosol Algorithm, Products, and Validation, Journal of the Atmospheric Sciences, 62, 947-973. doi:10.1175/JAS3385.1.

Renard, J.-B., Dulac, F., Berthet, G., et al., 2016. LOAC: a small aerosol optical counter/sizer for groundbased and balloon measurements of the size distribution and nature of atmospheric particles - Part 2: First results from balloon and unmanned aerial vehicle flights. Atmospheric Measurement Techniques 9, 3673-3686. https://doi.org/10.5194/amt-9-3673-2016.

Ridley, D. A., Heald, C. L., Pierce, J. R., Evans, M. J., 2013. Toward resolution-independent dust emissions in global models: Impacts on the seasonal and spatial distribution of dust. Geophysical Research Letters 40, 2873- 2877. doi:10.1002/grl.50409. 
Rieger, D., Steiner, A., Bachmann, V., et al., 2017. Impact of the 4 April 2014 Saharan dust outbreak on the photovoltaic power generation in Germany. Atmospheric Chemistry and Physics 17, 13391-13415. https://doi.org/10.5194/acp-17-13391-2017.

Rocha-Lima, A., Martins, J. V., Remer, L. A., et al., 2018. A detailed characterization of the Saharan dust collected during the Fennec campaign in 2011: in situ ground-based and laboratory measurements. Atmospheric Chemistry and Physics 18, 1023-1043. https://doi.org/10.5194/acp-18-1023-2018.

Rodríguez, S., Cuevas, E., Prospero, J.M., et al., 2015. Modulation of Saharan dust export by the North African dipole. Atmospheric Chemistry and Physics 15, 7471-7486. https://doi.org/10.5194/acp-157471-2015

Ryder, C. L., Highwood, E. J., Rosenberg, P. D., et al., 2013a. Optical properties of Saharan dust aerosol and contribution from the coarse mode as measured during the Fennec 2011 aircraft campaign. Atmospheric Chemistry and Physics 13, 303-325. doi:10.5194/acp-13-303-2013.

Ryder, C. L., Highwood, E. J., Lai, T. M., Sodemann, H., Marsham J. H., 2013b. Impact of atmospheric transport on the evolution of microphysical and optical properties of Saharan dust. Geophysical Research Letters 40, 2433-2438. doi: 10.1002/grl.50482.

Ryder, C. L., McQuaid, J. B., Flamant, C., et al., 2015. Advances in under-standing mineral dust and boundary layer processes over the Sahara from Fennec aircraft observations. Atmospheric Chemistry and Physics, 15, 8479-8520. doi:10.5194/acp-15-8479-2015.

Ryder, C. L., Marenco, F., Brooke, J. K., et al., 2018. Coarse-mode mineral dust size distributions, composition and optical properties from AER-D aircraft measurements over the tropical eastern Atlantic. Atmospheric Chemistry and Physics 18, 17225-17257. https://doi.org/10.5194/acp-18-17225-2018.

Ryder, C. L., Highwood, E. J., Walser, A., et al. 2019. Coarse and giant particles are ubiquitous in Saharan dust export regions and are radiatively significant over the Sahara. Atmospheric Chemistry and Physics 19, 15353-15376. doi:10.5194/acp-19-15353-2019.

Salvador, P., Alonso-Pérez, S., Pey, J., et al., 2014. African dust outbreaks over the western Mediterranean Basin: 11-year characterization of atmospheric circulation patterns and dust source areas. Atmospheric Chemistry and Physics 14, 6759-6775. https://doi.org/10.5194/acp-14-6759-2014

Sayer, A. M., Hsu, N. C., Bettenhausen, C., and M.-J.Jeong, 2013. Validation and uncertainty estimates for MODIS Collection 6 Deep Blue aerosol data, Journal of Geophysical Research Atmospheres, 118, 7864-7872. doi:10.1002/jgrd.50600.

Sayer, A. M., Hsu, N. C., Bettenhausen, C., et al., 2012. Global and regional evaluation of over-land spectral aerosol optical depth retrievals from SeaWiFS, Atmospheric Measurement Techniques, 5, 1761-1778. doi:10.5194/amt-5-1761-2012.

Schepanski, K., Tegen, I., Laurent, B., Heinold, B., and Macke, A., 2007. A new Saharan dust source activation frequency map derived from MSG-SEVIRI IR-channels, Geophysical Research Letters, 34. doi:10.1029/2007GL030168.

Schepanski, K., Heinold, B., Tegen, I., 2017. Harmattan, Saharan heat low, and West African monsoon circulation: Modulations on the Saharan dust outflow towards the North Atlantic. Atmospheric Chemistry and Physics 17, 10223-10243. https://doi.org/10.5194/acp-17-10223-2017

Scheuvens, D., Schütz L., Kandler K., Ebert, M., Weinbruch, S., 2013. Bulk composition of northern African dust and its source sediments - a compilation. Earth-Science Reviews 116, 170-194.

Scheuvens, D., Kandler, K., 2014. On Composition, Morphology, and Size Distribution of Airborne Mineral Dust. In: Mineral Dust: A Key Player in the Earth System, edited by: Knippertz, P. and Stuut, J.-B. W., Springer, 267-286. https://doi.org/10.1007/978-94-017-8978-3_13.

Schladitz, A., Müller, T., Kaaden, N., et al., 2009. In situ measurements of optical properties at Tinfou (Morocco) during the Saharan Mineral Dust Experiment SAMUM 2006. Tellus B 61, 64-78. doi:10.1111/j.1600-0889.2008.00397.x. 
Schmetz, J., Pili, P., Tjemkes, S., et al., 2002. An introduction to Meteosat Second Generation (MSG), Bulletin of the American Meteorological Society, 83, 977-992. doi:10.1175/15200477(2002)083<0977:AITMSG>2.3.CO;2.

Schütz, L., 1979. Sahara dust transport over the North Atlantic Ocea - Model calculations and measurements. In: Morales, C. (Ed.), Saharan Dust. Wiley, New York, pp. 267-277.

Shao, Y., Klose, M. and Wyrwoll, K. H., 2013. Recent global dust trend and connections to climate forcing, Journal of Geophysical Research: Atmospheres, 118(19), 11,107-11,118, doi:10.1002/jgrd.50836.

Shell, K. M., Somerville, R. C. J., 2007. Direct radiative effect of mineral dust and volcanic aerosols in a simple aerosol climate model. Journal of Geophysical Research 112, D03206, doi: 03210.01029/02006JD007198.

Shi, Z., Zhang, D., Hayashi, M., et al., 2008. Influences of sulfate and nitrate on the hygroscopic behaviour of coarse dust particles. Atmospheric Environment 42, 822-827.

Sholkovitz, E. R., Sedwick, P. N., Church, T. M., Baker, A. R., Powell, C. F., 2012. Fractional solubility of aerosol iron: synthesis of a global-scale data set. Geochimica and Cosmochimica Acta 89, 173-89.

Sinyuk, A., Torres, O., Dubovik, O., 2003. Combined use of satellite and surface observations to infer the imaginary part of refractive index of Saharan dust. Geophysical Research Letters 30(2), 1081. doi:10.1029/2002GL016189.

Skonieczny, C., McGee, D., Winckler, G., et al., 2019. Monsoon-driven Saharan dust variability over the past 240,000 years. Science Advances 5, 1-9. https://doi.org/10.1126/sciadv.aav1887.

Slingo, A., Ackerman, T. P., Allan, R. P., et al., 2006. Observations of the impact of a major Saharan dust storm on the atmospheric radiation balance. Geophysical Research Letters 33, L24817. doi:10.1029/2006GL027869.

Smirnov, A., Holben, B. N., Slutsker, I., et al., 2009. Maritime Aerosol Network as a component of Aerosol Robotic Network, Journal of Geophysical Research, 114. doi:10.1029/2008JD011257.

Sokolik, I., O. Toon, 1999. Incorporation of mineralogical composi-tion into models of the radiative properties of mineral aerosolfrom UV to IR wavelengths. J. Geophys. Res. 104, 9423-9444.

Stith, J. L., Ramanathan, V., Cooper et al., W. A., et al., 2009. An overview of aircraft observations from the Pacific Dust Experiment campaign. Journal of Geophysical Research 114, D05207. doi:10.1029/2008JD010924.

Stowe, L. L., Ignatov, A. M., and Singh, R. R., 1997. Development, validation, and potential enhancements to the second-generation operational aerosol product at the National Environmental Satellite, Data, and Information Service of the National Oceanic and Atmospheric Administration, Journal of Geophysical Research, 102, 16 923-16 934. doi:10.1029/96JD02132.

Sullivan, R. C., Guazzotti, S. A., Sodeman, D. A., Prather, K. A., 2007a. Direct observations of the atmospheric processing of Asian mineral dust. Atmospheric Chemistry and Physics 7, 1213-1236. doi:10.5194/acp-7-1213-2007.

Sullivan, R. C., Guazzotti, S. A., Sodeman, D. A., et al., 2007b. Mineral dust is a sink for chlorine in the marine boundary layer. Atmospheric Environment 41, 7166-7179.

Sullivan, R. C., Moore, M. J. K., Petters, M. D., et al., 2009a. Effect of chemical mixing state on the hygroscopicity and cloud nucleation properties of calcium mineral dust particles. Atmospheric Chemistry and Physics 9, 3303-3316. doi:10.5194/acp-9-3303-2009.

Sullivan, R. C., Moore, M. J. K., Petters, M. D., et al., 2009b. Timescale for hygroscopic conversion of calcite mineral particles through heterogeneous reaction with nitric acid. Physical Chemistry Chemical Physics 11, 7826-7837.

Sullivan, R. C., Petters, M. D., DeMott, P. J., et al., 2010. Irreversible loss of ice nucleation active sites in mineral dust particles caused by sulphuric acid condensation. Atmospheric Chemistry and Physics 10, 11471-11487, https://doi.org/10.5194/acp-10-11471-2010. 
Sun, J., Zhang, M., Liu, T., 2001. Spatial and temporal characteristics of dust storms in China and its surrounding regions, 1960-1999: Relations to source area and climate. Journal of Geophysical Research Atmospheres 106, 10325-10333. https://doi.org/10.1029/2000JD900665

Swap, R., Garstang, M., Greco, S., Talbot, R., Kallberg, P., 1992. Saharan dust in the Amazon Basin. Tellus 44B, 133-149. https://doi.org/10.3402/tellusb.v44i2.15434

Swap, R., Garstang, M., Macko, S.A., et al., 1996. The long-range transport of southern African aerosols to the tropical South Atlantic. Journal of Geophysical Research Atmospheres 101, 23777-23791. https://doi.org/10.1029/95jd01049

Tagliabue, A., Bowie, A. R., Boyd, P. W., Buck, K. N., Johnson, K. S., Saito, M. A., 2017. The integral role of iron in ocean biogeochemistry. Nature 543, 51-9.

Tanaka, T. Y., Aoki, T., Takahashi, H., et al., 2007. Study of the sensitivity of optical properties of mineral dust to the direct aerosol radiative perturbation using a global aerosol transport model. SOLA 3, 33-36.

Tanré, D., Kaufman, Y. J., Herman, M., and Mattoo, S., 1997. Remote sensing of aerosol properties over oceans using the MODIS/EOS spectral radiances, Journal of Geophysical Research, 102, 16,97116,988 .

Tanré, D., Haywood, J.M., Pelon, J., et al., 2003. Measurement and mod-eling of the Saharan dust radiative impact: Overview of the Saharan Dust Experiment (SHADE). Journal of Geophysical Research 108, 8574. doi:10.1029/2002JD003273.

Taylor, K.E., Stouffer, R.J., Meehl, G.A., 2012. An overview of CMIP5 and the experiment design, Bulletin of the American Meteorological Society, 93, 485-498. doi:10.1175/BAMS-D-11-00094.1

Thompson, L.G., Mosley-Thompson, E., 1981. Microparticle Concentration Variations Linked with Climatic Change: Evidence from Polar Ice Cores. Science 212, 812 LP - 815. https://doi.org/10.1126/science.212.4496.812

Tian, P., Zhang, L., Ma, J., et al., 2018. Radiative absorption enhancement of dust mixed with anthropogenic pollution over East Asia. Atmospheric Chemistry and Physics 18, 7815-7825, https://doi.org/10.5194/acp-18-7815-2018.

Todd, M. C., Washington, R., Martins, J. V., et al., 2007. Mineral dust emission from the Bodélé Depression, northern Chad, during BoDEx 2005, Journal of Geophysical Research, 112. doi:10.1029/2006JD007170.

Todd, M. C., Washington, R., Raghavan, S., Lizcano, G., and Knippertz, P., 2008. Regional Model Simulations of the Bodélé Low-Level Jet of Northern Chad during the Bodélé Dust Experiment (BoDEx 2005), Journal of Climate, 21, 995-1012. doi:10.1175/2007JCLI1766.1.

Toledano, C., Wiegner, M., Groß, S., et al., 2011. Optical properties of aerosol mixtures derived from sunsky radiometry during SAMUM-2. Tellus 63B, 635-648. doi:10.1111/j.1600-0889.2011.00573.x.

Torres, O., Tanskanen, A., Veihelmann, B., et al., 2007. Aerosols andsurface UV products from Ozone Monitoring Instrument observations: An overview. Journal of Geophysical Research 112, D24S47,doi:10.1029/2007JD008809.

Trochkine, D., Iwasaka, Y., Matsuki, A., et al., 2003. Mineral aerosol particles collected in Dunhuang, China, and their comparison with chemically modified particles collected over Japan. Journal of Geophysical Research 108, 8642. doi:10.1029/2002jd003268.

Tsiouri, V., Kakosimos, K.E., Kumar, P., 2015. Concentrations, sources and exposure risks associated with particulate matter in the Middle East Area-a review. Air Quality, Atmosphere and Health 8, 67-80, https://doi.org/10.1007/s11869-014-0277-4

Twohy, C. H., Kreidenweis, S., Eidhammer, T., et al., 2009. Saharan dust particles nucleate droplets in eastern Atlantic clouds. Geophysical Research Letters 36, L01807. doi:10.1029/2008GL035846. 
Uematsu, M., Duce, R.A., Prospero, J.M., et al., 1983. Transport of mineral aerosol from Asia over the North Pacific ocean. Journal of Geophysical Research 88, 5342-5352. https://doi.org/10.1029/jc088ic09p05343

Uno, I., Eguchi, K., Yumimoto, K., et al., 2009. Asian dust transported one full circuit around the globe. Nature Geoscience 2, 557-560. https://doi.org/10.1038/ngeo583

Usher, C. R., Michel, A. E., Grassian, V. H., 2003. Reactions on min-eral dust, Chemical Reviews, 103, 4883-4939.

Van Dingenen, R., Putaud, J.-P., Martins-Dos Santos, S., Raes, F., 2005. Physical aerosol properties and their relation to air mass origin at Monte Cimone (Italy) during the first MINATROC campaign. Atmospheric Chemistry and Physics 5, 2203-2226. https://doi.org/10.5194/acp-5-2203-2005.

Varga, G., Újvári, G., Kovács, J., 2014. Spatiotemporal patterns of Saharan dust outbreaks in the Mediterranean Basin. Aeolian Research 15, 151-160. https://doi.org/10.1016/j.aeolia.2014.06.005

Vickery, K. J., Eckardt, F. D., and Bryant, R. G., 2013. A sub-basin scale dust plume source frequency inventory for southern Africa, 2005-2008, Geophysical Research Letters, 40, 5274-5279. doi:10.1002/grl.50968.

Vincent, J., Laurent, B., Losno, R., et al., 2016. Variability of mineral dust deposition in the western Mediterranean basin and south-east of France. Atmospheric Chemistry and Physics 16, 8749-8766. https://doi.org/10.5194/acp-16-8749-2016

Vinoj, V., Rasch, P. J., Wang, H., et al., 2014. Short-term modulation of Indian summer monsoon rainfall by West Asian dust, Nature Geoscience, 7, 308-313. doi:10.1038/NGEO2107.

Volz, F. E., 1972. Longwave refractive index of atmospheric aerosol substances. Applied Optics 11, 755759.

Volz, F. E., 1973. Longwave optical constants of ammonium sulfate, Sahara dust, volcanic pumice and flyash. Applied Optics 12, 564-568.

Voss, K. K. and Evan, A. T., 2020: A new satellite-based global climatology of dust aerosol optical depth, J. Appl. Meteorol. Climatol., 59(1), 83-102, doi:10.1175/JAMC-D-19-0194.1.

Wagner, R., Ajtai, T., Kandler, K., et al., 2012. Complex refractive indices of Saharan dust samples at visible and near UV wavelengths: a laboratory study. Atmospheric Chemistry and Physics 12, 2491-2512. doi:10.5194/acp-12-2491-2012.

Wang, J., Christopher, S. A., Reid, J. S., et al., 2003. GOES 8 retrieval of dust aerosol optical thickness over the Atlantic Ocean during PRIDE, Journal of Geophysical Research, 108. doi:10.1029/2002JD002494.

Wang, W., Evan, A.T., Flamant, C., Lavaysse, C., 2015. On the decadal scale correlation between African dust and Sahel rainfall: The role of Saharan heat low-forced winds. Science Advances 1, 2010-2015. https://doi.org/10.1126/sciadv.1500646

Wang, W., Evan, A.T., Lavaysse, C., Flamant, C., 2017. The role the Saharan Heat Low plays in dust emission and transport during summertime in North Africa. Aeolian Research 28, 1-12. https://doi.org/10.1016/j.aeolia.2017.07.001

Wang, W., Mao, F., Pan, Z., et al., 2019. Evaluating Aerosol Optical Depth From Himawari-8 With Sun Photometer Network, Journal of Geophysical Research: Atmospheres, 124, 5516-5538. doi:10.1029/2018JD028599.

Washington, R., Todd, M., Middleton, N.J., Goudie, A.S., 2003. Dust-Storm Source Areas Determined by the Total Ozone Monitoring Spectrometer and Surface Observations. Annals of the American Association of Geographers 93, 297-313. https://doi.org/10.1111/1467-8306.9302003

Washington, R., Todd, M.C., 2005. Atmospheric controls on mineral dust emission from the Bodélé Depression, Chad: The role of the low level jet. Geophysical Research Letters 32, 1-5. https://doi.org/10.1029/2005GL023597 
Washington, R., Todd, M.C., Lizcano, G., et al., 2006. Links between topography , wind, deflation , lakes and dust: The case of the Bodélé Depression , Chad. Geophysical Research Letters 33, 1-4. https://doi.org/10.1029/2006GL025827

Weinzierl, B., Ansmann, A., Prospero, J. M., et al., 2017. The Saharan Aerosol Long-range Transport and Aerosol-cloud-interaction experiment: Overview and Selected Highlights. Bulletin of the American Meteorological Society 98, 1427-1451. https://doi.org/10.1175/BAMS-D-15-00142.

Weinzierl, B., Petzold, A., Esselborn, M., et al., 2009. Airborne measurements of dust layer properties, particle size distribution and mixing state of Saharan dust during SAMUM 2006. Tellus B 61, 96-117. https://doi.org/10.1111/j.1600-0889.2008.00392.x.

Weinzierl, B., Sauer, D., Esselborn, M., et al., 2011. Microphysical and optical properties of dust and tropical biomass burning aerosol layers in the Cape Verde region-an overview of the airborne in situ and lidar measurements during SAMUM-2. Tellus B 63, 589-618. https://doi.org/10.1111/j.16000889.2011.00566.x.

Welton, E. J., Campbell, J. R., Spinhirne, J. D., Scott, V. S., 2001. Global monitoring of clouds and aerosols using a network of micro-pulse lidar systems, Proc. SPIE, 4153, 151-158.

Williams, R.H., McGee, D., Kinsley, C.W., et al., 2016. Glacial to Holocene changes in trans-Atlantic Saharan dust transport and dust-climate feedbacks. Science Advances. 2, 1-12. https://doi.org/10.1126/sciadv.1600445

Winckler, G., Anderson, R.F., Fleisher, M.Q., McGee, D., Mahowald, N., 2008. Covariant GlacialInterglacial Dust Fluxes in the Equatorial Pacific and Antarctica. Science 320, 93 LP - 96. https://doi.org/10.1126/science.1150595

Winker, D. M., Vaughan, M. A., Omar, A., Hu, Y., and Powell, K. A., 2009. Overview of the CALIPSO Mission and CALIOP Data Processing Algorithms, Journal of Atmospheric and Oceanic Technology, 26, 2310-2323. doi:10.1175/2009JTECHA1281.1.

Woodward, S., 2001. Modeling the atmospheric life cycle and radiative impact of mineral dust in the Hadley Centre climate model. Journal of Geophysical Research 106, 18155-18166.

Wu, C., Lin, Z., Liu, X., et al., 2018. Can Climate Models Reproduce the Decadal Change of Dust Aerosol in East Asia? Geophysical Research Letters 45, 9953-9962. https://doi.org/10.1029/2018GL079376

Wurzler, S., Reisin, T. G., Levin, Z., 2000. Modification of mineral dust particles by cloud processing and subsequent effects on drop size distributions. Journal of Geophysical Research 105, 4501-4512. doi:https://doi.org/10.1029/1999JD900980.

Xi, X. and Sokolik, I. N., 2016. Quantifying the anthropogenic dust emission from agricultural land use and desiccation of the Aral Sea in Central Asia, Journal of Geophysical Research Atmospheres, 121, 12 270-12 281. doi:10.1002/2016JD025556.

Yin, Y., Wurzler, S., Levin, Z., Reisin, T.G., 2002. Interactions of mineral dust particles and clouds: effects on precipitation and cloud optical properties. Journal of Geophysical Research Atmospheres 107, 4724. doi:10.1029/2001JD001544.

Yoshioka, M., Mahowald, N.M., Conley, A.J., et al., 2007. Impact of desert dust radiative forcing on sahel precipitation: Relative importance of dust compared to sea surface temperature variations, vegetation changes, and greenhouse gas warming. Journal of Climate 20, 1445- 1467.

Yu, H., Chin, M., Winker, D. M., et al., 2010. Global view of aerosol vertical distributions from CALIPSO lidar measurements and GOCART simulations: Regional and seasonal variations. Journal of Geophysical Research 115, D00H30. doi:10.1029/2009JD013364.

Yu, H., Remer, L.A., Kahn, R.A., Chin, M., Zhang, Y., 2013. Satellite perspective of aerosol intercontinental transport: from qualitative tracking to quantitative characterization. Atmospheric Research 124, 73-100.

Yu, H., Tan, Q., Chin, M., et al., 2019. Estimates of African Dust Deposition Along the Trans-Atlantic Transit Using the Decadelong Record of Aerosol Measurements from CALIOP, MODIS, MISR, and IASI. 
Journal of Geophysical Research Atmospheres 124, 7975-7996. https://doi.org/10.1029/2019JD030574

Yu, Y., Kalashnikova, O. V., Garay, M.J., Lee, H., Notaro, M., 2018. Identification and Characterization of Dust Source Regions Across North Africa and the Middle East Using MISR Satellite Observations. Geophysical Research Letters 45, 6690-6701. https://doi.org/10.1029/2018GL078324

Yu, Y., Kalashnikova, O. V., Garay, M.J., Notaro, M., 2019. Climatology of Asian dust activation and transport potential based on MISR satellite observations and trajectory analysis. Atmospheric Chemistry and Physics 19, 363-378. https://doi.org/10.5194/acp-19-363-2019

Yu, Y., Notaro, M., Kalashnikova, O. V, Garay, M.J., 2015a. Climatology of summer Shamal wind in the Middle East. Journal of Geophysical Research Atmospheres 121, 289-305. https://doi.org/10.1002/2015JD024063

Yu, Y., Notaro, M., Liu, Z., et al., 2015b. Climatic controls on the interannual to decadal variability in Saudi Arabian dust activity: Toward the development of a seasonal dust prediction model. Journal of Geophysical Research 120, 1739-1758. https://doi.org/10.1002/2014JD022611

Yue, X., Wang, H., Liao, H., et al., 2010. Direct climatic effect of dust aerosol in the NCAR Community Atmosphere Model Version 3 (CAM3). Advances in Atmospheric Sciences 27, 230-242. https://doi.org/10.1007/s00376-009-8170-z.

Zhang, J., Liu, S.M., Lu, X., Huang, W.W., 1993. Characterizing Asian wind-dust transport to the Northwest Pacific Ocean. Direct measurements of the dust flux for two years. Tellus B 45, 335-345. doi:10.1034/j.1600-0889.1993.t01-3-00003.x.

Zhang, D., Zang, J., Shi, G., et al., 2003. Mixture state of individual Asian dust particles at a coastal site of Qingdao, China. Atmospheric Environment 37, 3895-3901

Zhou, M., Okada, K., Qian, F.,Wu, P.-M., Su, L., Casareto, B. E., Shimohara, T., 1996. Characteristics of duststorm particles and their long-range transport from China to Japan - case studies in April 1993. Atmospheric Research 40, 19-31, https://doi.org/10.1016/0169-8095(95)00023-2.

Zhu, A., Ramanathan, V., Li, F., Kim, D., 2007. Dust plumes over the Pacific, Indian, and Atlantic oceans: Climatology and radiative impact. Journal of Geophysical Research Atmospheres 112, 1-20. https://doi.org/10.1029/2007JD008427

Zuidema, P., Alvarez, C., Kramer, S.J., et al., 2019. Is Summer African Dust Arriving Earlier to Barbados? The Updated Long-Term In Situ Dust Mass Concentration Time Series from Ragged Point, Barbados, and Miami, Florida. Bulletin of the American Meteorological Society 100, 1981-1986. https://doi.org/10.1175/BAMS-D-18-0083.1 